\title{
INFLUÊNCIA DOS DESSENSIBILIZANTES DENTINÁRIOS NA RESISTÊNCIA AO \\ CISALHAMENTO DE DOIS SISTEMAS ADESIVOS \\ NA DENTINA CONDICIONADA \\ COM ÁCIDO FOSFÓRICO A 37\%
}

Vera Aun Penteado

Dissertação apresentada à Faculdade de Odontologia de Bauru, da Universidade de São Paulo, como parte integrante dos requisitos para obtenção do título de Mestre em Odontologia área de Dentística. Opção: Materiais Dentários.

BAURU - SP 
INFLUÊNCIA DOS DESSENSIBILIZANTES

DENTINÁRIOS NA RESISTÊNCIA AO

CISALHAMENTO DE DOIS SISTEMAS ADESIVOS

NA DENTINA CONDICIONADA

COM ÁCIDO FOSFÓRICO A 37\%

\section{Vera Aun Penteado}

Dissertação apresentada à Faculdade de Odontologia de Bauru, da Universidade de São Paulo, como parte integrante dos requisitos para obtenção do título de Mestre em Odontologia área de Dentística. Opção: Materiais Dentários.

Orientador: Prof. Dr. Paulo Afonso Silveira Francisconi

BAURU - SP 
Penteado, Vera Aun

P387i Influência dos dessensibilizantes dentinários na resistência ao cisalhamento de dois sistemas adesivos na dentina condicionada com ácido fosfórico a 37\% / Vera Aun Penteado. -- Bauru, 2005.

xxii, 132 p. : il. ; $30 \mathrm{~cm}$.

Dissertação (Mestrado) -- Faculdade de Odontologia de Bauru. Universidade de São Paulo.

Orientador: Prof. Dr. Paulo Afonso Silveira Francisconi

Autorizo, exclusivamente pra fins acadêmicos e científicos, a reprodução total ou parcial desta tese, por processo fotocopiadores oe/ou meios eletrônicos.

Assinatura do autor:

Data:

Comitê de Ética da FOB-USP

Protocolo n. ${ }^{\circ:}$ 131/2002

Data: 02/12/2002 
Nascimento

Filiação

1975-1978

1991

1994

2002-2005
17 de junho de 1957

Campinas - SP

Álvaro Hoffmann Penteado

Maria Aparecida Kalil Aun Penteado

Curso de Odontologia- Pontifícia Universidade Católica de Campinas PUCAMP - SP.

Curso de especialização em Dentística Restauradora, promovido pela Faculdade de Odontologia de Bauru - USP - SP.

Estágio - Department of Dental Materials and Technology - Royal Dental College, Copenhagen, Denmark.

Curso de Pós-Graduação em Dentística. Opção Materiais Dentários, em nível Mestrado, na Faculdade de Odontologia de Bauru - USP 
A Dens

Por ter iluminado a men caminho, até este momento impartante de minba vida.

Lowva a Ele e faço minbas as palauras do salmista.

"Eis que Deus é a meu ajudador. O Senhar é quem me unstenta a vida" (Salmo 54:4)

v 
DEDICATÓRIA

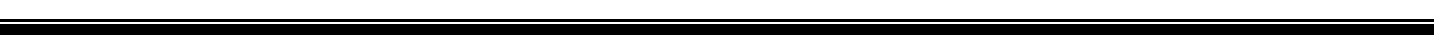




\section{DEDICATÓRIA}

Aos meus pais queridos,

Álvara Holfmann Penteada (in memoriam) e

Masia Aparecida Kalil Aun Penteada,

os quais agradeço, pois sem a influência deles isto não seria realidade.

Aos meus irmãos,

Rolesta e fermanda, que sempre procuraram me ajudar.

Aos meus sobrinhos, os quais amo imensamente,

Luis Hensique, grande companheiro, a quem posso contar sempre, em qualquer situação.

Fesmanda, que sempre participou com empolgação, torcendo sempre pelo meu bem.

Casla, amiga, que sempre estendeu sua mão e esteve ao meu lado.

Radrifa, pela amizade.

Rolesta e Masiana, pelo carinho que sempre me dedicam. 
Maria Edwarda e Mayara, por terem vindo ao mundo nos trazendo só felicidades.

À minha prima Sômia,

pela ajuda constante, pelo esforço, abdicação de seu tempo com intuito de me ajudar, cuidando dos meus queridos July e Flethes.

A vocês que amo, dedico esta conquista! 
AGRADECIMENTOS ESPECIAIS 


\section{AGRADECIMENTOS ESPECIAIS}

Ao Prof. Dr. Paula Afansa Silveira Francisconi, meu querido orientador, o meu muito obrigada, pois, mais do que um orientador, foi amigo, exemplo de humildade, honestidade, competência, sempre alegre e disposto a ajudar, não medindo esforços para que concluíssemos este trabalho.

Ao Prof. Dr. César Antures de Freitas, que esteve sempre disposto a me ouvir e me ensinar, ao qual tenho grande admiração e respeito.

Ao Prof. Dr. Paula Amarante de Araíja, que nunca se cansou aos meus pedidos de ajuda, na intenção de melhorar este trabalho.

Aos meus queridos colegas de mestrado, aos quais amo com grande intensidade, a vocês "meninas queridas, Carla Gianimi, Carla Porto, Juliana, Rosana" e Odislei. Nada disto teria valor sem vocês! 


\section{AGRADECIMENTOS}

Agradeço também,

\section{À Faculdade de Odontologia de Bausu- USP.}

Ao Departamento de Dentistica e a todos seus professores pelo exemplo e amizade.

Ao Prof. Dr. Ricarda Marions de Carvalba, exemplo de dedicação e competência, pela sua ajuda na realização deste trabalho.

Ao Prof. Dr. Jasé Roberta P. Lauris, pela sua ajuda na análise estatística deste trabalho.

Aos funcionários do Departamento, Sandra, Lasisvalda e Alcides, que estiveram sempre do meu lado, apoiando, e dispostos a ajudar.

A todos os funcionários da Pós Graduaçãa e da Bildiateca, pela atenção e amor que sempre me dedicaram. 
Ao Departamenta de Prótese, em especial ao Reivanilda, pela ajuda nos ensaios de resistência ao cisalhamento.

À Meise Von Zuben Dusante, por sua ajuda para a realização deste trabalho.

À $C N P Q$ pela ajuda, proporcionando a realização deste trabalho. 


\section{SUMÁRIO}

LISTA DE FIGURAS XV XV

LISTA DE QUADROS Xvii

LISTA DE ABREVIATURAS E SÍMBOLOS Xix

RESUMO XXi

1 INTRODUÇÃO ............................................................................... 2

2 REVISÃO DE LITERATURA ......................................................... 7

3 PROPOSIÇÃO …...................................................................... 88

4 MATERIAL E MÉTODOS ............................................................... 90

4.1 Seleção dos dentes ...................................................... 90

4.2 Preparo dos espécimes ................................................. 90

4.3 Materiais utilizados .......................................................... 92

4.4 Procedimento adesivo ........................................................ 95

5 RESULTADOS ................................................................................... 103

6 DISCUSSÃO .................................................................................. 110

7 CONCLUSÕES ......................................................................... 118

REFERÊNCIAS BIBLIOGRÁFICAS ................................................ 120

ABSTRACT ............................................................................ 131

APÊNDICE 


\section{LISTA DE FIGURAS}




\section{LISTA DE FIGURAS}

FIGURA 1 - Seqüência de inclusão. 1- matriz de silicona, 2- e com resina epóxica foi realizada a inclusão da porção coronária, 3- após a remoção e exposição da dentina com lixadeira, obtivemos o espécime para os testes .. 91

FIGURA 2 - $\quad$ Scothbond Multi-Purpose ....................................... 92

FIGURA 3 - $\quad$ One-Spet ........................................................ 92

FIGURA 4 - $\quad$ Gluma $₫$ Desensitizer ........................................... 93

FIGURA 5 - $\quad$ BisBlock ..................................................... 93

FIGURA 6 - $\quad$ Ácido fosfórico a $37 \%$....................................... 93

FIGURA 7 - $\quad$ Resina composta Z250 ...................................... 95

FIGURA 8 - $\quad$ Área demarcada ............................................. 95

FIGURA 9 - $\quad$ Aparelho para confecção da restauração .................... 98

FIGURA10 - Confecção da restauração ....................................... 99

FIGURA 11 - Polimerização .................................................. 99

FIGURA 12 - Restauração ................................................. 99

FIGURA 13 - Máquina de ensaio universal Kratos ....................... 100

FIGURA 14 - Espécime acoplado no dispositivo para o teste de resistência ao cisalhamento ................................. 100

FIGURA 15 - Gráfico das médias dos grupos em MPa. ................. 108 


\section{LISTA DE QUADROS}




\section{LISTA DE QUADROS}

QUADRO 1 - Materiais testados ............................................. 94

QUADRO 2 - Composição química dos sistemas empregados .... $\quad 94$

QUADRO 3 - $\quad$ Scotchbond Multi-Purpose ................................... 103

QUADRO 4 - $\quad$ One-Step .................................................. 104

QUADRO 5 - $\quad$ Resultados das médias dos grupos em MPa. ......... 104

QUADRO 6 - $\quad$ Análise da variância ............................................ 105

QUADRO 7 - Teste de homogeneidade de variância .................. 105

QUADRO 8 - $\quad$ Teste de homogeneidade de variância ................... 105

QUADRO 9 - $\quad$ Análise de variância a um critério .......................... 106

QUADR010 - $\quad$ Teste de Tukey para as comparações múltiplas ...... 106

QUADRO 11 - Tipos de falhas ........ 107 


\section{LISTA DE ABREVIATURAS E SÍMBOLOS}

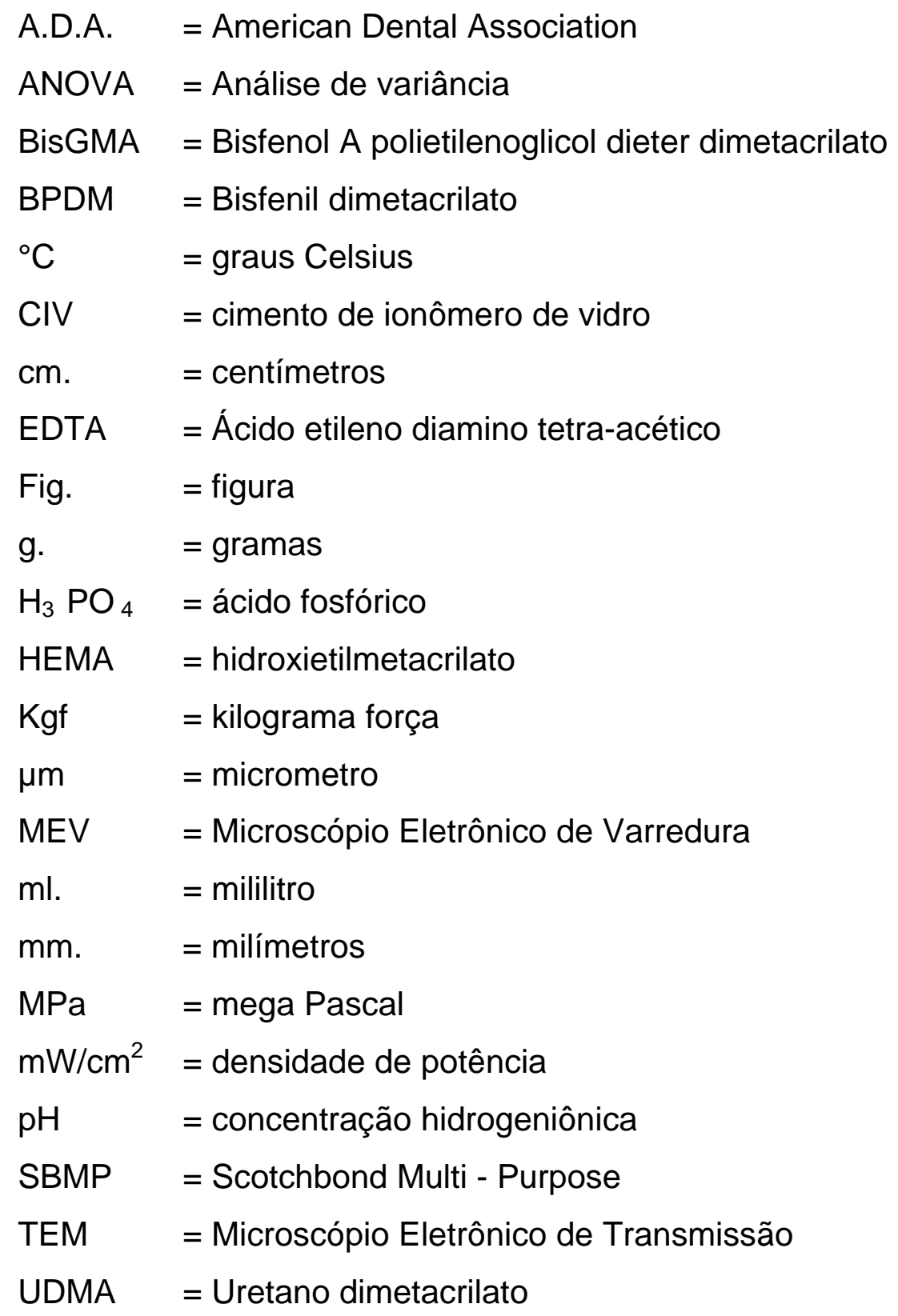


RESUMO 


\section{RESUMO}

Este estudo visou analisar e comparar as resistências adesivas ao cisalhamento das interfaces entre a dentina e uma resina restauradora fotopolimerizável, criadas por dois sistemas adesivos disponíveis no mercado: Scotchbond Multi-Purpose e One-Step, e a influência do prétratamento com os dessensibilizantes dentinários Gluma ${ }^{\circledR}$ Desensitizer e Bisblock, usados, respectivamente, após o condicionamento da dentina com ácido fosfórico a 37\%. Quarenta terceiros molares foram usados, livres de cáries, cujas camadas de dentina foram expostas numa tentativa de obter-se superfícies planas com smear layer padronizadas. Os sistemas adesivos, após o condicionamento ácido, foram aplicados de acordo com as instruções dos fabricantes, combinados ou não aos dessensibilizantes. A resistência adesiva ao cisalhamento foi medida após a imersão dos corposde-prova, resultantes da união de pequenos cilindros de resina composta, fotopolimerizável, à superfície dentinária, em água deionizada a $37^{\circ} \mathrm{C}$ por 7 dias, usando uma Máquina de Ensaios Universal (KRATOS, São Paulo-SP). Os dados foram analisados através dos testes de ANOVA, a um critério de classificação, e Tukey, o qual houve uma diferença significativa entre os grupos $(P<0,001)$. $\mathrm{Na}$ análise dos tipos de falhas o Grupo 2 apresentou $100 \%$ de falhas coesivas e o Grupo 4 apresentou 100\% de falhas adesivas. Concluiu-se que o uso dos dessensibilizantes influenciou na resistência ao cisalhamento dos dois sistemas adesivos testados, e a aplicação do Gluma ${ }^{\circledR}$ Desensitizer, após o condicionamento ácido da dentina, usado previamente ao

sistema 
adesivo Scotchbond Multi-Purpose, resultou em valores de resistência significativamente superiores do que quando não aplicado, ou seja, 19,72750 \pm 4,667893 MPa e 27,29000 \6,478825 MPa, após a aplicação do dessensibilizante. O Bisblock, aplicado após o condicionamento ácido da dentina e usado previamente ao sistema adesivo One-Step, apresentou valores de resistência significativamente mais baixos do que quando não

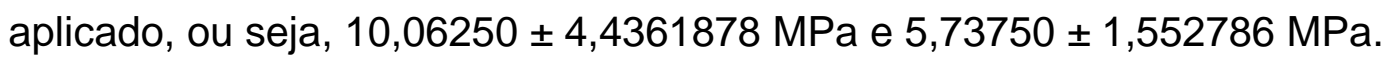


1 INTRODUÇÃO

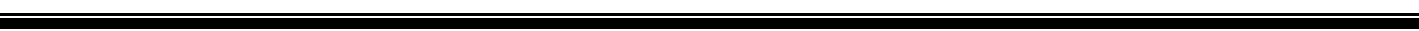




\section{INTRODUÇÃO}

A resina composta foi desenvolvida e lançada no comércio Odontológico no início dos anos sessenta por BOWEN ${ }^{12}$, tendo uma grande aceitação pela classe Odontológica e pelos pacientes que procuravam resultados mais favoráveis. Desde então, a Odontologia Restauradora preocupa-se, cada vez mais, com a estética, buscando materiais mais aperfeiçoados, a fim de garantir longevidade, qualidade e beleza nos trabalhos realizados.

Tem-se melhorado sensivelmente a resina composta, com propriedades positivas, tais como: maior resistência ao desgaste, estabilidade de cor e manchamento superficial. Porém, é reconhecido que as resinas contraem-se durante o processo de polimerização e apresentam um coeficiente de expansão térmica linear diferente da estrutura do dente, tornando a restauração suscetível à infiltração marginal (KIDD ${ }^{38}, 1976$; ARAÚJO; ASMUSSEN ${ }^{3}, 1990$ ) apresentando, como conseqüência, risco de cáries secundárias (BURKE, et al. ${ }^{16}$, 1999; HICKS; FLAITZ ${ }^{33}$, 2000; KIDD; TOFFENETTI; MJÖR ${ }^{39}$, 1992), pigmentação marginal e lesões na polpa dental (BURKE et al. ${ }^{16}, 1999$, ASMUSSEN; MUNKSGAARD ${ }^{7}, 1988$ ).

Quando a cavidade é rodeada somente por esmalte, o selamento marginal, em restaurações de resina composta, é obtido através do condicionamento ácido das paredes de esmalte, o qual resulta em 
microrentenções que tornam 0 selamento realmente efetivo (BUONOCORE ${ }^{15}$, 1955; BARKMEIER; LOS; TRIOLO $\left.{ }^{10}, 1995\right)$.

ASMUSSEN $^{5}$ (1974) e ARAÚJO; ASMUSSEN ${ }^{3}$ (1990) demonstraram que esta união é tão forte que a contração de polimerização das resinas compostas pode provocar até mesmo fratura nas margens do esmalte. Por outro lado, a capacidade de formar uma forte e durável união na dentina sempre foi uma propriedade altamente desejável em uma resina composta (ASMUSSEN $^{5}, 1974 ;$ ASMUSSEN; MUNKSGAARD $\left.{ }^{7}, 1988\right)$.

A introdução dos sistemas adesivos, com características hidrofílicas, permitiu a difusão e a interação do adesivo com o substrato dentinário e possibilitou uma adesão mais efetiva, embora esta adesão da resina composta à dentina seja considerada ainda mais fraca (TAO et al. $\left.{ }^{70}, 1988\right) \mathrm{e}$ menos previsível (SORENSEN; DIXIT ${ }^{67}$, 1991; SANTINI; PLASSCHAERT; MITCHELL $\left.{ }^{61}, 2001\right)$ que a adesão ao esmalte.

BARKMEIER; ERICKSON ${ }^{9}$, 1994; BARKMEIER; LOS; TRIOLO ${ }^{10}$, 1995, mostraram que a resistência adesiva da resina composta à dentina é inversamente proporcional ao tamanho da fenda (gap), resultante da contração da polimerização. Portanto, isto mostra que, para a escolha de um adesivo dentinário, é necessário que este apresente uma forte adesão ao substrato dentinário, para que seja capaz de resistir à contração da polimerização do material restaurador (MUNKSGAARD; IRIE; ASMUSSEN ${ }^{44}$, 1985, SORENSEN; DIXIT ${ }^{66}$, 1988; TAO; PASHLEY; BOYD ${ }^{70}$, 1988; ASMUSSEN; MUNKSGAARD $\left.{ }^{7}, 1988\right)$, uma vez que, se isto não ocorrer, além de permitir a infiltração de bactérias, que resulta em irritação e inflamação do tecido pulpar (BRÄNNSTROM ${ }^{13}, 1986$ ), outras complicações também têm sido relatadas, como a hipersensibilidade pós-operatória (POWELL et al. ${ }^{57}$, 1990; UNEMORI et al. ${ }^{75}$, 2001), tanto para restaurações diretas quanto para cimentações de restaurações indiretas e coroas totais. A identificação clínica e o tratamento para esta condição ainda é um grande 
desafio para a Dentística Restauradora (BRÄNNSTRÖM ${ }^{13}$, 1986, COBB; REINHARDT; VARGAS ${ }^{22}$, 1997; JOHNSON; LEPE; BALES ${ }^{36}$, 1998; YIM et al. $^{80}, 2000$; SOENO et al. $\left.{ }^{65}, 2001\right)$.

$\mathrm{Na}$ tentativa de combater a hipersensibilidade pós-operatória, os dessensibilizantes dentinários têm sido recomendados como uma opção para serem utilizados nas paredes de fundo do preparo cavitário, tanto para restaurações diretas como indiretas (PEREZ; SÉRGIO; SILVA ${ }^{56}$, 2003; PASHLEY et al. $^{50}$, 2001; SOARES; SOUZA; SANTIAGO ${ }^{64}$, 2001; DALL'OROLOGIO; LONE; FINGER ${ }^{23}$, 2002; FINGER; UNO ${ }^{28}, 1996$, BRÄNNSTRÖM ${ }^{13}$, 1986), os quais, segundo os fabricantes, vêm obtendo resultados satisfatórios.

Isto tem levado inúmeros pesquisadores a analisarem os diversos tipos de dessensibilizantes dentinários e suas interferências na força de adesão dos cimentos resinosos e resinas compostas, associados a um sistema adesivo (BABA; MATSUMURA; ATSUTA ${ }^{8}, 2002$; SEARA et al. ${ }^{63}$, 2002; PASHLEY et al. ${ }^{52}$, 1993; WOLFART; LINNEMANN; KERN ${ }^{79}$, 2003; PRATI, et al. ${ }^{58}$, 1992; SWIFT; LLOYD; FELTON ${ }^{69}$, 1997; PASHLEY et al. ${ }^{50}$, 2001; SOARES; SOUZA; SANTIAGO ${ }^{64}$, 2001; MAUSNER; GOLDSTEIN; GEORGESCU $^{41}, 1996$; CHRISTENSEN ${ }^{21}$, 2000; TAY et al. ${ }^{71}, 2003$; YIU et al. $^{81}$, 2005), bem como a possível influência de dessensibilizantes nas formações de fendas marginais quando aplicados previamente ao sistema adesivo (HANSEN; ASMUSSEN ${ }^{31}$, 1997).

Testes laboratoriais dos dessensibilizantes aplicados previamente aos adesivos dentinários são importantes para avaliar situações pré-clínicas dos materiais. Desta forma, os ensaios de resistência de união vêm sendo um dos métodos de escolha na avaliação da força, sob a ação da qual a junção adesiva se rompe, destacando-se os testes de resistência ao cisalhamento e à tração (NAKAMICHI; IWAKU; FUSAYAMA ${ }^{46}$, 1983; VAN NOORT et al. ${ }^{76}$, 1989; RETIEF ${ }^{59}$, 1991; JOHNSON et al. ${ }^{37}$, 1991). 
Portanto, o objetivo deste estudo foi analisar e comparar a força adesiva de alguns sistemas adesivos dentinários e a influência do prétratamento com dessensibilizante dentinário, após o condicionamento ácido da dentina, utilizando-se dentes humanos como substrato dentinário. Com intuito de orientar o cirurgião-dentista na escolha de um dessensibilizante dentinário que possa ser utilizado com um sistema adesivo dentinário, possibilitando melhorar ou não interferir no selamento marginal, reduzindo a sensibilidade pós-operatória. 
2 REVISÃO DE LITERATURA 



\section{REVISÃO DE LITERATURA}

BUONOCORE $^{15}$, em 1955, relatou que uma das maiores desvantagens dos acrílicos e de outros materiais restauradores era a falta de adesão à estrutura dental. Como tentativa para se obter uma melhor união entre a resina acrílica e a estrutura dental, o autor submeteu o esmalte das faces vestibulares de dentes de pacientes, à ação de duas substâncias ácidas: ácido fosfomolibdato oxálico a $50 \%$ e ácido fosfórico a $85 \%$. O tratamento com ácido fosfórico, além de ter dado melhores resultados, foi mais simples de usar. O condicionamento na superfície do esmalte promoveu um aumento na área da superfície, permitindo um contato mais íntimo entre a resina e o esmalte, aumentando a adesão. Desta maneira, houve maior adaptação da resina às margens da cavidade, diminuindo, consideravelmente, a microinfiltração.

Em 1972, BRÄNNSTRÖM; ÄSTRÖM ${ }^{14}$, analisaram a sensibilidade dentinária quando esta recebe estímulos, como: variações de temperatura, raspagem, aplicações de soluções hipertônicas, jatos de ar frio, etc. Averiguaram que a soma das áreas dos túbulos dentinários localizados no terço médio correspondem a um tubo com diâmetro de $0.3 \mathrm{~mm}$, aproximadamente, semelhante ao tamanho do forame apical. Estes inúmeros túbulos, preenchidos principalmente com material extracelular, constituem uma estrutura ideal para a ação de forças capilares. Assim, todos os estímulos, exceto o elétrico, são capazes de produzir um movimento no conteúdo tubular. A pressão pulpar normal é de $30 \mathrm{~mm} \mathrm{Hg}$ e é capaz de esvaziar um túbulo aberto durante 24 horas. Eles observaram que é razoável 
concluir que o deslocamento rápido do fluido de tantos túbulos ativem mecanicamente os nervos presentes na área pulpo-dentinária, passando a admitir a existência de mecano-receptor nesta região. Também explicam que a dor aguda e imediata ocorre quando o fluido dentinário vai para fora dos túbulos, como acontece com estímulos de desgaste, fricção do explorador, jatos de ar e frio. Já, a dor que ocorre após um intervalo maior e de maior duração, aparece quando o fluido dirige-se para dentro da polpa, como no caso de se aplicar o calor. Os autores puderam concluir que, através desse experimento, suportam a hipótese da teoria hidrodinâmica, a qual considera o fluxo de fluido e o deslocamento do conteúdo tubular como responsáveis pela condução da dor na dentina. Desse modo, as alterações de fluido dos túbulos dentinários, após a estimulação da superfície dentinária, alcançariam as estruturas nervosas localizadas na polpa ou área de pré-dentina.

ASMUSSEN; JORGENSEN ${ }^{6}$, em 1972, avaliaram a efetividade de pesquisas realizadas em temperatura ambiente e compararam com a influência da temperatura oral, sobre a adesão, o tempo de polimerização, viscosidade e tempo necessário para os materiais plásticos expandirem, através da absorção de água, a qual compensaria a contração da polimerização. Desta forma, os autores procuraram realizar este trabalho em temperatura ambiente e de um modo que fosse o mais parecido com o da situação clínica, a uma temperatura de $37^{\circ} \mathrm{C}$. Eles analisaram a contração da polimerização, através da adaptação nas interfaces dente-restauração, com o uso de microscópio, a qual foram feitas imediatamente após a presa, e após um período em que os espécimes permaneceram em água, que variaram entre $24,48,96,192,384$ ou 768 horas, com o objetivo de analisar a influência do tempo na absorção da água. Os materiais testados foram: Adaptic, Addent, Concise, DFR, Palakav, Palakav capsulated, TD 71, Palavit 55, Serviton e Swedon. Para este estudo, foram utilizados dentes humanos permanentes, extraídos, nos quais foram feitas cavidades cilíndricas, na junção esmalte/dentina, num total de 10 amostras para cada tipo de material. O material foi misturado à temperatura ambiente, de acordo com as 
instruções do fabricante e depois as cavidades foram restauradas; estas foram polidas e analisadas microscopicamente, em um ambiente cuja temperatura era de $37^{\circ} \mathrm{C}$. Os autores observaram que em muitos casos ocorreram fraturas nas margens do esmalte e analisaram a medida das fendas encontradas entre o dente e o material restaurador e classificaramnas, de acordo com a qualidade da margem do esmalte, da seguinte forma: 1- extensivas; 2- esporádicas; 3- fraturas descontínuas ou, em alguns casos pequenas fraturas. As fendas na dentina foram também analisadas. Os autores observaram a influência do armazenamento, após as extrações dos dentes, em solução de Cloramina a 1\%, e a sua interferência em relação à adaptação do material às paredes das cavidades. Compararam restaurações em dentes recém extraídos com dentes que permaneceram em contato com a cloramina e, puderam concluir que, de acordo com os resultados, não houve diferença estatística entre eles. Constataram que, quando as restaurações foram polidas e inspecionadas imediatamente após a presa, foram encontradas fraturas nas margens do esmalte em todas as amostras, com fendas que variaram de 20 a $40 \mu \mathrm{m}$ de largura e, com freqüentes perdas de fragmentos de esmalte; esta situação foi melhorada somente quando as amostras permaneceram em água, sendo que, para algumas marcas, as fendas foram completamente fechadas em menos de 32 dias. Os autores acreditam que a magnitude da efetividade da contração, deve ser uma condição de equilíbrio, entre a força de adesão e força de contração, onde o resultado obtido é uma restauração que apresente, em alguns lugares, uma perfeita adaptação e em outros, fendas. As fraturas de esmalte poderiam, também, ocorrer devido: 1- tipo do preparo cavitário; 2- estresse de contração do material restaurador e, 3- abrasivo e polimento. Observaram que, quando usaram Palakav, não encontraram fendas, quando estas restaurações foram abrasionadas e polidas após 2 dias ou mais. Puderam observar também, que o tamanho das fendas iniciais não variaram muito com a temperatura, embora fecharam mais à temperatura de $37^{\circ} \mathrm{C}$ do que à temperatura ambiente, explicando que isto ocorreu devido ao aumento da difusão de água pelo aumento da temperatura. Os autores concluíram que a 
fratura da margem do esmalte resultante da abrasão pode ser reduzida, se este passo for adiado até a contração das fendas se fecharem, em conseqüência da absorção da água e, com isso, o risco de danos secundários é também diminuído.

ASMUSSEN ${ }^{5}$, em 1974, investigou o relacionamento entre a redução de temperatura e o tamanho das fendas marginais, e estudou o efeito de um aumento de temperatura inicial sobre a influência na formação de fendas marginais durante o resfriamento subseqüente sobre as restaurações de resina composta que estavam mais ou menos expandidas contra a parede da cavidade, devido à absorção de água. Foram usadas, nesta investigação, Adpatic $(A)$, Blendànt $(B)$, Concise $(C)$, Opotow (D), Servriton (E) e Swedon (F). Na região de esmalte, as fendas da cavidade ficaram próximas da parede, após 12 horas de absorção de água da marca $\mathrm{E}$ e após 8 dias de absorção de água da marca A, B, C, D e F. O autor inspecionou, microscópicamente, a margem de esmalte e restaurações de resina, as quais foram feitas em dentes humanos extraídos, após armazenados em água antes de serem polidas, num período que variou de 18 a 64 dias, ou seja, 64 para a marca E, e de 8 a 64 dias para as marcas A, B, C, D, e F. Cinco restaurações de cada marca foram examinadas, para observar-se 0 lugar do polimento do dente, após 1 ou 8 dias, sendo que 10 das restaurações foram polidas após 64 dias. Imediatamente após o polimento, a área marginal da restauração foi inspecionada, microscopicamente, e, em todos os casos, confirmou-se que as fendas entre restaurações e dente estavam fechadas. Esta inspeção foi feita em uma sala com temperatura de $37^{\circ} \mathrm{C}$, dois minutos depois. A seguir, as restaurações foram colocadas em água com diferentes temperaturas, de $23^{\circ} \mathrm{C}, 15^{\circ} \mathrm{C}, 10^{\circ} \mathrm{C}$ e $2^{\circ} \mathrm{C}$, e as possíveis larguras máximas das fendas foram encontradas e expressas em porcentagem. Para avaliação do diâmetro da cavidade, as restaurações foram mantidas por 2 minutos em cada temperatura, antes das medidas começarem. Os dentes restaurados foram, depois, colocados em água, a uma temperatura de $50^{\circ} \mathrm{C}$ por 2 minutos e, mais tarde, novamente em água 
a $60^{\circ} \mathrm{C}$ por 2 minutos. Após cada aquecimento, as fendas marginais foram medidas sob água a $2^{\circ} \mathrm{C}$, por aproximadamente 10 minutos cada; neste período de tempo, nenhuma alteração na largura das fendas foram foi observada. A última medida das fendas de cada restauração individual levou, aproximadamente 90 minutos, após a remoção da estufa. Pôde-se observar que as restaurações dos dentes poderiam ser resfriadas através de uma certa variação de temperatura, sem formar fendas marginais, dependendo da idade da restauração. Após 64 dias de absorção de água das restaurações das marcas $A, B, C, D$ e $E$, elas puderam ser resfriadas de $37^{\circ} \mathrm{C}$ a $10^{\circ} \mathrm{C}$, sem formação de fendas. Com a marca $\mathrm{F}$, as fendas estiveram presentes, quando os dentes restaurados foram resfriados a $23^{\circ} \mathrm{C}$. $\mathrm{O}$ tratamento de aquecimento descrito mostrou que as restaurações tiveram uma tendência a aumentar a largura das fendas, formadas durante o subseqüente resfriamento. As larguras das fendas foram aumentadas de 1 $\mu \mathrm{m}$ para $3 \mu \mathrm{m}$. $\mathrm{O}$ aquecimento de $60^{\circ} \mathrm{C}$ apresentou um efeito muito pequeno sobre a largura da fenda, nas restaurações com as marcas A, B, C, e D, mas um efeito maior com as marcas E e F. As fendas localizadas ao longo da margem das restaurações, exceto com a marca $E$, onde foram encontradas com freqüência no esmalte, também. A média das distâncias das fendas nas margens das restaurações foi por volta de $3 \mu \mathrm{m}$. Pôde-se concluir que foi demonstrado que as restaurações feitas com as marcas examinadas podem ser resfriadas através de uma certa variação de temperatura sem formar fendas marginais. $\mathrm{O}$ tamanho das fendas a $2^{\circ} \mathrm{C}$ teve um pequeno efeito pelo prévio aquecimento de $50^{\circ} \mathrm{C}$. O aquecimento de $60^{\circ} \mathrm{C}$ aumentou o tamanho da fenda a $2^{\circ} \mathrm{C}$ somente nas resinas sem carga.

$\mathrm{KIDD}^{38}$, em 1976, fez uma revisão na literatura sobre microinfiltração, e a definiu como sendo a passagem de bactérias, fluídos, moléculas ou íons entre a parede da cavidade e o material restaurador. Ela é a causa de uma série de problemas, incluindo cáries secundárias, descoloração do dente abaixo do amálgama, hipersensibilidade de dentes restaurados, alterações pulpares e uma acelerada degradação de certos materiais restauradores. 
Neste estudo, enfatizou-se o fato de ainda não existir um material restaurador que se una quimicamente à substância do dente, capaz de formar um selamento perfeito, resistente à umidade do meio ambiente oral e às mudanças de temperatura. Muitas técnicas de laboratório têm sido propostas, objetivando estudar a permeabilidade marginal na interface entre dente e restauração. Entre os vários testes de microinfiltrações disponíveis, a técnica de cárie artificial parece ser de particular relevância clínica para a autora, uma vez que há conexão entre microinfiltração e a conseqüente formação de lesão. Os resultados dos testes de microinfiltração evidenciam a ocorrência de uma extensiva infiltração marginal ao redor do amálgama recém feito. Estas infiltrações podem ser reduzidas, enormemente, pelo uso de um verniz cavitário. Ela enfatizou que poucos testes de microinfiltrações têm sido realizados com os novos materiais compostos. Com referência às resinas, estas parecem particularmente sensíveis às infiltrações após estresse térmico. Entretanto, há algumas evidências de estes materiais compostos mais novos proporcionarem um bom selamento da cavidade. Concluiu-se que há novos materiais em desenvolvimento, porém há necessidade de um material que se una física ou quimicamente ao tecido dental. São poucos os estudos na literatura que abordam as microinfiltrações das resinas compostas.

GARBEROGLIO; BRÄNNSTRÖM ${ }^{29}$, em 1976, investigaram, através de microscópio eletrônico (SEM), fraturas de dentinas. Utilizaram para isto 30 dentes humanos, sendo 24 pré-molares, 5 molares e 1 incisivo. Observaram que próximo à polpa, o número de túbulos por milímetro quadrado foi de 45.000 e apresentavam diâmetro de $2.5 \mu \mathrm{m}$; na região do meio da dentina foi de $29.500 / \mathrm{mm}^{2}$ e apresentavam diâmetro de $1.2 \mu \mathrm{m}$, e na região periférica o número encontrado foi de $20.000 / \mathrm{mm}^{2}$ e apresentavam diâmetro de $0.9 \mu \mathrm{m}$. O volume dos túbulos da dentina coronária foi calculado como 10 por cento. Nenhuma diferença grande foi observada entre os dentes de pessoas idosas e jovens. Os diâmetros dos túbulos aumentaram consideravelmente devido à superfície fraturada estar descalcificada, em 
conseqüência de uma total remoção da dentina peritubular. Observaram, também, que os odontoblastos somente puderam ser vistos dentro dos túbulos mais próximos à polpa.

$\mathrm{Na}$ tentativa de encontrar um substituto para dentes humanos nos testes de adesão, NAKAMICHI; IWAKU; FUSAYAMA ${ }^{46}$, em 1983, compararam a resistência adesiva de dentes bovinos e dentes humanos utilizando 5 cimentos odontológicos e duas resinas compostas. Os autores também estudaram o efeito da profundidade da dentina e do tempo de estocagem dos dentes após a extração na resistência de união da dentina (menos que 5 dias e mais que 6 dias). A adesão com esmalte e a camada superficial de dentina não mostraram diferenças estatisticamente significante entre dentes bovinos e humanos com quaisquer utilizados, mas os valores médios foram sempre mais baixos com dentes bovinos. A adesão com a dentina bovina diminuiu consideravelmente com a profundidade da dentina. A resistência adesiva com dentina bovina foi de 1,6 a 10,7 vezes maior em dentina superficial que em profunda. Os autores determinaram que a densidade mais baixa dos túbulos dentinários, em conexão com pouca dentina intertubular por unidade de área, foi responsável pela resistência adesiva mais baixa em dentina profunda. Um tempo de estocagem maior dos dentes sempre mostrou valores médios de união com a dentina um pouco maior que os dentes extraídos recentemente. Somente a resina com adesivo quimicamente ativado e com condicionamento ácido apresentou diferenças significantes com relação ao tempo de estocagem. Os autores concluíram que os dente bovinos foram úteis nos testes de adesão como substitutos para dentes humanos utilizando esmalte e dentina superficial.

MUNKSGAARD; IRIE; ASMUSSEN ${ }^{44}$, em 1985, realizaram um estudo para verificar a resistência adesiva à tração e ao cisalhamento da dentina tratada com Gluma ${ }^{\circledR}$ e coberta com várias resinas, com composições diferentes, antes da aplicação de uma resina composta de micropartículas (Silux - 3M). Foram usados para este estudo dentes humanos, extraídos, 
nos quais foram preparadas cavidades em dentina e tratadas. Foram divididos em 7 grupos, sendo que, após a aplicação do Gluma®, usaram uma resina diferente para cada grupo e todos foram restaurados com a resina composta. As margens das restaurações foram expostas para análise, através do microscópio, para observação das possíveis fendas marginais. Para os testes de resistência ao cisalhamento e à tração, aplainaram as superfícies dos dentes, expondo a dentina e, sobre esta, foi colocada uma matriz de Teflon cilíndrica de $3.6 \mathrm{~mm}$ de diâmetro por $5 \mathrm{~mm}$ de altura; foram aplicados em cada uma das superfícies os diferentes tipos de resina e as cavidades foram preenchidas com resina composta e, posteriormente, submetidas a testes em uma máquina Universal Instron. Verificou-se que as resinas contendo propanol promoveram resistências adesivas em torno de $15 \mathrm{MPa}$, e a resistência à tração excedeu a $22 \mathrm{MPa}$. por uma das resinas, cuja medição não foi feita devido à freqüente ruptura na resina composta. Cerca de 30 a $70 \%$ das resinas usadas nas restaurações, que continham em sua composição o propanol ou o ptoluenosulfonato, não apresentaram fenda de contração. Os resultados sugerem que, embora a inibição da polimerização pelo oxigênio impeça a adesividade na superfície dentinária, as resinas contendo agentes redutores podem reduzir esta inibição provocada pelo oxigênio e aumentar a capacidade de adesividade do agente de união.

Em 1986, BRÄNNSTRÖM ${ }^{13}$, apresentou a primeira conferência sobre a dor pulpar, em New York. Ele analisou as causas de hipersensibilidade pós-operatória e como reduzi-la. Acreditava que, para a redução de sensibilidade nas restaurações feitas com amálgama e CIV, era essencial a remoção da smear layer superficial infectada, pois a presença de microorganismos nesta região pode se multiplicar após poucas semanas. As paredes das cavidades devem ser desinfectadas. O uso de um verniz ou forramento deveria ser aplicado em todas as paredes das cavidades com o objetivo de bloquear a comunicação entre os túbulos dentinários e os fluidos os quais estão no interior das fendas que são desenvolvidas durante a 
contração dos materiais de restauração. Uma base fina antibacteriana deveria ser aplicada, também, nas paredes das cavidades para prevenir a contaminação de bactérias antes da restauração ser realizada. Para as resinas compostas, a presença de uma base é necessária para eliminar a sensibilidade pós-operatória e diminuir o risco de injúrias pulpares e cáries secundárias. Mesmo em cimentação de coroas, deve-se fazer antes um correto diagnóstico sobre a vitalidade do dente, e a possibilidade do próprio preparo associado a anestésicos pode levar a problemas pulpares. Por isso, ele aconselha que, para diminuir este problema, deve-se esperar uns dias, com uma cimentação provisória antes da cimentação definitiva, e que antes da cimentação provisória, a dentina deve estar limpa e deve-se remover a smear layer superficial com o uso de detergentes antibacterianos, fazendo ajustes oclusais; também, a dentina deve estar seca antes do uso do agente adesivo (a ausência do fluido dentinário permite uma ligação mecânica entre o material e o dente). Quando a dentina é exposta e está desprotegida, os orifícios dos túbulos dentinários devem ser, o mais breve possível, selados para reduzir o risco de infecção pulpar. Acredita, também, que as células de defesa, bloqueando os túbulos na região da polpa, e a outra extremidade exposta sendo bloqueada com o material restaurador, as bactérias teriam menos oportunidade de sobreviver, acrescentando que a deposição de sais minerais dentro dos túbulos abertos seria gradualmente aumentada, obstruindo a dentina através de uma dentina esclerosada. Recomendou que, quando se usa uma resina composta, deve-se associá-la ao hidróxido de cálcio e o uso de fluoretos, apresentando, também, uma outra alternativa para o tratamento com oxalato de potássio. Por outro lado, acreditava que a aplicação de fluoretos ou oxalatos de cálcio limitaria a difusão dos ingredientes através dos túbulos.

SORENSEN; DIXIT ${ }^{66}$, em 1988, realizaram um estudo feito em molares humanos, extraídos, comparando as resistências adesivas ao cisalhamento de vários agentes adesivos em superfícies dentinárias e de esmalte, as quais foram aplainadas com disco de lixa de granulação 600 . Os 
resultados mostraram que o grupo Enamel-Scotchbond II/Silux apresentou as maiores forças adesivas, seguido dos grupos 3, steps Tenure/Ultrabond, Scotchobond II/ Silux e Ketac Bond/ Visio-Dispers, que não foram significativamente diferentes. O grupo formado pelo Glumaß/LumaBond apresentou a menor resistência adesiva.

ASMUSSEN; MUNKSGAARD ${ }^{7}$, em 1988, observaram que, em conjunto com a técnica de condicionamento ácido para unir a restauração de resina composta ao esmalte, uma adesão efetiva em dentina eliminaria a necessidade de retenções adicionais e asseguraria um verdadeiro selamento marginal. A união à dentina pode ser feita através de adesivos dentinários. Estes adesivos podem ser divididos em $\mathrm{Ca}^{2+}$ - adesivo, e colágeno-adesivo. Muitos dos $\mathrm{Ca}^{2+}$ - agente adesivo estão baseados no fosfato metacrilato. Os adesivos deste tipo proporcionam uma força adesiva à dentina, não excedendo a $10 \mathrm{MPa}$. Em compensação, o sistema adesivo de Bowen e o de Gluma ${ }^{\circledR}$ originaram um sistema adesivo mais alto do que 10MPa., e, recentemente, foi concedida uma versão mais simplificada para estes dois sistemas. Os autores observaram que as cavidades restauradas com resinas compostas apresentam fendas menores quando estas são tratadas com um sistema adesivo e que o tamanho e a forma da cavidade influenciam na largura da fenda marginal, ou seja, nas cavidades em forma de "V" ocorreram fendas marginais menores, quando comparadas às cavidades em forma de caixa. Nas técnicas de restaurações, usando-se duas porções, ao invés de uma só, reduziu-se a largura da fenda. A combinação de certos $\mathrm{Ca}^{2+}$ - adesivo e colágeno-adesivo resultou no aumento da força adesiva e em fendas marginais menores.

TAO; PASHLEY; BOYD ${ }^{70}$, em 1988, realizaram um estudo comparando a resistência adesiva ao cisalhamento do Scotchbond, associado à resina Silux, em esmalte e dentina, os quais foram preparados com brocas de alta e baixa velocidade, com discos de lixa de carbeto de silício de granulação 320 e 600, e com disco de diamante em baixa 
velocidade. Foi observado que não houve diferença estatística significante quando as ligações foram feitas em smear layer, tanto em esmalte quanto em dentina. Verificou-se, ainda, que a smear layer dentinária criada com brocas de baixa velocidade ou com lixa de carbeto de silício, nas duas granulações utilizadas, forneceram as mesmas resistências adesivas. A microscopia eletrônica de varredura, de ambos os lados dos espécimes fraturados, indicou falhas coesivas da smear layer, isto é, as forças que mantiveram a smear layer presa à superfície pareceram limitar, em última instância, a adesão do sistema Scotchbond/Silux.

Em 1962, iniciou-se uma nova era na odontologia, quando BOWEN ${ }^{12}$, após várias pesquisas, juntou a resina epóxica com a resina acrílica obtendo o BIS-Gma, dando origem à Resina de Bowen, que é a parte orgânica da resina composta.

ARAÚJO; ASMUSSEN² ${ }^{2}$ em 1989, analisaram várias modificações na formulação do chamado Gluma ${ }^{\circledR}$ Resin, sistema formulado à base de acetona com o propósito de obter um pré-tratamento de mais fácil aplicação clínica. A quantidade de acetona nas formulações foi alterada ou a acetona, como também parte da água, foram substituídas por um dos vários componentes voláteis. Algumas alterações de $\mathrm{pH}$ da mistura também foram realizadas e, então, testadas. Espécimes de dentina foram condicionadas com uma solução de glicina e oxalato de alumínio. As superfícies foram depois tratadas com as misturas do Gluma ${ }^{\circledR}$ Resin modificadas com resina composta e, então, submetidas ao teste de resistência ao cisalhamento. Um dos solventes utilizados na substituição da acetona foi o tetrahidrofurano e os grupos que apresentavam esse solvente em sua formulação apresentaram valores aceitáveis de resistência ao cisalhamento. Altos valores de resistência ao cisalhamento foram obtidos nos grupos onde as formulações apresentavam pH ácido. 
FELTON; BERGENHOLTZ; COX ${ }^{26}$, em 1989, investigaram o efeito de GLUMA® (HEMA 35\%, e Glutaraldeido 5\%), sobre a colonização de bactérias, em cavidades com dentina infectada e restauradas com resina composta, correlacionando a curto e longo tempo a resposta da polpa dental. Cinco macacos foram usados nesta pesquisa, com um total de 120 dentes. Uma semana antes de se iniciar o experimento, os dentes de cada animal foram limpos e selecionados, aos quais foram realizados preparos cavitários Classe $V$ na face vestibular. Todas as cavidades foram padronizadas no tamanho de $2 \mathrm{~mm}$ Ocluso-cervical e $3 \mathrm{~mm}$ Mesio-Distal, sendo que a margem estava localizada a $2 \mathrm{~mm}$ oclusalmente na junção esmalte-cemento. A parede axial estava a $0.5 \mathrm{~mm}$ da polpa. Os dentes foram divididos em 6 grupos. Todas as cavidades, com exceção as do Grupo $\mathrm{V}$, as quais foram condicionadas com ácido cítrico, foram lavadas para remoção da smear layer; todas as outras cavidades ficaram abertas por 48 horas para permitir o acúmulo de placa bacteriana. Após este período, as cavidades foram limpas. A margem do esmalte foi biselado e a restauração foi realizada da seguinte forma: Grupo I- (tratamento com Gluma®), 30 segundos com EDTA, lavagem e secagem, aplicação de GLUMA® Dentin Bond (Glutaraldeido a 5\% e HEMA a 35\%); a margem do esmalte foi condicionada, lavada e seca, aplicado Bayer Resin L, e restaurada com a resina composta Lumifor. Grupo II- as cavidades receberam o tratamento completo de GLUMA® e foram restauradas com o mesmo material, não foi feito o condicionamento ácido do esmalte depois. Grupo III- as cavidades somente foram restauradas com resina composta. Grupo IV- as cavidades foram tratadas com Scotchbond, incluindo condicionamento ácido na margem do esmalte, e restauradas com a resina composta Silux. Grupo Vas cavidades foram imediatamente restauradas com o tratamento completo GLUMA®, seguido pelo condicionamento ácido do esmalte, aplicação de resina sem carga e resina composta Lumifor. Grupo VI- as cavidades não receberam nenhum tratamento, permanecendo abertas ao meio oral. Foi realizado análise histológica - o dente foi analisado por duas vezes: A primeira, 8 dias depois e a outra 90 dias. Os espécimes foram seccionados 
de 120 a 200 vezes. As secções foram avaliadas por 3 diferentes investigadores antes de se identificar o tipo de tratamento. Foram notadas a presença ou ausência de células inflamatórias, organização do tecido pulpar e a extensão da reparação do tecido duro. Presença ou ausência de bactérias na interface cavidade/restauração. No caso de presença, foi relatado onde havia abundância de bactérias e onde a bactéria estava localizada. As bactérias não puderam ser localizadas nas cavidades tratadas com GLUMA® (Grupos I, II e V). Quando foram restauradas só com resina (Grupo II) ou com Scotchbond (Grupo IV) ou quando não receberam tratamento (Grupo VI), foram claramente encontradas bactérias na maioria das cavidades, em ambos com intervalo de tempo de 8 a 90 dias. Na análise da resposta do tecido pulpar, após 8 dias, três apresentaram respostas do tecido pulpar idênticos. Aproximadamente $40 \%$ dos dentes apresentaram polpa com ausência de células inflamatórias e morfologia do tecido pulpar normal, exceto para a minoria de troca estrutural da camada de odontoblastos subjacentes ao preparo cavitário. Outro dentes exibiram similares características nas amostras, localizados infiltrados MNL. A terceira categoria apresentou-se com definida infiltração PMN. Em todos os casos com infiltração inflamatória foram confirmados na porção coronal da polpa. Quatro dentes, sendo 1 do Grupo II ; 2 do Grupo III e 1 do Grupo VI, apresentaram micro-abscessos. Os Grupos foram comparados, e o Grupo IV mostrou mais dentes com lesões agudas do que os do Grupo I, e, também, o Grupo VI mais do que os Grupos I e V. Em geral, a resposta da polpa em 90 dias foi caracterizada pela cicatrização e reparação. Foi encontrada dentina reparadora subjacente ao prepara cavitário, menos no grupo experimental. Um dente do Grupo II, próximo à polpa apresentou uma lesão aguda. Nenhuma diferença foi constatada entre os grupos, em relação à quantidade de dentina, separando o piso da cavidade da polpa. Nesta investigação foi demonstrado que a restauração com cavidades sem base com uma resina composta, seguida de pré tratamento da parede da cavidade com GLUMA $®$ Dentin Bond, resultou em injúria pulpar mínima, e, após 90 dias havia a formação de dentina reparadora. A ausência da inflamação pulpar, em 
dentes restaurados com GLUMA®, é possível que com a aplicação de Gluma ${ }^{\circledR}$, por conter glutaraldeido que inibe ou previne a colonização microbiana ao longo das paredes da cavidade; mesmo em restaurações colocadas sem o uso de condicionamento ácido, não foram encontradas as bactérias. Estas descobertas indicam que Gluma ${ }^{\circledR}$ apresenta um efeito antibacteriano. Os pesquisadores puderam observar que a polpa, em dentes restaurados com pré-tratamento com GLUMA®, não mostrou inflamação nos diferentes intervalos de tempo. A favorável resposta pulpar das restaurações de resina composta com pré-tratamento com o uso de GLUMA® deve ser em função da redução da permeabilidade dentinária, pois o glutaraldeido tem a capacidade de fixar, biologicamente, o qual deve desnaturar as proteínas do fluido dentinário superficialmente mínima, assim que a proteína do plug seja formada. O glutaraldeido do GLUMA® deve apresentar efeitos benéficos sobre a polpa de 3 formas: 1- facilitando a união da resina composta à dentina, eliminando ou reduzindo as fendas; 2- a invasão de bactérias de alguma fenda restante é prevenida e, 3- é reduzida a permeabilidade dentinária ou bloqueada. Houve diferença na resposta pulpar entre os grupos, tanto em 8 e 90 dias. A inflamação observada no menor tempo foi na exposição prévia por 48 horas. A presença de lesões agudas sugerem que componentes da bactéria têm efeito pulpar continuado. $O$ Gluma ${ }^{\circledR}$ promete uma resposta mais rápida de cicatrização do que o Scotchbond, pela eliminação mais efetiva da contaminação bacteriana. Os autores puderam concluir que, do ponto de vista clínico, é importante que se realize o selamento hermético da margem da cavidade; eliminando-se as bactérias invasoras como prevenção para reduzir reações adversas sobre a polpa. A partir destes dados, parece, a longo prazo, que a infiltração de bactérias não está arriscando a vitalidade da polpa.

VAN NOORT et al. ${ }^{76}$, em 1989, avaliaram vários métodos de análise e medida da resistência adesiva e discutiram alguns procedimentos padrões e de controle para estes testes. A falta de valores consistentes para a resistência adesiva à dentina em testes de cisalhamento ou tensão, que são 
procedimentos experimentais superficialmente idênticos, tem levado a uma ambigüidade na interpretação dos dados. Estas variações na resistência adesiva são consideradas, usualmente, por estarem relacionadas aos diferentes procedimentos adesivos. Utilizando uma análise de elemento finito, os autores calcularam a sensibilidade da resistência adesiva em diversas condições de teste. A resistência adesiva em teste de tensão ou cisalhamento é altamente dependente da geometria do corpo-de-prova, tipo de carga utilizada e da dureza dos materiais envolvidos. Os autores afirmam que há necessidade de padronização dos testes de resistência adesiva para que as medidas possam ser comparadas com outros trabalhos, e demonstraram que não há uma tensão ou cisalhamento uniforme na interface entre a dentina e a resina composta

ARAUJO; ASMUSSEN ${ }^{3}$, em 1990, analisaram o efeito de dois adesivos (Scotchbond 2 e Tenure), e investigaram, também, duas recentes modificações no sistema Glumaß. Analisaram a adaptação das resinas compostas em relação às paredes das cavidades rodeadas por esmalte e condicionadas por ácido. Utilizaram, neste trabalho, dentes molares humanos, extraídos, nos quais foram confeccionadas cavidades com $4.0 \mathrm{~mm}$ de comprimento, $3.0 \mathrm{~mm}$ de largura e $2.0 \mathrm{~mm}$ de profundidade. Foi aplicado, nas cavidades, o adesivo e, depois, estas foram restauradas com resina composta (Tenure, P50 e Estilux Posterior). Os autores observaram que, devido à contração de polimerização das resinas compostas, a presença de fendas no esmalte foi sempre encontrada e associada a fraturas na margem do esmalte. Eles concluíram que o adesivo dentinário não deve aumentar a qualidade da restauração de resina composta em cavidades rodeadas por esmalte condicionado por ácido. Nenhum adesivo dentinário, até 0 momento, foi capaz de evitar a contração da resina composta.

POWELL et al. ${ }^{57}$, em 1990, avaliaram a efetividade do material restaurador em relação à redução da sensibilidade, e também foi feita uma comparação entre alguns materiais. Para isto, foram selecionados 24 
pacientes, sendo que cada um apresentava no mínimo 3 lesões, as quais possuíam $1 \mathrm{~mm}$ de profundidade. O número de lesões observadas foram 108 e estas foram restauradas usando-se 3 tipos de materiais diferentes, da seguinte forma: 1- material restaurador CIV Ketac (ESPE - Primer); 2- resina composta de micropartícula Silux Plus (3M Dental Products) usada com 0 sistema adesivo Scotchbond 2 (3M) e 3- tendo como forramento o CIV Vitrabond e restaurada como no Grupo 2. Cada paciente recebeu os 3 tipos de tratamento. Quando foi usado o CIV, foi aplicado antes, na cavidade, o ácido poliacrílico a 10\%. Quando o sistema adesivo foi usado, as cavidades foram condicionadas com ácido fosfórico, previamente, ao sistema adesivo. Quando foi usado o CIV como base na dentina, ela não recebeu nenhum tido de condicionamento. Em todas as restaurações, após o término, foram removidos os excessos com instrumentos manuais e brocas carbide, e estas foram polidas com discos de lixas Sof-Lex (3M). Depois, todos os dentes foram submetidos a avaliação pré- operatória para se avaliar o grau de sensibilidade e este teste foi repetido após 1 semana e após 6 meses novamente. Os testes aplicados para avaliação da sensibilidade foram feitos com água fria, água quente e ar. As respostas foram avaliadas da seguinte forma: $0=$ nenhuma sensibilidade; 1=desconforto médio; 2=desconforto moderado e 3=desconforto severo. As respostas foram analisadas estatisticamente. Os autores concluíram que a resina composta, quando usada com o CIV como base, diminuiu significativamente a sensibilidade ao ar, água fria e quente. As restaurações com CIV e resina composta usada com um sistema adesivo, diminuiu a sensibilidade, embora foram também associadas a um aumento de sensibilidade ao ar e frio, respectivamente, em $20 \%$ à $30 \%$ após 6 meses, quando foram reavaliadas.

$\mathrm{Na}$ tentativa de padronizar os testes de adesão de laboratório devido a grande variação de metodologias que dificulta e não permite a comparação dos resultados dos diferentes estudos, RETIEF $^{59}$, em 1991, descreveu a metodologia de testes de cisalhamento, microinfiltração marginal e avaliação da dimensão do gap marginal na interface dente/restauração. Com relação 
aos testes de cisalhamento, o autor considera que as forças sofridas pela restauração clinicamente não são reproduzidas em laboratório, mas o considera atualmente mais preciso, apesar de concordar que a resina composta unida à superfície de dentina ao sofrer carregamento ou tensão, tem o estresse distribuído ao longo da interface de forma extremamente irregular. Quanto ao fato de alguns pesquisadores estarem usando dente bovino em testes de adesão pela dificuldade de se conseguir dentes humanos extraídos e intactos, citam vários resultados de trabalhos que concluíra não haver diferenças significantes entre os testes de cisalhamento no esmalte e dentina de ambos. O período de estocagem dos dentes da realização dos preparos também foi comentado, e com base em alguns estudos concluíram não haver diferença na estocagem de dois dias e 6 meses. Os líquidos para estocagem mais comum são: formalina, cloramina, álcool soro fisiológico e timol, de acordo com o autor, somente ocorreram diferenças significantes nos testes de cisalhamento quando os dentes foram estocados em álcool a 70\%. Considerou como decisivo a seleção da área do dente a ser preparado devido ao tamanho dos túbulos e relatou que nas superfícies proximais de molares não foram notadas diferenças significantes quando comparadas com a dentina da superfície oclusal. A rugosidade superficial da dentina também pode influenciar nos testes de cisalhamento, entretanto considerou este fator muito controverso na literatura. Outro parâmetro crítico que afeta consideravelmente a adesão, segundo o autor é a espessura da dentina depois de preparado, vários estudos comprovaram que quanto mais próximo da polpa, menores são os valores encontrados, provavelmente pelo diâmetro e número dos túbulos dentinários desta região. A área de demarcação para a união também pode afetar a adesão, e o excesso de material nas margens desta área pré-determinada pode aumentar significantemente o valor do teste, citou como diâmetro ideal para o teste uma área circular de $3 \mathrm{~mm}$. A aplicação do sistema adesivo, de acordo com o autor deve seguir as instruções do fabricante. Sua última consideração sobre os testes de cisalhamento foi sobre as bases aplicadoras da força que pode ser retangular ou em forma de ponta de faca, 
alguns estudos mostraram que a segunda apresentou resultados maiores. Sugeriu que para ficar mais fácil a comparação entre os dados de trabalhos diferentes, os resultados fossem expressos em MPa. Ao examinar a literatura com relação aos testes de microinfiltração encontrou uma enorme variação de testes, a começar pela localização das margens do preparo que podem ser abrangendo esmalte e dentina ao longo da junção amelodentinária, entretanto a ADA, estipulou que para testes com materiais adesivos dentinários, o preparo deverá ser exclusivamente em dentina. Os procedimentos restauradores devem seguir instruções do fabricante e a restauração realizada em 2 fases e a resina aplicada de forma obliqua que reduz em aproximadamente $25 \%$ o gap marginal. O acabamento das restaurações pode ser realizado 15 minutos após o final da polimerização e depois estocado em água destilada por 24 horas antes da ciclagem, diminuindo substancialmente o "gap" marginal. A ciclagem ideal segundo o autor seria de 500 ciclos com banhos entre $\pm 50^{\circ} \mathrm{C}$ e $\pm 8^{\circ} \mathrm{C}$, permanecendo 15 segundos em cada banho, isto porque nenhum alimento permanece intraoralmente por um tempo maior que este. Com relação à metodologia de leitura da infiltração citou os métodos qualitativos e quantitativos, sendo este último mais preciso. Finalmente ao analisar testes que avaliam a dimensão dos gaps marginais na interface dente/restauração recomendou o método de van Dijken e Horstedt, que utilizam réplicas de resina epóxica.

WATANABE et al. ${ }^{78}$, em 1991, examinaram fisiologicamente os efeitos de primers dentinários sobre a sensibilidade da dentina. Os agentes adesivos testados foram: HEMA; GA-HEMA; MASA; GM. Foram usados neste estudo coelhos, em cujos dentes incisivos centrais inferiores foram preparadas, na face vestibular, cavidades classe $\mathrm{V}$, em dentina a qual sofreu uma irritação com jatos de ar comprimido. Depois das medidas das irritações, os dentes foram extraídos e seccionados ao longo da parede axial no centro da cavidade, sendo, depois, as fatias analisadas através do microscópio eletrônico. Os autores concluíram que a aplicação combinada de uma solução aquosa de hidroxietilmetacrilato a $35 \%$ e um agente 
adesivo dentinário foi eficaz na redução da irritação repetitiva e na manutenção de um efeito "sedativo". Embora os túbulos dentinários tenham sido selados mecanicamente através de material resinoso, foi impossível explicar o mecanismo pelo qual a aplicação de primer dentinário pudesse reduzir a irritação.

SORENSEN; DIXIT ${ }^{67}$, em 1991, avaliaram a resistência adesiva, através do teste de cisalhamento, de vários agentes adesivos dentinários de última geração (Scotchbond, Tenure, Gluma ${ }^{\circledR}$ e Dentin Adhesit) os quais foram aplicados à dentina humana. Cada adesivo foi usado com sua respectiva resina composta, fotopolimerizável, de acordo com as instruções do fabricante para confecção dos corpos de prova que, após o término, foram armazenados em água a $37^{\circ} \mathrm{C}$ por 21 dias, sendo, em seguida, submetidos à ciclagem térmica. Os autores observaram que: a capacidade de resistir ao armazenamento e à termociclagem variou significativamente entre os materiais; registraram-se grandes coeficientes de variação para todos os adesivos dentinários; o maior valor de resistência obtido entre os agentes adesivos utilizados foi com o Tenure, cujo valor representou apenas $37 \%$ do obtido no grupo-controle que verificou a união adesiva ocorrida entre o esmalte e a resina (19 MPa.). Como estes sistemas não puderam estabelecer uma união adesiva semelhante à apresentada ao esmalte, eles foram considerados somente como uma melhoria da primeira geração de adesivos.

PASHLEY ${ }^{48}$, em 1992, pesquisou, através de levantamentos bibliográficos, os efeitos do condicionamento do ácido sobre o complexo pulpo dentinário, usado por muitos sistemas adesivos, para remover a smear layer e permitir a aderência diretamente à matriz dentinária. Embora estudos em animais indicassem que o condicionamento com ácidos causasse reações pulpares de moderadas a severas, há uma grande probabilidade de que a irritação pulpar possa ter ocorrido devido à microinfiltração de bactérias e seus produtos. Como estas reações não foram observadas após 
o condicionamento ácido de dentina, usando-se sistemas adesivos dentinários mais novos, está claro que uma dentina condicionada com ácido deverá ser selada com sistemas adesivos subsequentemente aplicados. Porque o condicionamento ácido aumenta a permeabilidade e umidade dentinária, a aderência bem sucedida de resinas adesivas à dentina condicionada com ácido requer o uso de resinas hidrofílicas que aderem muito bem tanto a dentina peritubular quanto a intratubular. As tendências futuras parecem estar voltadas tanto para a menor concentração de ácidos quanto para diminuição do tempo de condicionamento de dentina. Enquanto todos os sistemas adesivos devem ser cuidadosamente examinados antes de sua comercialização, o futuro parece muito promissor para o uso de resinas dentinárias na dentina condicionada com ácido.

PASHLEY et al. ${ }^{51}$, em 1992, compararam 6 agentes adesivos de terceira geração em suas habilidades de selamento dos túbulos dentinários em preparos de coroas totais. Usaram para este trabalho, in vitro, dentes humanos, terceiros molares após um mês da extração. As raízes dos dentes foram seccionadas a $2 \mathrm{~mm}$ abaixo da junção cemento-esmalte. A parte coronária foi cimentada em um bloco de Plexiglas, e foi usado, para isto, Zapit-brand (DVA, Anaheim, CA 92808) de ciano acrilato. O Pexiglas foi perfurado por uma agulha, o que permitiu preencher a câmara pulpar com uma solução salina tamponada, para simular a pressão do sistema do fluido dentinário. O preparo da coroa total foi feito a 1,5 - $2 \mathrm{~mm}$ acima da junção cemento-esmalte, e se encontrava a uma altura de 4 a $5 \mathrm{~mm}$ da margem gengival com redução oclusal. Foram usados dois métodos diferentes para se avaliar o selamento dos túbulos. A primeira técnica avaliou a quantidade de infiltração do fluido através da dentina, antes e após o tratamento com o agente adesivo, analisando-se, também, variações de tempo de 1 hora, 1 dia, 1 semana e, depois, 1 mês; sendo, depois, submetida à termociclagem. O segundo método adotado foi feito com nitrato de prata, onde analisaram o seu grau de penetração na interface entre o agente adesivo e a dentina. Ambos os métodos foram correlacionados entre si. O melhor selamento foi 
obtido quando usou-se o sistema Prisma Universal Bond 2 e também o Super Bond Power Plus líquido. O pior selamento foi obtido quando usou-se - GLUMA® e apenas o Superbond líquido. O Clearfil Photobond, o Amalgambond e o Scotchbond 2 apresentaram resultados intermediários. Os autores concluíram que, embora os dados sugerem que alguns agentes adesivos, como o Prisma Universal Bond 2 ou o Superbond, poderiam ser úteis no selamento da dentina exposta em preparos de coroas totais, mais pesquisas devam ser realizadas antes do seu uso clínico.

PRATI et al. ${ }^{58}$, em 1992, compararam o efeito de 9 diferentes tipos de tratamentos dentinários com SEM, comparando a aparência e resistência à adesão dos CIV Vitrabond, em dentina humana, in vitro, numa tentativa de descobrir qual é o pré-tratamento que produz a mais alta resistência ao cisalhamento na interface dentina/vitrabond. Foram usados dentes humanos, terceiros molares extraídos de pacientes jovens, livre de fraturas, defeitos e cáries. Os dentes foram incluídos em resina acrílica e lixados até expor a dentina. Cada espécime recebeu o seguinte tratamento: Solução Salina, $\mathrm{pH}=7.4$ (2 minutos); Hipoclorito de sódio a 3\%, $\mathrm{pH}=10.1$ (1 minuto); ácido pirúvico a 10\% w/w, pH=1.0 (1 minuto); ácido poliacrílico gel a 10\%, pH 2.6 (10 segundos); ácido maleico a 10\% W/W +glicina a $10 \% \mathrm{w} / \mathrm{w} \mathrm{pH} 1.0$ (1 minuto); glicina a $10 \% \mathrm{w} / \mathrm{w} \mathrm{pH}=3.9$ (1 minuto); ácido maleico a $10 \% \mathrm{w} / \mathrm{w}$ $\mathrm{pH}=2.0$ (1 minuto) ; ácido tânico a $25 \% \mathrm{w} / \mathrm{w}$ pH 3.9 (1 minuto); EDTA pH=7.4 (1 minuto); Oxalato dipotássio 30\%, pH=9.0 (2 minutos). Amostras cilíndricas de Vitrabond foram confeccionadas sobre cada superfície. Algumas amostras foram testadas após 5 minutos para determinar a força de resistência imediata. $O$ resto das amostras foi armazenado a $37^{\circ} \mathrm{C} \mathrm{em}$ umidade relativa a $100 \%$ por 24 horas. Os espécimes foram levados a uma máquina de teste universal, aplicando-se uma carga de cisalhamento através de uma alça de aço inoxidável no nível da superfície da dentina a uma, velocidade de $0,5 \mathrm{~cm} /$ minutos. Após as falhas de união as amostras foram observadas sob microscópio para avaliação do tipo de fratura. Os resultados foram analisados estatisticamente pelo método ANOVA e pelo 
teste de Dunca's. A solução salina (grupo controle) apresentou uma resistência ao cisalhamento de 4.36 MPa. para 5 minutos e, após 24 horas, foi de $5.94 \mathrm{MPa}$. Quando foi usado ácido poliacrílico ou pirúvico, a resistência ao cisalhamento caiu um pouco em relação ao grupo controle, embora, estatisticamente, insignificante. O tratamento com o hipoclorito de sódio provocou uma acentuada redução de resistência ao cisalhamento, sendo o menos resistente. Os outros foram capazes de aumentar a resistência adesiva embora não apresentando estatisticamente aumento significante, exceto para o grupo de oxalato, cujo tratamento apresentou a mais alta resistência ao cisalhamento após 24 horas e uma resistência adesiva quase igual à resistência coesiva do vitrabond, sendo que em 3 das 9 amostras as falhas foram coesivas. Para todos os outros pré-tratamentos as falhas foram adesivas. Na análise com SEM da superfície da dentina pode-se observar que: o hipoclorito de sódio resultou em uma aparência normal da smear layer; o ácido pirúvico removeu ambas smear layer e smear plug, alargando os orifícios dos túbulo, expondo as fibras colâgenas dentro e entre os túbulos; o ácido poliacrílico produziu uma parcial remoção das smear layer superficial; o ácido maleico, mais a glicina, produziram um tratamento similar ao ácido pirúvido aumentando os orifícios tubulares; a solução de glicina removeu apenas parcialmente a smear layer; o ácido maleico produziu uma extensiva desmineralização na superfície expondo mais as fibras colágenas do que as outras superfícies tratadas; o ácido tânico produziu menos condicionamento da superfície; a solução de EDTA removeu a smear layer e smear plug, embora não evidenciando as fibras colágenas; a solução de oxalato produziu uma camada de cristais de oxalato sobre toda a superfície. Os autores puderam concluir que o uso do hipoclorito de sódio resultou na mais baixa resistência ao cisalhamento, seguindo, em ordem crescente, o poliacrílico, o pirúvico, o grupo controle de solução salina, o maleico mais glicina, a glicina, o maleico, o tânico, o EDTA e, o melhor de todos, a solução de oxalato. Embora a resistência ao cisalhamento do CIV foi aumentada somente com o uso da solução de oxalato é que realmente apresentou um aumento significante. 
Em 1992, KIDD ${ }^{39}$ fez uma revisão na literatura sobre cárie secundária, que é a principal causa de falhas nas restaurações e, portanto, merece atenção para que a Odontologia operante tenha um resultado satisfatório. Com base nesta revisão constatou-se que há dificuldades em se diagnosticar estas cáries, e que, nem sempre, podem ser completamente tratadas através de um controle ativo. Terapias preventivas são essenciais, porém dependem dos pacientes se cuidarem. Entretanto, a qualidade do material restaurador e a habilidade com que se manipula este material é relevante para prevenir novas falhas.

PASHLEY; TAO; PASHLEY ${ }^{52}$, em 1993, observaram o quanto o tratamento tópico com oxalato de potássio, usado previamente, interferiu na adesividade de um adesivo dentinário resinoso. Utilizaram, neste estudo, terceiros molares humanos, extraídos, os quais foram armazenados por 5 dias a $4^{\circ} \mathrm{C}$ em PBS; depois as raízes foram seccionadas na junção esmaltedentina e o esmalte oclusal foi removido, sendo que a superfície oclusal de cada coroa foi tratada com Protect (oxalato de potássio). Utilizaram os adesivos dentinários Prisma Universal Bond 3 e ALL Bond No Etch, que não requeriam a remoção da smear layer. Utilizaram, também, Superbond C \& B, Scotchbond 2, Tenure e Bayer experimental, os quais requeriam a remoção da smear layer. Na área pré-estabelecida da dentina as amostras foram tratadas da seguinte forma: 1- Somente com o sistema adesivo; 2- Utilizaram o Protect, previamente, no sistema adesivo; 3- Utilizaram Protect depois foi feito um polimento com pedra pomes, e em seguida o sistema adesivo. Sobre esta área foi utilizada uma matriz de nylon cilíndrica e restaurada com Silux Pluz. Para os 7 sistemas adesivos foram utilizados 5 amostras, que foram armazenadas, posteriormente, em solução isotônica a $37^{\circ} \mathrm{C}$ por 24 horas. Após este período, foram submetidas a teste de cisalhamento e observadas após o teste, microscopicamente, para observar se as falhas foram adesivas, coesivas, em resina ou dentina. A resistência foi calculada em MPa. Os resultados apresentados foram: (1) sem o uso do oxalato: Superbond $16.5 \pm 2.4$; All Bond No Etch 9,2 \pm 1,5; All Bond 7,1 \pm 1,6; 
Scotchbond 2 8,9 \pm 1,3; Prisma Universal Bond 3 3,6 4 1,8; Tenure 3,4 4 0,7; Experimental Bayer 1,6 $\pm 1,1$; (2) com Oxalato: Superbond 1,1 \pm 0,6; All Bond No Etch 3,9 \pm 1,4; All Bond 7,1 \pm 1,6; Scotchbond 2 2,3 \pm 1,5; Prisma Universal Bond 3 2,1 \pm 1,0; Tenure 2,3 \pm 1,5; Bayer 0,9 \pm 0,6; (3) Com pedra pomes: Superbond 13,6 \pm 1,0; All Bond No Etch 11,8 \pm 1,0; All Bond 6,1 \pm 2,1; Scotchbond 2 2,9 \pm 1,7; Prima Universal Bond 3 4,6 $6 \pm$ 1,9; Tenure $5,3 \pm 1,4$; Bayer 0 . Os resultados indicaram que quando o oxalate foi usado sob os adesivos Superbond, All Bond e Scotchbond 2, houve uma diminuição na resistência ao cisalhamento e uma resistência igual para o Superbond, All Bond, quando foi utilizado a pedra pomes antes dos adesivos. Concluíram que, o tratamento com oxalato de potássio usado como agente dessensibilizante na base de cavidade, pode interferir na habilidade de adesividade de alguns sistemas adesivos.

DALL'OROLOGIO; MALFERRARI ${ }^{24}$, em 1993, avaliaram, in vivo, e compararam a efetividade do Gluma ${ }^{\circledR} 3$ Primer $(G L)$ e de uma solução condicionadora de Gluma ${ }^{\circledR} 2000$ Conditioner (GT) sobre a hipersensibilidade dentinária. Foram selecionados 34 pacientes adultos, apresentando sensibilidade dentinária em superfícies radiculares expostas. Os pacientes foram distribuídos em grupos, por idade, e os dentes foram divididos em arcada superior e inferior, por dentes (incisivos, caninos, prémolares e molares). Os pacientes apresentavam, em comum, dor intensa em áreas cervicais, quando expostos a estímulos frios. De 166 dentes, 40 foram tratados com Gluma® 3 Primer, 42 com Gluma ${ }^{\circledR}$ Condicioner e 34 serviram de grupo controle (não receberam tratamento). Quatro dentistas identificavam os pacientes e os registravam, usando um método comum para determinar o grau de sensibilidade: 1- Estímulo tátil, utilizando-se, para isto, uma sonda exploradora; 2- Estímulo térmico, aplicando-se ar frio por 2 segundos. Foi feito uma escala de sensibilidade, sendo: 0=não desconforto; 1=desconforto leve; 2=desconforto severo; 3=dor severa e continuada, mesmo removendo os estímulos. Os pacientes expressavam verbalmente a dor ou desconforto, e apresentavam no mínimo o grau 2. Quando a dor era 
em 2 dentes (lado direito e esquerdo), um lado servia como grupo controle, e o outro recebia um dos tratamentos. Quando apresentavam 3 dentes, um era usado como grupo controle, outro recebia tratamento de Gluma $\mathbb{} 3$ Primer e o outro Gluma ${ }^{\circledR} 2000$ Conditioner. Os pacientes foram chamados para avaliação após 1 semana, 1 mês, e 6 meses. Os relatos dos estímulos foram analisados estatisticamente pelo teste Kruskal-Wallis. Com ambos GL e GT houve uma redução acentuada da dor. Não apresentando diferença entre as duas soluções, em termos de capacidade de dessensibilização. Houve uma redução de sensibilidade tanto para estímulos térmico e tátil. Os autores concluíram que o tratamento com Gluma ${ }^{\circledR} 3$ Primer mostrou uma redução significativa na sensibilidade $e$, com a administração tópica de Gluma 3 Primer ou Gluma ${ }^{\circledR} 2000$ Condicioner, ambas apresentaram efetividades iguais em todos os retornos de reavaliações. A redução da sensibilidade, após 1 mês, foi mantida por 6 meses, somente para o grupo controle e a dor registrada em 1 mês diminuiu após 6 meses.

Em 1994, HAVEMAN; CHARLTON ${ }^{32}$ avaliaram, através do teste de cisalhamento, a superfície da dentina quando submetida ao tratamento com uma solução de oxalato e utilizado juntamente com o material restaurador cimento de ionômero de vidro fotoativado. Analisaram, também, através de microscópio eletrônico, o efeito de diferentes tipos de tratamentos dentinários. Para o teste de cisalhamento foram utilizados 90 dentes molares humanos, extraídos. A superfície oclusal foi aplainada até chegar na dentina. Depois, os dentes foram montados em anéis de resina, deixando a face oclusal exposta a qual recebeu polimento. Os dentes foram divididos em 6 grupos, contendo 15 dentes em cada grupo, e tratados da seguinte forma: Grupo 1- A superfície da dentina foi tratada com ácido poliacrílico a 10\%, por 20 segundos, lavada e seca. Sobre a área condicionada foi colocado um molde de politetra-fluoretano, com uma perfuração central de $5 \mathrm{~mm}$ de diâmetro e com $3 \mathrm{~mm}$ de profundidade o qual foi preenchido com o material restaurador Fuji II LC e fotopolimerizado. O material foi protegido com uma camada de adesivo Scotchbond Multi Purpose e fotopolimerizado. Os 
espécimes foram armazenados em água e mantidos em estufa a uma temperatura de $23 \pm 2^{\circ} \mathrm{C}$. Grupo 2- Foi aplicado na superfície da dentina o Protect Dentin Desensitizer, por 2 minutos e depois foi lavada e secada. Sobre esta área foi colocado o molde e preenchido com Fuji II LC, como no grupo 1. Grupo 3- Foi aplicado o Protect Dentin Desensitizer como no grupo 2, depois foi aplicado o GC Conditioner e sobre esta superfície foi colocado o molde e preenchido com Fuji II LC como no Grupo 1. Grupo 4- Foi aplicado na dentina o primer do Prisma Universal Bond 3, seco a ar e sobre esta área foi colocado o molde e preenchido com VariGlass VLC como no Grupo 1; depois, foi fotopolimerizado e armazenado em água. Grupo 5- foi aplicada na superfície da dentina uma solução de oxalato como no Grupo 2, e o molde foi preenchido com VariGlass VLC como no Grupo 4. Grupo 6- Na superfície da dentina foi aplicada uma solução de oxalato, como no Grupo 2; depois foi aplicado o primer do Prisma Universal Bond sobre está área e foi colocado o molde e preenchido com VariGlass VLC como no Grupo 4. Todas as amostras foram armazenadas por 72 horas e posteriormente foram submetidas a termocilagem por 500 ciclos em temperaturas que variaram de $5^{\circ}$ a $55^{\circ} \mathrm{C}$ (40 segundos em cada ciclo). Após 7 dias, todas as amostras foram submetidas ao teste de cisalhamento e, após a fratura, cada espécime foi analisado microscopicamente para determinar o tipo de fratura. Os resultados foram analisados estatisticamente através do teste ANOVA e Scheffé teste-F $(P<0.05)$. Separadamente, foram formados outros grupos com molares humanos extraídos e tratados como os dos Grupos 1, 4 e 6, e estes foram analisados através de microscópio eletrônico. Como resultado, observaram que o uso da solução de oxalato afetou, de forma adversa, a resistência ao cisalhamento, apresentando uma diminuição significativa da resistência adesiva quando aplicada previamente ao cimento de ionômero de vidro Fuji II LC e VariGlass VLC.

HOLTAN et al. ${ }^{34}$, em 1994, compararam e classificaram a força de adesão à dentina, em molares humanos, extraídos, de cinco sistemas adesivos dentinários disponíveis no mercado (XR Bond, Scotchbond Multi- 
Purpose, Syntac, All-Bond 2, Denthesive), usando o Scotchbond 2, como controle, e construíram pequenos cilindros com a resina Silux Plus sobre a superfície dentinária. Os sistemas adesivos e a resina composta foram usados de acordo com as instruções dos fabricantes. Após a confecção dos corpos de prova, estes foram enrolados em gaze umedecida com água e armazenados à temperatura ambiente por 24 horas, antes de serem submetidos ao teste de cisalhamento. Os resultados mostraram que três dos materiais testados sobressaíram em relação à força de adesão à dentina, quando comparados com Scotchbond 2 (4,9 \pm 3,0 MPa.), sendo eles: XR Bond (17,1 \pm 5,1 MPa.), Scotchbond Multi-purpose (15,9 \pm 6,5 MPa.) e o Sybtac (13,5 \pm 8,6 MPa.). Foi observado, através de lupas binoculares, que as falhas dos espécimes fraturados do XR Bond e do Scotchbond MultiPurpose foram de natureza coesiva, isto é, as falhas ocorreram no interior da resina composta ou na própria dentina, mas não na interface adesivo/dentina (falhas adesivas). O Syntac falhou principalmente de forma coesiva e os outros produtos apresentaram apenas falhas coesivas ocasionais. A melhoria destes três materiais em relação ao controle (Scotchbond 2) foi atribuída pelos autores às mudanças nos primers destes materiais, tornando-os mais hidrofílicos em relação ao primer do Scotchbond 2. Foi constatado que os primers hidrofílicos são mais capazes de penetrar completamente na superfície dentinária, e que, uma vez polimerizados, produzem uma grande camada dentinária reforçada, que é tida como a responsável pelas maiores resistências adesivas ao cisalhamento observadas. Os autores notaram, ainda, que existe uma preocupação, por parte dos fabricantes, com relação à diminuição do tempo gasto com o processo restaurador, o que vai ensejar um menor tempo de sessão clínica. Um bom exemplo disto é que o Scotchbond Multi-Purpose não requer quase nenhuma espera após a aplicação do primer, enquanto que seu antecessor, Scotchbond 2, requer um tempo de espera de 60 segundos para reação do primer. 
CHAPPEL; EICK ${ }^{20}$, em 1994, verificaram e compararam, em dentes terceiro molares humanos, extraídos, a resistência de adesão, com testes de cisalhamento de 6 sistemas adesivos dentinários: All-Bond 2, Syntac, Prisma Universal Bond 3, Scotchbond Multi-Purpose, Tenure Solution e Adhesive By Choice. Os autores observaram, ainda, os padrões de fratura através da microscopia eletrônica de varredura. Foram utilizados nos espécimes os sistemas adesivos, segundo as instruções do fabricante e, em seguida, foram construídos cilindros de resina sobre a área de dentina devidamente tratada. Os corpos de prova foram depois armazenados em soro fisiológico por 72 horas a $37^{\circ} \mathrm{C}$, antes de serem submetidos ao teste. Como resultado, puderam observar que houve diferença significativa entre o Scotchbond Multi-Purpose e os outros adesivos, sendo que o Scotchbond Multi-Purpose foi considerado o de maior resistência adesiva (25MPa), em comparação com os outros empregados neste estudo. O mesmo não aconteceu entre os 5 adesivos restantes. Este mesmo teste foi realizado novamente após um período de 8 meses, usando o mesmo material e mostrou que o resultado obtido foi muito próximo ao do primeiro teste, indicando, assim, que não houve deteriorização do Scotchbond Multi-Purpose com o tempo. O ácido maleico, sem utilização da sílica como espessante, removeu a smear layer, abriu os túbulos dentinários e desmineralizou a dentina intertubular. Com os altos valores de resistência ao cisalhamento obtidos com este sistema, houve a penetração do primer e do adesivo na dentina desmineralizada e a maioria das fraturas ocorridas foi de ordem coesiva, quer da dentina, quer da resina composta. O primer, que é composto por uma solução aquosa de HEMA e ácido polialquenóico, não ocluiu os túbulos dentinários. Contudo, o material adesivo aplicado sobre ele os fechou. A superfície de fratura mostrou que houve uma extensa fratura coesiva na dentina e que a junção entre o adesivo e a dentina não mostrou qualquer evidência de separação ou porosidade.

BARKMEIER; ERICKSON ${ }^{9}$, em 1994, avaliaram a resistência ao cisalhamento da união adesiva ao esmalte e à dentina, utilizando o sistema 
adesivo Scotchbond Multi-Purpose, associado à resina composta restauradora P50. As forças adesivas do esmalte foram determinadas em dentes humanos e dentes bovinos. Foram utilizados, neste trabalho, 50 dentes molares humanos, os quais foram divididos em 5 grupos com 10 espécimes em cada grupo. As forças adesivas do esmalte foram determinadas usando-se o novo sistema adesivo SMP de acordo com as instruções do fabricante com o material restaurador P50 (Grupo 5) e com uma variedade de outras técnicas adesivas (Grupos 1-4). As áreas adesiva com esmalte foram condicionadas ou com ácido fosfórico a $37 \%$ ou com ácido maleico a $10 \%$ por 15 segundos. Os agentes condicionantes foram lavados a partir da superfície com um spray de água por 15 segundos. Nos grupos 3 e 5, SMP Primer foi aplicado a superfícies de esmalte condicionadas com uma pequena escova e levemente secas com ar por 5 segundos, deixando uma película brilhante na superfície. Não foi usado primer nos grupos 1, 2 e 4. No grupo 1, foi aplicado Enamel Bond Resina, com uma pequena escova as áreas adesivas, levemente afinadas com ar e foto-curadas por 10 segundos. O material restaurador P50, foi, aplicado nas áreas adesivas, usando-se uma matriz plástica de forma cilíndrica que resultou num cilindro de resina de $3.66 \mathrm{~mm}$ de diâmetro e de aproximadamente $1.8 \mathrm{~mm}$ de comprimento. Os espécimes foram fotopolimerizados por 60 segundos. As forças adesivas de dentina foram determinadas usando-se os sistemas adesivos SMP de acordo com as instruções do fabricante. As áreas adesivas de dentina foram preparadas nas superfícies vestibulares de 10 molares humanos. Os períodos de aplicação e os procedimentos de tratamento foram idênticos ao descrito anteriormente para o Grupo 5 (grupo de esmalte tratado conforme a s instruções do fabricante). Para os dentes bovinos, além destas condições, foram testadas duas outras: a secagem excessiva do primer até o aparecimento de uma superfície fosca e o excessivo afinamento do adesivo, ambos obtidos pela aplicação de ar comprimido, por um período de aproximadamente 15 segundos. Para isto, foram usados 50 dentes incisivos, os quais foram embebidos em anéis de alumínio de 1 polegada com resina 
acrílica. As superfícies vestibulares foram desgastadas com lixa de granulações de 600, e os espécimes adesivos de esmalte foram divididos em dois grupos de 10 dentes cada, e depois tratados. As superfícies de esmalte foram condicionadas com ou com ácido fosfórico gel ou SMP Etchant. Os procedimentos de tratamento do esmalte foram idênticos ao do descrito para os grupos humanos (Grupos 2 e 4). Depois da aplicação do sistema adesivo, foi colocado sobre a superfície condicionada um molde de teflon, e aplicado resina composta P50, formando um molde cilíndrico, a qual foi fotopolimerizada por $60 \mathrm{seg}$., com diâmetro de $4.77 \mathrm{~mm}$ e $2.5 \mathrm{~mm}$ de altura. Os espécimes adesivos de dentina foram divididos em três grupos de 10 dentes. Os períodos de tratamento, e os procedimentos para o grupo 9 foram idênticos ao descrito para os Grupos 5 e 6 (instruções do fabricante), exceto ao do molde de teflon. Como uma variação como as instruções do produto, no grupo 10 o primer foi seco com vapor de ar por 15 segundos. No grupo 11 foi introduzido uma variável final. O adesivo SMP foi agressivamente afinado com ar até que a resina móvel fosse detectável na superfície (aproximadamente por 15 segundos). Todos os espécimes aderidos foram depois armazenados em água destilada a $37^{\circ} \mathrm{C}$ por 24 horas. Seguindo este período de armazenagem, os dentes molares humanos foram montados em resina quimicamente ativadas para fornecer uma base de teste. Os dentes bovinos, anteriormente montados em acrílico, e os dentes molares humanos foram depois levados a uma máquina de ensaio Instron para serem submetidos à determinação das forças adesivas. A força média de adesão para dentina humana sob as condições testadas foi de $25.5 \pm 7.5$ MPa. foi também semelhante à encontrada para dentina bovina (23.4 4.9 MPa.). As variações na técnica de aplicação recomendada foram examinadas na dentina bovina. Com a secagem de ar extrema do primer reduziu levemente a média da força adesiva ao cisalhamento (19.7 \pm 6.4 MPa.) enquanto que em uma significativa redução foi observada quando a resina adesiva foi agressivamente afinada com o ar (10.1 \pm 6.6 MPa.). De acordo com os resultados obtidos, os autores concluiram que o condicionamento do esmalte tanto com ácido maleico a $10 \%$ ou com ácido 
fosfórico a 37\%, promovem resistências adesivas iguais. O uso do primer do SBMP no esmalte humano, condicionado tanto com ácido maleico a $10 \%$ quanto com o fosfórico a $37 \%$, provocou uma redução na resistência adesiva ao cisalhamento de P50 para o esmalte. As forças adesivas ao esmalte bovino foi aproximadamente $35 \%$ mais baixa do que no esmalte humano, usando-se procedimentos adesivos idênticos. Entretanto, com o esmalte humano, não houve uma diferença significativa nas forças adesivas quando o condicionamento com ácido fosfórico foi comparado ao condicionamento com ácido maleico usado juntamente com o sistema SMP e o material restaurador $\mathrm{P} 50$. Na resistência de união da dentina bovina foi similar a encontrada na dentina humana, quando o sistema adesivo foi utilizado seguindo as instruções do fabricante e houve uma redução da união a dentina quando a secagem foi agressiva, provavelmente se deva ao fato da presença do oxigênio que impediu a adequada polimerização da resina adesiva na superfície dentinária. As alterações nas técnicas de tratamento avaliadas neste estudo mostraram que as forças adesivas na dentina foram reduzidas quando os procedimentos de tratamento recomendados não foram seguidos.

MIERS JR.; CHARLTON; HERMESCH ${ }^{42}$, em 1995, avaliaram os efeitos da umidade e do tempo de armazenamento na resistência adesiva do Scotchbond Multi Purpose como mediador da união entre a resina composta e a dentina. Foram usados, para este estudo, 60 dentes humanos, molares, extraídos, os quais foram armazenados em cloramina $\mathrm{T}$, antes do uso. Os espécimes foram divididos em 4 grupos e tratados da seguinte forma: Grupo 1- a superfície dentinária, após o ataque ácido e lavagem, foi seca com jatos de ar por 10 segundos; no Grupo 2- a dentina foi deixada ligeiramente úmida através da secagem com gaze. Depois, foi aplicado o sistema adesivo Scotchbond Multi Purpose nas áreas condicionadas dos espécimes dos dois grupos, e estas foram restauradas com resina composta Z100. Foram, depois, armazenados por 24 horas em água destilada a $37^{\circ} \mathrm{C}$, sendo posteriormente submetidos ao teste de cisalhamento. $O$ mesmo 
procedimento de tratamento da superfície dentinária foi realizado nos Grupos 3 e 4, e os testes foram feitos, após um período de armazenamento de 90 dias. Os resultados mostraram que, após a armazenagem por 24 horas, o grupo em que a dentina estava seca apresentou uma resistência de 13,30 \pm 5,1 MPa e o da dentina úmida foi de 13,64 \pm 4,9 MPa. Após 90 dias de armazenamento, o grupo com a dentina seca apresentou valores de 13,07 \pm 3,8 MPa e, o da dentina úmida, 15,58 \pm 5,3 MPa. Não foram observadas diferenças estatisticamente significativas na resistência ao cisalhamento da dentina seca e úmida, para qualquer um dos tempos de armazenamento empregado. Os autores observaram, também, que a maioria das falhas foram de natureza coesiva, sendo que quase todas ocorreram dentro da dentina.

PENTEADO; ASMUSSEN ${ }^{53}$, em 1995, analisaram fendas marginais em restaurações de resina composta e cimento de ionômero de vidro. A investigação foi feita em dentes humanos extraídos, utilizando-se cavidades com 3,0 mm de diâmetro por 1,0 a 1,5 mm de profundidade, preparadas em dentina, sendo um total de 42 cavidades e divididas em 7 grupos, sendo que, cada grupo era composto por 6 dentes e, tratados da seguinte forma: Grupo A- resina composta Pekafil (como grupo controle); Grupo B- CIV Fuji LC; Grupo C- ácido fosfórico a 10\%, Gluma ${ }^{\circledR}$ 3, Gluma ${ }^{\circledR} 4$ e resina composta Pekafil; Grupo D- àcido fosfórico a 10\%, CIV Fuji II LC; Grupo Eácido fosfórico a 10\%, Gluma® 3, CIV Fuji II LC; Grupo F- ácido fosfórico, Gluma ${ }^{\circledR}$ 3, CIV Photac-Bond Aplicap, Pekafill. As cavidades dos Grupos C, $E, F$ e $G$, depois do condicionamento com ácido fosfórico a 10\%, por 30 segundos, as cavidades foram lavadas por 20 segundos e secas com leves jatos de ar. Depois, foram tratadas com o primer dentinário Gluma ${ }^{\circledR}$, o qual foi aplicado com uma pequena esponja por 30 segundos e secas com leves jatos de ar por 10 segundos, sobre os Grupos C e F foi aplicado resina de baixa viscosidade Gluma ${ }^{\circledR}$ 4, sendo em seguida fotopolimerizado. No Grupo $C$, a resina foi fotopolimerizada junto com a resina composta Pekafill, No Grupo F, a resina foi polimerizada por 20 segundos, antes de ser aplicado o 
CIV. Nos Grupos B, D, E e F, as cavidades foram restauradas com Fuji II LC. O CIV Fuji II LC, foi preparado seguindo as instruções do fabricante. No Grupo G, foi usado o CIV Photac-Bond Aplicap, como base. Este foi preparado seguindo as instruções do fabricante. Nos Grupos A e G, as cavidades foram restauradas com a resina composta Pekafill, a qual foi colocada na cavidade com ajuda de uma seringa "centrix", coberta com uma matriz (3M, USA) e fotopolimerizada por 20 segundos. Os espécimes dos grupos $A, B, C, D, E$ e $F$ foram armazenados em água por 20 minutos, enquanto, o Grupo G foi armazenado em água por 24 horas. O Grupo G permaneceu por mais tempo para observarem o efeito da expansão higroscópica do material restaurador. As superfícies dos dentes foram polidas com papel de carborundum, para expor a superfície da interface dente-restauração, as quais foram analisadas com microscópio óptico comum (Leitz, Wetzlar, Germany), com uma medida ocular de amplitude de $80 \times 0,8 \times 8$. Os resultados foram analisados estaticamente pelo teste MannWhitney, teste $U$ e de Kruskal-Wallis. Os autores puderam concluir que algumas combinações de pré-tratamento, adesivos dentinários e material restaurador CIV ou estes associados com resina composta, em cavidades de dentina, resultaram em restaurações com fendas marginais pequenas ou até mesmo nenhuma fenda marginal, apresentando um excelente selamento.

BARKMEIER; LOS; TRIOLO ${ }^{10}$, em 1995, avaliaram o sistema adesivo dentinário Clearfil Liner Bond 2, tendo como objetivo observar: 1- a resistência ao cisalhamento; 2- microinfiltrações marginais e, 3- fazer uma análise microscópica, tanto na dentina quanto no esmalte. No teste de cisalhamento foram usados 50 dentes molares humanos (25 para teste de esmalte e 25 para teste de dentina), cujas superfícies vestibulares, tanto do esmalte quanto da dentina, foram aplainadas e, nesta área, foi aplicado o sistema adesivo (de acordo com as instruções do fabricante). Sobre esta superfície condicionada foi confeccionado, através de uma técnica de cápsula de gelatina um cilindro de resina composta (Clearfil AP-Xa ) com 4.5 
$\mathrm{mm}$ de diâmetro (cápsula de gelatina $\mathrm{n}$. 5) para o esmalte, e $5 \mathrm{~mm}$ de diâmetro (cápsula de gelatina n. 4) para a dentina. Todos os espécimes foram, posteriormente, armazenados em água destilada a $37^{\circ} \mathrm{C}$ por 24 horas. Posteriormente, cada dente foi colocado em um anel de resina e levado para teste de cisalhamento, em uma máquina de ensaios Instron. Após o teste, todas as amostras foram analisadas, microscopicamente, para avaliação do tipo de fratura. No teste de microinfiltração, foram utilizados 25 molares humanos, extraídos. Nas faces vestibular e lingual de cada dente foi confeccionada uma cavidade em forma de $\mathrm{V}$, na região da junção cemento/esmalte, com dimensões de $5 \mathrm{~mm}$ de comprimento, $4 \mathrm{~mm}$ de largura e $2 \mathrm{~mm}$ de profundidade. Os pesquisadores obtiveram desta forma, um total de 50 cavidades. Nestas cavidades foi aplicado o sistema adesivo (seguindo as orientações do fabricante) e estas foram restauradas com a resina composta, as quais, após o término, foram polidas e armazenadas em água destilada a $37^{\circ} \mathrm{C}$ por 24 horas. Decorrido este tempo, os dentes foram submetidos a ciclagem térmica, por um período de 24 horas, em banhos que variaram de $5^{\circ} \pm 2^{\circ} \mathrm{C}$ e $55^{\circ} \pm 2^{\circ} \mathrm{C}$, num total de 650 ciclos, levando-se 1 minuto em cada banho. Em seguida, todos os dentes foram protegidos com esmalte de unhas, deixando apenas a restauração à mostra e $1 \mathrm{~mm}$ à sua volta. Posteriormente, foram submetidos a uma solução de nitrato de prata por 24 horas. As amostras foram lavadas e seccionadas, no sentido longitudinal, no centro da restauração. O grau de microinfiltração foi determinado de acordo com a penetração do nitrato de prata, o qual foi analisado com ajuda de um microscópio (10X). A análise com SEM teve como objetivo avaliar o efeito da solução auto-condicionante do primer, tanto sobre o esmalte quanto sobre a dentina. Foram, também, avaliadas a espessura da película primer/adesivo resinoso, e a interface resina/esmalte e resina/dentina. $O$ resultado do teste de cisalhamento foi o seguinte: para o esmalte, $28.2 \pm 4.9 \mathrm{MPa}$. e para a dentina, $19.4 \pm 3 \mathrm{MPa}$. Através de uma análise estatística teste $\mathrm{T}$, revelou-se que a resistência adesiva no esmalte foi, significativamente, maior do que na dentina $(P<0.05)$. Nenhuma infiltração pôde ser observada na margem entre o esmalte e a restauração; 
apenas em três restaurações observou-se infiltrações entre a margem do cemento. O exame com SEM mostrou que houve penetração de resina em ambas as superfícies, esmalte e dentina condicionados. Os autores concluíram que, com o uso do sistema, a força adesiva se torna mais alta, tanto no esmalte quanto na dentina, e a microinfiltração é mínima, e seu uso é simples.

TRIOLO; SWIFT; BARKMEIER ${ }^{74}$, em 1995, avaliaram a resistência ao cisalhamento de seis sistemas adesivos à dentina. Os sistemas adesivos testados foram: All-Bond 2 (Bisco Inc, Itasca); Imperva Bond (Shofu Dental, Menlo Park); Optibond (Kerr Manufacturing Company, Romulus); Permagen (Ultradent Products, South Jordan); ProBond (Caulk/Dentsply, Milford) e Scotchbond Mult-Purpose (3M Dental Products, St Paul). Para este trabalho foram utilizados 60 dentes molares humanos, extraídos. Todos os sistemas adesivos foram aplicados seguindo as orientações dos fabricantes. Foi realizado ataque ácido da dentina para todos os materiais, exceto para o ProBond. Embora não tenha sido fornecido um ácido com o Optibond, seu uso foi necessário; por isso, foi utilizado o ácido fosfórico a $37 \%$ e após a sua aplicação a dentina foi lavada. Para a aplicação do primer dos sistemas All-Bond 2, Permagen e ProBond as instruções indicavam que a dentina fosse mantida úmida; desta forma, para que isso fosse possível, foi utilizado papel absorvente para a secagem da dentina. Para os sistemas Optbond e Imperva Bond, a dentina foi secada com jatos de ar, mas tomando-se cuidado para não dessecá-la. Foram confeccionados pequenos cilindros de resina composta de micropartículas (Bis-Fil) sobre a dentina tratada. Depois, os espécimes foram armazenados em água destilada a $37^{\circ} \mathrm{C}$ por 24 horas. Decorrido este tempo, os corpos-de-prova foram submetidos ao teste de cisalhamento. Os tipos de fraturas foram examinados visualmente para determinação do tipo de falha ocorrida durante a descolagem. As forças de adesão do Scotchbond Multi-Purpose e do All-Bond 2 foram significativamente maiores do que as do Permagen e ProBond. Os resultados obtidos com o Imperva Bond e com o Optbond foram 
equivalentes aos do Scotchbond Multi-Purpose e do All-Bond 2. Falhas coesivas da dentina ocorreram em todos os dez espécimes tratados com o Scotchbond Multi-Purpose, e seis com All-Bond 2 e Imperva Bond, e em apenas três dos tratados com o Optibond e ProBond. Não foram observadas falhas coesivas da dentina com o grupo do Permagen. Comparando-se as primeiras e a última geração de adesivos, os autores concluíram que os agentes adesivos de última geração são capazes de ultrapassar o limiar de resistência adesiva necessária para resistir à contração de polimerização das resinas compostas restauradoras, o mesmo não ocorrendo com as primeiras gerações destes materiais.

Testes de adesão de agentes adesivos dentinários foram revisados por PASHLEY et al. ${ }^{49}$, em 1995. Os autores discutiram os tipos de adesão do substrato, o preparo da superfície de dentina, as variáveis envolvidas no condicionamento, primer e agente adesivo. Discutiram, também, os tipos de testes de adesão mais utilizados, sendo o método mais fácil é o de resistência ao cisalhamento, embora haja uma forte tendência de ocorrer uma flexão em muitos testes de cisalhamento. A substituição de uma resina composta de alto módulo de elasticidade por uma de mais baixo módulo pode aumentar significativamente a resistência ao cisalhamento. Muitos estudos realizados com o intuito de padronizar estas variáveis foram discutidos pelos autores e, dentre estes, foi observado um grande número de falhas coesivas em dentina com valores em torno de 20-30 MPa., embora a dentina desmineralizada apresenta-se uma resistência três vezes maior que esta; portanto, isso sugere que a distribuição do estresse não é uniforme durante os testes. Os autores citam, também, um novo método, que é o teste de microtração, no qual a área de união é muito pequena e, por esta razão, este método tende a produzir valores mais altos de resistência de união. A razão para este aumento da resistência de união com diminuição da área da superfície unida deve-se à presença de defeitos ou estresses na interface unida ou dentro do substrato. Há um número de vantagens e desvantagens no método de microtração. A maior vantagem é que as falhas 
obtidas podem ser exclusivamente do material, se a área de união for em torno de $1 \mathrm{~mm}^{2}$. As desvantagens do método de microtração se devem ao fato dele ser tecnicamente difícil e muitas uniões podem falhar durante o preparo do espécime. Os autores concluíram que novos métodos devem ser desenvolvidos para que os resultados sejam confiáveis e que os métodos convencionais não podem ser usados amplamente para detectar uma melhora no desenvolvimento de produtos ou procedimentos de união.

HAMID; SUTTON; HUME $^{30}$, em 1996, analisaram se, de fato, concentrações diferentes e tempos maiores de tratamento com ácido fosfórico, se afetariam a dentina, aumentando a permeabilidade do HEMA através da dentina in vitro. Utilizaram para este estudo 70 terceiros molares humanos, livres de cáries, e estes foram divididos em 7 grupos $(n=10)$. As raízes foram seccionadas a $2 \mathrm{~mm}$ da junção cemento-esmalte. Em cada espécime foi feito na superfície oclusal um preparo cavitário de $6 \mathrm{~mm}$, permanecendo uma espessura de dentina de 1,0 a 1,5 entre a parede pulpar e a câmara pulpar. Foi adicionada na câmara pulpar $1 \mathrm{ml}$. de água destilada. A dentina foi condiciionada com ácido fosfórico a $10 \%$ em diferente tempos: 10, 30 e 60 segundos. No grupo controle os espécimes não receberam condicionamento. Em seguida, na área condicionada, foram aplicados o primer do Scotchbond Multi-Purpose e o adesivo, e depois foram fotopolimerizados e restaurados com resina composta Z100. As amostra foram avaliadas em tempos variados de 4,32, 14,4, 43,2, 144 e 432 minutos, durante 1,3 e 10 dias. A análise foi feita através do desempenho do líquido pela cromatografia. Como resultado, os autores observaram que o HEMA foi detectado na câmara pulpar em todos os dentes em 4,32 minutos após a sua aplicação. A média total liberada em 10 dias para todos os grupos oscilou entre 2 - $4 \mu \mathrm{mol}$. A taxa de difusão mais alta do HEMA ocorreu em 4,32 minutos após a aplicação e variou de 6 - 13 vezes maior do que a do grupo controle; nos grupos a $10 \%$ - 15 segundos, $10 \%$ - 30 segundos, $10 \%$ 60 segundos, 37\% -15 segundos,e 37\% - 30 segundos. Inesperadamente, puderam observar que a taxa mais alta de 4,32 minutos foi no grupo de 
37\%-60 segundos. Os autores observaram, que a redução na permeabilidade ocorreu em apenas nos minutos iniciais após a aplicação da resina. O grupo de $37 \%$ - 60 segundos teve taxa semelhantes de difusão com os outros grupos após aquele tempo. A liberação total (acumulativa) em 10 dias para o grupo de $37 \%$ - 60 segundos não foi mais baixa do que a de qualquer outro grupo. Seria interessante comparar a resistência adesiva entre os parâmetros do tratamento que os autores descreveram e também determinar in vivo se a permeabilidade inicial mais baixa pode relacionar-se a variações em potencial tóxico.

MAUSNER; GOLDSTEIN; GEORGESCU ${ }^{41}$, em 1996, analisaram o efeito de dois agentes dessensibilizantes em relação à retenção de quatro tipos de cimentos, usados para cimentação de coroas totais. Foram usados para este estudo dentes humanos, terceiros molares, extraídos. As raízes de cada dente foram aprisionadas em um anel de resina acrílica, ficando apenas a coroa exposta. Em cada dente foi feito um desgaste para receber uma coroa total. Todos os preparos foram feitos por um mesmo dentista. Foi analisada a influência do agente de união Imperva e o agente dessensibilizante All-Bond, em relação à retenção da coroa. Os cimentos utilizados neste estudo foram: cimento de fosfato; policarboxilato; cimento de ionômero de vidro; cimento resinoso. Os dentes foram divididos em três grupos com 32 dentes em cada grupo. No Grupo 1 foi utilizado o agente dessensibilizante All-Bond; no Grupo 2 foi utilizado o agente de união Imperva e, no Grupo 3 não foi feito nenhum tratamento. As coroas foram cimentadas e, depois submetidas ao teste de resistência, através de uma máquina de ensaio Instron. Os resultados mostraram que houve uma redução na retenção das coroas, quando o agente dessensibilizante AllBond foi utilizado previamente ao cimento de policarboxilato e também com o cimento de fosfato. O uso do Imperva antes do cimento de ionômero de vidro também demonstrou diminuição na retenção. Quando se utilizou o cimento resinoso, foi observado uma maior resistência com o uso do agente adesivo Imperva, seguido do All-Bond, o qual foi um pouco menor, e, então, 
por último, o grupo que não recebeu nenhum tratamento. Entretanto, a diferença entre estes não foi estatisticamente significativa. O grupo que não recebeu nenhum tratamento e foi usado o cimento de fosfato de zinco apresentou uma retenção maior do que o do cimento de ionômero de vidro com PCC e RLA. De acordo com os resultados, os autores concluíram que: 1- a aplicação do agente dessensibilizante All-Bond com cimento de policarboxilato resultou em maior perda de retenção para todos os espécimes testados; 2- a aplicação do agente dessensibilizante All-Bond, usado previamente ao cimento de fosfato de zinco resultou em uma diminuição na retenção das coroas; e, 3- a aplicação do agente de união Imperva previamente ao cimento de ionômero de vidro, resultou em uma diminuição na retenção das coroas.

FINGER; UNO ${ }^{28}$, em 1996, analisaram a efetividade do Gluma ${ }^{\circledR}$ Primer, o qual é composto por glutaraldeido a 5\%, HEMA a 35\% e dissolvido em água ou acetona, com o objetivo de comparar qual teria maior eficácia sobre a força de união e adaptação à margem da cavidade, quando usados em dentina úmida ou seca, respectivamente. Foram utilizados, neste trabalho, pré-molares e molares humanos, os quais foram armazenados em solução de cloramina T a 1\%, logo após as extrações. Os espécimes foram aplainados em papel de carbeto de silício de granulação 240 até 600 para expor uma área de dentina periférica e, sobre esta área foi colocada uma matriz com uma perfuração central com $3.5 \mathrm{~mm}$ de diâmetro. Os dentes foram condicionados com ácido fosfórico a $20 \%$ por 30 segundos e lavados com água deionizada por 30 segundos. Foram utilizadas quatro técnicas para aplicação dos sistemas adesivos: 1- técnica úmida (o excesso de água foi removido com bolinhas de algodão); 2- técnica convencional (a dentina foi seca com jatos de ar por 2 segundos); 3- técnica seca (a dentina foi seca com jatos de ar por 10 segundos); 4- técnica do remolhamento (após secagem por 10 segundos, a dentina foi remolhada por 30 segundos, e o excesso removido com bolinha de algodão). Os primers foram aplicados por 20 segundos, secados, e a resina de união Gluma ${ }^{\circledR}$ Sealer foi aplicada e 
fotoativada por 20 segundos. Depois, as restaurações foram confeccionadas com resina composta, as quais foram fotopolimerizadas por 60 segundos $e$, logo em seguida, foram colocadas em água deionizada e mantidas por 24 horas. Decorrido este tempo, os espécimes foram submetidos ao teste de cisalhamento em uma máquina universal com uma velocidade de deslocamento de $1 \mathrm{~mm} /$ minuto. Foram preparados 5 espécimes para cada uma das 8 condições testadas. O desempenho marginal foi determinado em restaurações realizadas em dentina na superfície proximal, sendo 6 restaurações por grupo. As margens das cavidades foram analisadas através do uso de um microscópio óptico com um aumento de 500X. A resistência de união dos grupos preparados pela técnica úmida foi aproximadamente de $18 \mathrm{MPa}$.., independente do solvente do primer. A técnica convencional proporcionou uma resistência de união quase tão alta, ou seja, de 16.5 MPa. e a técnica do remolhamento foi altamente efetiva com os dois solventes estudados. A técnica seca mostrou uma resistência de união moderada para o primer dissolvido em água e pobre em acetona. As margens das cavidades dos espécimes tratados com primer à base de acetona não apresentaram gaps com a técnica úmida. Os outros 7 grupos mostraram entre 2 e 6 gaps em cada grupo de 6 espécimes. Os autores concluíram que a acetona é um excelente solvente e uma boa alternativa para a água que é usada na solução Gluma® Primer original. A acetona apresenta a vantagem de evaporar mais rapidamente do que a água, portanto, facilitando a utilização do sistema Gluma® e assegurando uma união mais eficiente.

MIYAZAKI et.al. ${ }^{43}$, em 1996, tiveram como proposta avaliar, in vitro, a influência do processo de aplicação do primer dentinário e o seu tempo de secagem da superfície, à qual foi aplicada, em relação à sua resistência adesiva, a dentina humana. Os materiais empregados como sistemas adesivos foram Imperva Bond/Lite-fil II A e Scotchbond Multi-Purpose/Z 100. Foram utilizados molares humanos extraídos, cujas raízes foram seccionadas. A superfície vestibular foi planificada e os dentes colocados 
dentro de uma resina acrílica, deixando exposta apenas a área aplainada da dentina, cuja superfície foi limpada com ultrassom e água e, após seca, com jatos de ar. A superfície da dentina foi condicionada por 10 segundos com ácido fosfórico para o Imperva Bond e, por 15 segundos, com ácido maleico a $10 \%$ para o Scotchbond Multi-Purpose, Duas variações foram designadas neste estudo para avaliar a influência do método da aplicação do primer sobre a resistência adesiva na dentina: 1- Efeito do procedimento da aplicação : - o primer foi apenas aplicado (chamado de aplicação inativa), ou foi aplicado de uma forma agitada comescova (aplicação ativa) - 30 segundos para o Imperva Bond e 10 segundos para o Scotchbond MultiPurpose; 2- Efeito do tempo de secagem: - o primer foi aplicado na dentina de acordo com as instruções do fabricante. A dentina foi secada por diferentes espaços de tempo: 0, 5, 10, 20 e 30 segundos (a uma distância de $10 \mathrm{~cm}$. Acima da superfície da dentina). Após o condicionamento da área desejada com o respectivo adesivo, foi utilizado um molde de Teflon e colocado sobre esta área condicionada e preenchida com as respectivas resinas compostas. Foram depois, mantidos em água deionizada a uma temperatura de $37^{\circ} \mathrm{C}$ por 24 horas. Foram testados 10 espécimes de cada grupo para observar a resistência ao cisalhamento, através de uma máquina para teste Instron. A resistência ao cisalhamento foi avaliada em MPa. Os dados foram submetidos à análise estatística ANOVA e seguidos pelo teste de comparação Newman-Keuls. Após os testes, os espécimes foram avaliados através de um microscópio óptico para definir a localização da falha de adesão, e o tipo de falha foi determinado, baseado na porcentagem de substrato de material livre: adesivo (A), adesivo-coesiva (AC) e Coesiva (C). A resistência adesiva foi maior para a aplicação ativa do que a da inativa, mas não houve diferença significativa entre os dois procedimentos de aplicação. As fraturas nos espécimes que receberam a aplicação ativa mostraram ter tendência à falhas coesivas ou uma mistura. Os resultados de resistência ao cisalhamento e fratura com variação de tempo mostraram que o máximo de resistência ao cisalhamento foi obtido com o tempo de secagem de ar de 20 segundos, para o Imperva Bond e 5 segundos para o 
Scotchbond Multi-Purpose. A resistência adesiva mais baixa de cada sistema se deu quando o primer dentinário não foi secado com ar. Quando o tempo de secagem aumentou, os tipos de fratura tenderam a mudar de falhas adesivas para coesivas e, com uma secagem mais longa, as falhas tenderam a aumentar como falhas adesivas. Os autores concluíram que a resistência ao cisalhamento, com a aplicação do primer, de forma ativa, foi maior do que a aplicação inativa, mas não houve diferença significativa entre as duas aplicações. Na observação dos espécimes fraturados, a aplicação ativa proporcionou a penetração do primer dentro da dentina. O tempo de secagem do primer na superfície da dentina afetou a resistência à adesão. A reação de polimerização dos agentes adesivos deve ser inibida pela presença do primer, quando ocorre uma secagem inadequada. Por outro lado, o excesso de secagem do primer da superfície da dentina deve alterar a natureza da camada híbrida. Em ambas as formas, houve uma tendência em reduzir a resistência à adesão.

Muitos investigadores têm realizado uma variedade de pesquisas para determinar as propriedades da avaliação dos sistemas adesivos dentinários. Os métodos as variáveis dos testes utilizadas em 50 artigos publicados de resistência de união foram analisadas por AL-SALEHI; BURKE¹, em 1997. Entre os trabalhos analisados, os testes de cisalhamento predominaram sendo utilizados em $80 \%$ dos estudos. Superfícies de dentina de molares humanos foram os substratos eleitos na maioria das vezes $(88 \%$ das investigações). O tempo de estocagem dos espécimes que predominou, antes dos testes de resistência de união, foi de 24 horas. Entretanto, um número de variáveis não foram registrados em um grande número de artigos, entre estes a espessura do filme, o tipo de dentina testada e a condição da superfície (molhada, úmida ou seca). O modo de falha foi registrado em somente $42 \%$ das investigações acessadas. Os autores concluíram que há pouca padronização dos métodos dos testes em estudos de resistência de união à dentina e que o número de variáveis são muitas vezes não relatados ou registrados. 
COBB; REINHARDT; VARGAS ${ }^{22}$, em 1997, avaliaram in vitro, o efeito de Gluma ${ }^{\circledR}$ Desensitizer $(G)$ e Health Dent Desensitizer $(H)$, a resistência ao cisalhamento e a força adesiva da resina sobre a dentina, quando aplicados em : 1- preparos cavitários, 2- cimentação, 3- em ambas situações. Foram usados 70 dentes humanos, extraídos, terceiros molares, livres de cáries. A superfície oclusal de cada dente foi desgastada até que todo o esmalte fosse removido, ficando a dentina totalmente exposta. Os dentes foram distribuídos, aleatoriamente, em 3 grupos de 20, 20 e 30 dentes, tratados da seguinte forma: Grupo Gluma® $(G)$ - enxaguados com água e secos com ar, aplicação de Gluma® por 30 segundos, secos com ar; Grupo Health $(\mathrm{H})$ Aplicação de dessensibilizante por 30 segundos, secos com ar; Grupo Wusados apenas água. Depois foram armazenados em água destilada a $37^{\circ} \mathrm{C}$ por 7 dias. Durante este período, 70 restaurações cilíndricas de resina composta foram fabricadas no laboratório usando a resina composta microhíbrida Tetric. Depois de terem sido preparadas, foram microcondicionadas com jatos de óxido de alumínio. Todos os grupos foram, posteriormente, e aleatoriamente, subdivididos em 10 dentes. Para a cimentação, a superfície da dentina foi condicionada com ácido fosfórico a $37 \%$ e, posteriormente, foi novamente aplicado Gluma® (GG) em 10 espécimes; nos outros 10 foram aplicados, agora, somente água (WG). Para o Grupo Health $(\mathrm{HH})$ foi também condicionada a dentina e reaplicado o Health, em 10 espécimes; os outros 10 receberam condicionamento ácido e foram tratados somente com água (WH). Para o grupo água (WW), 10 receberam novamente somente água e 10 receberam Gluma® a dentina não foi previamente condicionada e nos outros 10 foram aplicados Health da mesma forma que o grupo Gluma $®$; a seguir a dentina foi condicionada com ácido fosfórico e usado ALL- Bond 2 e cimento dual para a cimentação. Depois, os espécimes foram armazenados em água destilada por 24 horas a $37^{\circ} \mathrm{C}$ e, posteriormente, termociclados 300 vezes a uma temperatura de $5^{\circ} \mathrm{C}$ à $55^{\circ} \mathrm{C}$. Foram aplicadas as forças para medir a resistência ao cisalhamento, cujo resultado foi dado pelo computador. Os dados foram analisados pelo teste estatística ANOVA e Tukey. Os resultados obtidos da resistência à 
adesão foi dado em Mpa, sendo: $\mathrm{GM}=7.4 \pm 6.0, \mathrm{WW}=7.7 \pm 5.8, \mathrm{HW}=8.2 \pm$ 4.3, $\mathrm{WH}=10.8 \pm 6.2, \mathrm{GG}=13.5 \pm 6.0, \mathrm{HH}=13.8 \pm 7.1, \mathrm{WG}=19.9 \pm 8.8$. Não houve diferença entre os grupos em resistência à adesão GW, WW, HW, WH e GG. A resistência ao cisalhamento de WG e HH foi significantemente mais alto do que todos os grupos, exceto para GG. Os autores concluíram que nenhum dos agentes dessensibilizantes interferiram com a resistência à adesão dos cimentos resinosos à dentina, parecendo mesmo que, para o uso dos materiais resinosos de cimentação com estes procedimentos prévios $(G$ e $H)$, realmente deve-se aumentar a resistência à adesão do cimento à dentina. Isto deve ser devido à penetração adicional de HEMA resultado em uma "dupla aplicação" de primer na superfície da dentina. Isto leva a acreditar que este fator aumente a penetração do primer resinoso dentro da dentina. Subsequentemente, o HEMA polimerizará e copolimerizará com o primer da resina, e esta combinação deve promover um mais completo selamento dos túbulos dentinários.

HANSEN; ASMUSSEN ${ }^{31}$, em 1997, analisaram in vitro os efeitos de vários pré-tratamentos na formação de fendas marginais, com o uso de diferentes sistemas adesivos e a possível influência em sua redução, quando estes sistemas adesivos eram combinados com o sistema adesivo Gluma ${ }^{\circledR}$ número 3 , o qual é uma solução aquosa, composta de 35 wt\% de HEMA e 5 wt\% de glutaraldeido. A investigação foi feita em dentes humanos, extraídos, utilizando-se cavidades cilíndricas com $4 \mathrm{~mm}$ de diâmetro por 1,5 $\mathrm{mm}$ de profundidade, preparadas em dentina. Ela foram divididas em dois grupos, da seguinte forma: Grupo 1- Aelitebond, ALL-Bond 2, ANA Bonding Agent, Clearfil Liner Vond 2, Fuji Bond LC, Gluma ${ }$, Optibond, Primer \& Bond, Prisma Universal Bond 3, Scotchbond Multi Purpose M ( àcido maleico), Scotchbond Multi Purpose P ( ácido fosfórico) e Syntac. Foi usado o sistema adesivo, seguindo as orientações do fabricante, em cada cavidade, a qual foi restaurada com a resina composta Z100. Também foi confeccionado um agrupo controle, cujas cavidades foram restauradas com a resina composta Z100, sem o uso prévio do sistema 
adesivo. Grupo 2- Após o condicionamento da dentina com ácido, ou combinados o condicionamento e o primer dos sistemas adesivos, aplicouse sobre ela o sistema Gluma ${ }^{\circledR}$ do frasco 3 por 10 segundos; depois foi usado o agente de união de cada respectivo adesivo e as cavidades foram restauradas com a resina composta Z100. As restaurações foram mantidas em água por 10 minutos, depois as fendas foram medidas microscopicamente. Os autores concluíram que, quando o Gluma $₫ 3$ foi usado em combinação com o sistema adesivo sem condicionamento ácido, o ANA não apresentou nenhuma melhora na adaptação marginal. A mesma coisa foi observada para o sistema adesivo Syntac. Acreditou-se que, por ambos terem a concentração de glutaraldeido de $5 \%$, deveria ser este o motivo da não efetividade do Gluma $\AA$ 3. Para o sistema adesivo Prisma Universl Bond 3, obteve-se o pior resultado com o sistema Gluma $\circledast$, talvez por este possuir $<1 \%$ de glutaraldeído e, com isto, possivelmente, resultou em um aumento na concentração de glutaraldeido. Nos outros casos eles concluíram que o uso do Gluma® 3, como segundo passo, foi significante na efetividade da redução das fendas marginais. A razão, talvez, seja devido ao glutaraldeido, que é um dos componentes do sistema Gluma® que reforça a parte orgânica da camada híbrida pelo encadiamento cruzado das fibras colágenas, mas não descartaram a possibilidade de haver uma outra possibilidade para explicar a melhora encontrada.

SWIFT; LLOYD; FELTON ${ }^{69}$, em 1997, investigaram o efeito de dois agentes dessensibilizantes dentinários à base de resina e suas influências sobre a retenção na cimentação de coroas com vários cimentos dentais. Foram usados 30 dentes humanos molares, extraídos, nos quais foram feitos preparos para coroas totais, que foram padronizados. Os espécimes foram divididos em 3 grupos, contendo 10 amostras em cada grupo. Foram confeccionadas coroas fundidas de prata-paládio e estas foram cimentadas com: 1) Cimento de fosfato de zinco; 2) Cimento de ionômero de vidro convencional (Fuji I); 3) Cimento de ionômero de vidro modificado por resina (Vitremer). Cada grupo foi cimentado da seguinte forma: apenas os materiais 
de cimentação, como grupo controle; o uso do agente dessensibilizante Gluma ${ }^{\circledR}$ Desensitizer, antes da cimentação, e o uso de um agente adesivo dentinário One-Step antes da cimentação, ou seja: 1- só cimento de fosfato de zinco; Gluma® desensitizer + Cimento de fosfato de zinco; One-Step + cimento de fosfato de zinco. 2- só cimento de ionômero de vidro; Gluma ${ }$ Desensitizer + cimento de ionômero de vidro; One-Step + cimento de ionômero de vidro. 3- Só cimento de ionômero de vidro modificado por resina; Gluma ${ }^{\circledR}$ desensitizer + cimento de ionômero de vidro modificado por resina; One-Step + cimento de ionômero de vidro modificado por resina. O resultado deste estudo mostrou que os espécimes do Grupo Cimento de ionômero de vidro apresentaram a mais alta retenção das coroas. Os espécimes do grupo cimento de fosfato de zinco foram os que apresentaram a menor resistência à retenção. O cimento de ionômero de vidro modificado por resina foi o único grupo que apresentou um aumento na retenção com o uso do Gluma ${ }^{\circledR}$ Desensitizer e, também, embora um pouco menos, com One-Step, em relação ao grupo controle. O grupo Cimento de vidro convencional, com o uso do Gluma® Desensitizer, provocou uma diminuição na resistência à retenção, e o grupo One-Step aumentou a retenção. Os cimentos de fosfato de zinco, tanto com o Gluma ${ }^{\circledR}$ Desensitizer quanto com o One-Step, apresentaram uma diminuição na retenção. Em todos os grupos houve uma mistura nas falhas, sendo que algumas foram nas coroas e outras no preparo. Estatisticamente, puderam observar que, para ambos os cimentos de ionômeros de vidros a retenção foi mais alta do que para o cimento de fosfato de zinco. Os autores concluíram que, de acordo com este estudo, o uso de primer-resinoso ou sistemas adesivos não afetam as propriedades de retenção dos três diferentes cimentos; entretanto, não respondem a questão de que se tais agentes dessensibilizantes precisam ser usados.

SCHÜPBACH P.; LUTZ F.; FINGER ${ }^{62}$, em 1997, avaliaram o efeito do Gluma ${ }^{\circledR}$ Desensitizer, sobre a dentina humana, in vivo. Esse trabalho foi realizado em 12 pacientes, os quais tinham molares indicados para 
extrações e estes não apresentavam restaurações. Antes da extração, estes dentes foram desgastados até a exposição da dentina, com $2 \mathrm{~mm} \times 2$ $\mathrm{mm}$ de largura e, nesta área, foi realizado o tratamento; cada dente foi tratado de 6 formas diferentes, sendo: Grupo 1- Aplicação de Gluma® 2 (ácido ), Gluma® 3 (primer) e Gluma ${ }^{\circledR}$ (Bond); Grupo 2- $\mathrm{H}_{2} \mathrm{O}$ com 0.1\% de Fluorescein (no lugar do Gluma® 2) e os outros passos foram iguais aos do Grupo 1. Grupo 3- nenhum tratamento (ao invés do Gluma® 2) e os outros passos foram iguais aos do grupo 1. Grupo 4- Gluma® 2, Glutaraldeido a 5\% com $0.1 \%$ Fluorescein (no lugar do Gluma ${ }^{\circledR} 3$ ), Gluma ${ }^{\circledR} 4$. Grupo 5- Gluma ${ }^{\circledR}$ 2, Gluma® 3. Grupo 6- Gluma® 2, HEMA 35\% com $0.1 \%$ Fluorescein e Gluma ${ }^{\circledR}$ 4. Logo depois os dentes foram extraídos e preparados para serem avaliados com microscópio, SEM, TEM e CLSM. Nos espécimes dos Grupos 1 e 5, pôde-se observar a oclusão dos túbulos a uma profundidade de 200 $\mu \mathrm{m}$. Nos espécimes do grupo 4, a oclusão dos túbulos foi observada a uma profundidade de $50 \mu \mathrm{m}$. Não foram observadas oclusões dos túbulos no grupo 2, onde a smear layer não foi removida, no grupo 3 e no grupo 6 . Os autores concluíram que com a aplicação tópica do Gluma ${ }^{\circledR} 3$ (primer) houve a formação de uma barreira periférica e intrínsica dos túbulos dentinários. Concluíram também que a remoção da smear layer é um pré-requisito para este fenômeno, e que o Glutaraldeído do Gluma® 3 provavelmente seria o componente responsável pela oclusão dos túbulos, onde o GA produz um efeito sobre a proteína do plasma, do fluido dentinário e, desta forma, a oclusão periférica dos túbulos dentinários neutraliza o mecanismo hidrodinâmico da hipersensibilidade dentinária e isto deve explicar o efeito do Gluma® Desensitizer.

CAMPS et al. $^{18}$, em 1998, compararam, in vitro, o efeito de três agentes dessensibilizantes: à base de oxalato (Protect); à base de resina (Gluma ${ }^{\circledR}$ Desensitizer); e á base de resina e oxalato (MS Coat), e suas longevidades em relação á permeabilidade da dentina humana. Foram utilizados 40 dentes humanos, terceiros molares, extraídos, não erupcionados. Os dentes foram cortados, com o objetivo de se obter fatias 
de dentina, as quais deveriam estar localizadas, o mais próximo possível, da câmara pulpar, mas sem expor os cornos pulpares. O lado pulpar dos discos de dentina obtidos, foi condicionado com ácido fosfórico a 37\% por 15 segundos e, então, lavados com água. O lado coronário do disco foi mantido preso em um anel de acrílico com um buraco no centro de 0,8 cm de diâmetro. A parte coronária da dentina foi conectada a um pequeno tubo de 0,5 mm de diâmetro, o qual foi preenchido com soro a $20 \%$ (Serovial). Um tubo de vidro, com diâmetro interno de 0,7 mm, foi conectado ao capilar horizontal e preenchido com a mesma solução. No interior deste tubo, havia uma pequena bolha de ar que se encontrava sobre uma pressão hidrostática de $15 \mathrm{~cm}$ de água. O movimento do fluido era calculado através do movimento da bolha, o qual era monitorado através de uma luz infravermelha; o movimento da bolha era medido a cada $5 \mu \mathrm{m}$ de movimento. A condutibilidade hidráulica de cada amostra de dentina foi medida antes do uso do agente dessensibilizante, e este valor foi designado como $100 \%$. Para isto, três discos foram tratados. A condutibilidade hidráulica foi reavaliada, expressa em porcentagem e comparada com as amostras anteriores. Os dentes foram armazenados por 1 mês a $37^{\circ} \mathrm{C}$ em água deionizada e a condutibilidade hidráulica foi novamente observada em 40 discos de dentina. Dez discos de dentina não receberam nenhum tratamento e serviram como grupo controle. Como resultado, observaram que não houve diferença estatística entre os 3 grupos, após o tratamento. Depois de 1 mês de armazenagem, o grupo controle mostrou uma condutibilidade hidráulica estatisticamente mais alta do que a dos 3 grupos que receberam tratamento. Os autores concluíram que, estatisticamente, não houve diferença nos 3 grupos que foram tratados com agentes dessensibilizantes, e que todos foram efetivos na redução da permeabilidade da dentina de 60$85 \%$.

JOHNSON; LEPE; BALES ${ }^{36}$, em 1998, tiveram como propósito determinar se a aplicação prévia do Gluma® Desensitizer (dessensibilizante) em dentina preparada para cimentação de coroas afetaria a retenção destas. 
Foram usados, neste trabalho, molares extraídos, não restaurados. As raízes dos dentes foram fixadas em um anel, ficando a parte coronária exposta, a qual recebeu um preparo padronizado, com $1 \mathrm{~mm}$ de desgaste, com uma inclinação de 20 graus, e altura da parede axial de $4 \mathrm{~mm}$, e, desta forma, foram divididos em 6 grupos. O Gluma® Desensitizer foi usado para selar a dentina antes da cimentação provisória e, depois para a cimentação definitiva. Foram feitas coroas de ligas de porcelana Olympia, sendo que todas as coroas receberam internamente jatos com óxido de alumínio com $50 \mu \mathrm{m}$ e depois foram limpadas para remoção dos debris. Foram usados para cimentação: cimento de fosfato de zinco, cimento de ionômero de vidro, cimento resinoso em combinação com adesivo dentinário One-Step (Bisco). A cimentação foi feita da seguinte forma: Grupo 1- cimento de fosfato de zinco ( Mizzy's); Grupo 2- Selamento (Gluma® desensitizer) + cimento de fosfato de zinco; Grupo3- Cimento de ionômero de vidro (ketac-cem) Grupo 4- Cimento resinoso com seu respectivo adesivo One-Step; Grupo 5selamento ( Gluma ${ }^{\circledR}$ desesnsitizer) + cimento resinoso com seu respectivo adesivo One-Step. O dessensibilizante foi aplicado nos preparos, e depois as coroas foram cimentadas temporariamente: um grupo com Temp Bond contendo eugenol e um outro grupo com Temp Bond sem eugenol. Depois foram cimentados com seus respectivos cimentos. A princípio, as coroas foram pressionadas com o dedo, depois foram levadas a uma máquina a qual exercia uma pressão de $20 \mathrm{Kgf}$, por 10 minutos, para padronização da cimentação. A seguir os dentes foram submetidos à ciclagem térmica com 2.500 ciclos com temperaturas de $5^{\circ} \mathrm{C}$ a $55^{\circ} \mathrm{C}$. As amostras, foram, então, levadas a uma máquina para teste de resistência Instron, para observação das falhas. Os resultados foram analisados estatisticamente com análise de variância ANOVA e student Newman-Keul's para comparação das médias. Apresentaram como resultado a média de estresse de deslocamento sem selamento e com selamento 6.3 e $6.4 \mathrm{MPa}$., respectivamente, para o cimento de fosfato de zinco; 9.1 e 10.1 MPa. para o Cimento de ionômero de vidro e 12.1 e $12.6 \mathrm{MPa}$. para o cimento resinoso. Os autores puderam concluir que o uso de um sistema dessensibilizante à base de glutaraldeído, 
usado previamente a preparos de coroas antes da cimentação destas, não afetou as suas retenções em nenhum dos cimentos avaliados e, para o cimento resinoso, produziu uma média mais alta de deslocamento pelo estresse que excedeu a resistência do próprio dente, ocorrendo a fratura do mesma.

BURKE et al. ${ }^{16}$, em 1999, na Inglaterra examinaram a longevidade, bem como o motivo da colocação e recolocação de restaurações por VDPs (Vocational dental Practitioners) e seus aprendizes. Desde 1993 é obrigatório para os dentistas recém- formados trabalharem durante um ano como VD, aperfeiçoando-se em clínicas de treinamento especialmente selecionadas, caso desejem subseqüentemente exercer a profissão sob a regulamentação do Serviço Nacional de Saúde. Os VDPs aprendem através de estudos fundamentados em conferências, seminários e outros. Cada curso é organizado pelo consultor de um VDP. O principal objetivo deste treinamento é proporcionar aos novos graduados um início com qualidade na prática dental em geral. Este estudo foi realizado com 667 VDPs e 712 aprendizes. Todos receberam uma carta de apresentação e uma folha com instruções, incluindo descrições das várias razões para a colocação das restaurações. Solicitou-se aos VDPs que anotassem um motivo para cada colocação e recolocação das restaurações. Eles também tinham que anotar, para cada restauração e recolocação, a idade (tempo) da restauração, seu tipo, seu material e o material selecionado para a recolocação da restauração. Os participantes anotaram se o material usado era um compômero, resina composta, CIV modificado por resina ou CIV convencional. Quando havia mais de uma razão para a substituição, anotouse apenas o motivo principal da intervenção. Os dados coletados foram computadorizados e analisados estatisticamente. Os motivos observados foram: 3.726 cáries primárias, 1.975 cáries secundárias, 580 fraturas de dentes, 527 defeitos sem cáries, 461 fraturas da massa das restaurações, 379 dores, 163 descolorações marginais, 100 descolorações do material, 56 formas anatômicas pobres, 54 substituições do material e 464 outras 
causas. Os autores concluíram que o principal motivo da colocação da restauração foram cáries primárias. O segundo motivo foram cáries secundárias, sendo recolocadas as restaurações de amálgama, compósitos e CIV. As restaurações de amálgama apresentaram longevidade significativamente maior do que as resinas compostas e os CIVs. Não foi notada nenhuma diferença nos padrões, exceto que os VDPs realizaram maior número de restaurações do que os aprendizes, a não ser com relação ao número de restaurações colocadas por cáries primárias e secundárias.

YIM et al. ${ }^{80}$, em 2000, analisaram, in vitro, o efeito dos dessensibilizantes dentinários, quando aplicados previamente nas cimentações de coroas totais, e sua interferência em relação à força de resistência. Os dessensibilizantes usados foram o All-Bond 2 e Gluma ${ }^{\circledR}$ Desensitizer, e os cimentos testados foram: cimento de fosfato de zinco (Fleck's), cimento de ionômero de vidro (Ketac-Cem), cimento de ionômero de vidro modificado por resina (Fuji II), e cimento resinoso (Panávia). Como grupo controle,não foi aplicado dessensibilizante. Os preparos foram padronizados e apresentavam altos ângulos de convergência. Foram usados, neste trabalho, 144 molares humanos, extraídos. Cada raiz foi colocada dentro de um anel de PVC e embebido com gesso, ficando apenas a coroa exposta, e esta foi, então, preparada com auxílio de um pantógrafo e foi padronizada. As coroas preparadas foram divididas em grupo, compostos por 12 coroas em cada um. Foram confeccionadas coroas individuais de liga metálica (Rexilliu III), as quais foram cimentadas em três formas diferentes, ou seja: 1- as coroas foram cimentadas apenas com os cimentos; 2- foi aplicado dessensibilizante dentinário previamente à cimentação e, 3- foi aplicado o Gluma ${ }^{\circledR}$ Desensitizer antes da cimentação. Depois, os anéis de PVC com as coroas foram armazenados a $26^{\circ} \mathrm{C}$ em $100 \%$ de umidade relativa durante 48 horas. Decorrido este tempo, os anéis com as coroas foram levados para teste em uma máquina universal de teste. A proporção do cimento retido sobre o dente e coroa, após a desunião, foi qualificada de acordo com o tratamento. Os resultados foram analisados estatisticamente, 
incluindo 1- e 2- ANOVAs, seguidos pelo Teste de Tukey-Kramer. Como resultado, os cimentos resinosos apresentaram a força de retenção mais alta de todos os tratamentos dentinários, e uma significativa diferença nos valores de retenção All-Bond $2(5.68 \pm 0.70 \mathrm{MPa})>$ controle $(4.67 \pm 0.48$ $\mathrm{MPa})>\operatorname{Gluma}{ }^{\circledR}(4,12 \pm 0,37 \mathrm{MPa})$. As retenções do grupo cimento de ionômero de vidro estavam entre os grupos de cimento resinoso e cimento de ionômero de vidro, sendo: All-Bond $2(3,46 \pm 0,26 \mathrm{MPa})>\operatorname{Gluma}{ }^{\circledR}(2,81$ $\pm 0,15 \mathrm{MPa})=$ controle $(2,96 \pm 0,18 \mathrm{MPa})$. $\mathrm{O}$ cimento de ionômero de vidro convencional apresentou valores de retenções entre o grupo Fuji II e o grupo cimento de fosfato de zinco, sendo: All-Bond $2(2,23 \pm 0,20 \mathrm{MPa})=$ controle $(2,36 \pm 0,20 \mathrm{MPa})>\operatorname{Gluma}{ }^{\circledR}(1,98 \pm 0,23 \mathrm{MPa})$. O grupo do cimento de fosfato de zinco teve os valores mais baixos, sendo: controle $(1,68 \pm 0,08$ $\mathrm{MPa})>\operatorname{Gluma}(0,81 \pm 0,11 \mathrm{MPa})>$ All-Bond $2(0,67 \pm 0,14 \mathrm{MPa}) . \mathrm{A}$ maioria dos cimentos estava retida sobre a superfície do dente desunido versus a coroa, com exceção do fosfato de zinco quando usado no prétratamento dentinário. Os autores puderam concluir que a força de retenção relativa de agentes cimentantes foram: cimento resinoso > cimento de ionômero de vidro modificado por resina > cimento de ionômero de vidro> cimento de fosfato de zinco. A força retentiva das coroas cimentadas, com um pré-tratamento de dessensibilizante dentinário, depende da combinação entre o dessensibilizante e o agente cimentante. A combinação do cimento resinoso com o dessensibilizante dentinário polimerizável produziu o maior valora de retenção. O uso do dessensibilizante dentinário não-polimerizado produziu uma diminuição na força de retenção, quando usado com um cimento resinoso, cimento de ionômero de vidro ou um cimento de fosfato de zinco. A aplicação de um dessensibilizante dentinário polimerizável produziu um aumento na retenção da coroa, quando foi usado conjuntamente com o cimento resinoso ou um cimento de ionômero de vidro modificado por resina. O uso de um dessensibilizante usado previamente ao cimento de fosfato de zinco reduz a retenção da coroa. O método de padronização dos preparos das coroas produziu uma diminuição nas variações dos valores de retenções. 
UNEMORI et al. ${ }^{75}$, em 2001, pesquisaram a sensibilidade pósoperatória, em paciente com restaurações de resina composta, feitas por estudantes de graduação, supervisionados. Analisaram, também, a relação entre profundidade da cavidade e forramentos, em relação à sensibilidade pós-operatória. Acompanharam, clinicamente, 151 pacientes, com idades que variaram de 16 a 83 anos. Os pacientes tiveram seus dentes restaurados com resina composta, em um período de 4 anos. Os instrutores eram os responsáveis pelo diagnóstico, se havia ou não necessidade de proteção pulpar. Os dentes foram divididos em 4 grupos, de acordo com o tipo de proteção pulpar, ou seja: Grupo 1- sem nenhuma proteção; Grupo 2proteção pulpar com hidróxido de cálcio; Grupo 3- proteção pulpar com cimento de ionômero de vidro; e, Grupo 4- proteção com hidróxido de cálcio (como base) em combinação com cimento de ionômero de vidro. Foram utilizados, neste trabalho, seis agentes adesivos dentinários (Clearfil New Bond, Super Bond C\&B; Bond Well LC; Clearfil Liner Bond II; Fluoro Bond e Mac-Bond) e sete resinas compostas (Clearfil F II; Clearfil F III; Clearfil posterior; Estio LC; Clearfil AP-X; Lite Fil II e Palfique Estelite). As cavidades foram classificadas em rasas e profundas. Todas as cavidades foram condicionadas com soluções ácidas e, depois foram lavadas com água. $\mathrm{O}$ primer foi aplicado de acordo com as instruções do fabricante. As resinas foram colocadas e tratadas de acordo com o tipo (quimicamente ativadas ou fotopolimerizadas). O sistema adesivo não era necessariamente do mesmo fabricante que a resina composta. Após uma semana, as restaurações receberam polimento e os dentes foram analisados quanto à sensibilidade. $A$ ausência ou a sensibilidade pós-operatória foi determinada, usando-se 3 critérios: 1- dor espontânea; 2- sensibilidade térmica. 3- sensibilidade à percursão. A incidência de sensibilidade pós-operatória (IPS) foi independentemente calculada de acordo com as variáveis: 1- tipo de proteção, 2- tipo de cavidade. 3- profundidade da cavidade e, 4- tipo de adesivo dentinário utilizado. Como resultado, os autores puderam concluir que: a incidência de sensibilidade pós-operatória não foi significativamente diferente entre os Grupos 1, 2 e 3, mas foi significativamente mais baixa no 
Grupo 1 do que no Grupo 4. As restaurações feitas em cavidades rasas e médias demonstraram significativamente menos sensibilidade do que em cavidades profundas. Os agentes adesivos dentinários mais recentes mostraram uma significativa diminuição na incidência de sensibilidade pósoperatória, do que nos grupos onde usaram as de primeira geração. Os autores puderam concluir que a sensibilidade pós-operatória em restaurações com resina composta não foi constatada com a ausência de camada de proteção pulpar, mas sim foi aumentada quando a cavidade era profunda. O tipo de agente adesivo dentinário poderia também ser um fator responsável pela sensibilidade pós-operatória.

CHRISTENSEN $^{21}$, em 2000, fez um debate sobre a necessidade de cimentos resinosos para cimentação de coroas, e descreve, também, como prevenir a sensibilidade pós-operatória, e o porquê ou quando ela ocorre. As recomendações principais para o uso de cimentos resinosos são para as coroas de cerâmica, coroas de polímeros e coroas metálicas que precisam de maiores resistências. O autor fez uma análise de vários sistemas e seus respectivos cimentos. Para prevenir a sensibilidade pós-operatória, relacionou as técnicas e os métodos para impedir a hipersensibilidade, ressaltando a necessidade da correta utilização dos sistemas adesivos e a necessidade da colocação correta da espessura do agente adesivo, para que este não interfira na cimentação. Ele questionou a possibilidade de se utilizar o agente adesivo, assim que o dente fosse preparado, pois existe a possibilidade deste interferir sobre o material de impressão, e, além do que, talvez o tempo pudesse torná-lo inativo. Analisa, também, que depois do condicionamento com ácido, o dentista poderia colocar um dessensibilizante, e a seguir utilizar uma solução adesiva de um primer-bond para a cimentação com um cimento resinoso. Ele acredita que um dessensibilisante, como o Gluma ${ }^{\circledR}$ Desensitizer ou o Microprime, podem também ser usados com sucesso. O uso de Panávia apresenta bom resultado e o uso do cimento 4 META e C\&B Metabond não induz a sensibilidade, embora alguns dentistas consideram-no difícil de ser usado 
em procedimentos de rotina. Um novo produto Parkell 4 META, Total Bond, atualmente está sendo observado pelos clínicos para determinar o seu potencial na dessensibilização e cimentação adequada da coroa. Ele sugere, também, o uso de ZOE como cimentação provisória, por 2 semanas, antes da cimentação definitiva com cimento resinoso, ou se necessário, tratamento endodôntico. Concluiu que a sensibilidade pós-operatória, após a cimentação de coroas com cimentos resinosos, é um problema para a Odontologia e que, após o condicionamento ácido, expondo os túbulos dentinários, deve ser feito um tratamento adequado para que isto não ocorra. Um dos conceitos mais lógicos de dessensibilização é deixar a smear layer nos dentes preparados e impregná-la com uma camada de primer auto-condicionante. Este conceito tem sido até o momento um dos mais previsíveis e bem sucedidos. Como a sensibilidade pós operatória é um problema comum, há necessidade de mais pesquisas nesta área.

HICHS, FLAITZ ${ }^{33}$, em 2000, compararam o efeito de um cimento de ionômero de vidro modificado por resina (Photac-Fil Quick Aplicap, ESPE) com o efeito de um material restaurador, resina composta (Z100, 3M Dental), em relação à formação da cárie secundária. Usou-se, para este trabalho, 12 dentes molares humanos, extraídos, livres de cáries, os quais foram seccionados em quarto de dente, nos quais foram preparadas cavidades sem bisel nas superfícies vestibular e lingual. Os dentes foram restaurados da seguinte forma: Grupo 1- CIV modificado por resina (Photac-Fil Quick Aplicap) com adesivo ESB (ESPE) usado no quarto do dente mesiovestibular e mesio-lingual e, Grupo 2- resina composta Z 100, com o sistema adesivo Scotchbond Multi-Purpose como pré-tratamento, sendo usado no quarto do dente disto-vestibular e disto lingual. Um verniz ácidoresistente foi aplicado a $1 \mathrm{~mm}$ da margem da restauração. Os espécimes foram submetidos a termociclagem $\left(500\right.$ ciclos de $5^{\circ} \mathrm{C}$ e $50^{\circ} \mathrm{C}$ por um tempo de 30 segundos em cada temperatura) em saliva artificial. Foram formadas cáries secundárias com gel de gelatina acidificada dialisada. Depois que os espécimes foram mantidos neste gel acidificado por 6 semanas, 2 seções 
longitudinais para cada quarto do dente foram avaliadas para observar se houve formação de cáries secundárias (iniciação da lesão). Um verniz resistente ao ácido foi aplicado nas superfícies cortadas, e reaplicado às superfícies anteriormente restauradas, dos quartos de dentes restantes, quando necessário. As porções restantes dos quartos de dentes foram colocadas em contato com gel de gelatina acidificada dialisada, por mais 4 semanas, para avaliar a progressão de cáries secundárias (progressão da lesão). Duas seções longitudinais para cada quarto de dente foram feitas após o progresso da lesão. As seções longitudinais, obtidas após a iniciação da lesão e os períodos de progressão, foram avaliadas através do microscópio polarizado de luz enquanto imersas em água. Os espécimes foram avaliados pela média da profundidade da lesão da superfície e freqüência das lesões nas paredes. Foram feitas comparações entre o CIV modificado por resina e resina composta. Os espécimes de CIV modificado por resina tiveram lesões primárias de superfície, significativamente mais rasas, em ambas as lesões iniciais de 35\% e progressão de $45 \%$, do que as do grupo de resina composta, ao passo que as lesões de parede apresentaram três vezes menos freqüência nos grupos com CIV modificado por resina do que no grupo de resina composta. Os autores concluíram que as restaurações com CIV modificado por resina reduzem a suscetibilidade às cáries em áreas não restauradas de esmalte adjacentes às restaurações, controlando a constante difusão pelo ataque dos ácidos e inibindo a desmineralização ao longo da interface esmalte-restauração, comparadas com restaurações de resina composta que não contem flúor, uma vez que a contínua liberação de flúor do material CIV deve diminuir a prevalência de cárie secundária in vivo.

PEREIRA; PAULILLO; DIAS ${ }^{54}$, em 2000, avaliaram a resistência ao cisalhamento de dois sistemas adesivos quando aplicados com diferentes graus de umidade. Após o condicionamento com ácido fosfórico a 35\%, os espécimes foram lavados, e, posteriormente, sete formas diferentes de secagem foram testadas, tais como: Grupos 1 e 2: secagem com jatos de ar 
por 30 segundos; Grupos 3 e 4: secagem com jatos de ar por 5 segundos; Grupos 5 e 6: sem secagem e a dentina foi deixada úmida; Grupos 7 e 8 : secagem com bolinhas de algodão; Grupos 9 e 10: bolinhas de algodão úmidas; Grupos 11 e 12: secagem com microbrush; grupos 13 e 14: filtro de papel absorvente. Foram aplicados os sistemas adesivos Primer \& Bond 2.1 e Scotchbond Mult-Purpose. Cilindros de resina composta Z100 com $3 \mathrm{~mm}$ de diâmetro foram construídos na área onde foram aplicados os adesivos, e após 7 dias de armazenagem os espécimes foram submetidos ao teste de resistência ao cisalhamento em uma velocidade de $0,5 \mathrm{~mm} / \mathrm{min}$.. Os resultados foram os seguintes: G 9=23.2 $\mathrm{MPa}(\mathrm{a}), \mathrm{G} 3=21.3 \mathrm{MPa}(\mathrm{ab})$; G2=19.5 MPa (bc); G10=18.6MPa (bc), G14=16.3 MPa (cd); G8=16.1 MPa (cd); G4 + 14.6 MPa (de); G 13=14.0 MPa (de); G=11 + 13.9 MPa (de); G7=13.7 MPa (de), G12=12.1 MPa (e), G1=8.2 MPa (f), G5=2.7 MPa (g); $\mathrm{G6}=2.4 \mathrm{MPa}(\mathrm{g})$. Através da análise estatística, concluiu-se que os valores da adesão foram afetados pelo grau de umidade da dentina e pela composição do sistema adesivo.

SOENO et al. ${ }^{65}$, em 2001, analisaram a resistência adesiva, em dentina bovina, de 2 agentes cimentantes à base de resina em combinação com 3 tipos de dessensibilizantes. Os agentes dessensibilizantes usados foram: Gluma ${ }^{\circledR}$ CPS Desensitizer, Ms Coat e Saforide. Como cimento resinoso foram usados: Panavia Fluoro Cement e Super- Bond C \& B. Os agentes condicionantes usados foram : AD Gel (10\% de hipocloreto de sódio), ED Primer líquido A (HEMA, MDP, 5-NMSA) líquido B (5-N-MAS), Green conditioner (ácido cítrico a 10\% com cloreto férrico a 3\%) e Panavia Etching Agent (ácido fosfórico a 40\%). Foram utilizados, para este trabalho, a face vestibular de 60 dentes bovinos anteriores. Estes dentes foram divididos em grupos de 15 dentes, sendo que 15 não receberam tratamento com agentes dessensibilizantes, enquanto que nos outros foram aplicados agentes dessensibilizantes. Logo depois foi colocada uma tira de aço e aplicada uma tensão por 24 horas e, depois, os resultados foram analisados estatisticamente. Quando não foi aplicado o dessensibilizante, a resistência 
de união dos 2 grupos: Super-Bond, que foi de 10.2 MPa e Ad Gel+ Panavia, que foi de 11.5 MPa., foi comparada e eles apresentaram uma resistência adesiva maior do que os grupos não unidos com o material Panavia sem nenhum condicionamento com gel (7.1 MPa.). Quando foi aplicado o Saforide, a resistência foi reduzida em ambos os cimentos Super-Bond e Panavia, enquanto que para o MS Coat o agente polimérico afetou negativamente a resistência adesiva somente do Panavia. $O$ uso do dessensibilizante Gluma ${ }^{\circledR}$ não afetou a resistência adesiva de nenhum dos 3 sistemas, e a resistência adesiva do cimento Panavia com gel AD não foi reduzida pela aplicação de nenhum dos 3 dessensibilizantes. Os autores, concluíram que, em consideração à mudança da cor do dente. $\mathrm{O} A g\left(\mathrm{NH}_{3}\right)_{2}$ F não é um componente ideal para ser usado como um dessensibilizante. Portanto, concluiram que as quatro combinações dos dois agentes dessensibilizantes Ms Coat e Gluma ${ }^{\circledR}$ CPS e dos dois sistemas adesivos Super Bond CE B e AD Gel + Panavia, são clinicamente aceitáveis. Como não só os dessensibilizantes, mas também os cimentos temporários freqüentemente cobrem a superfície da dentina antes da adesão em situações clínicas, estudos posteriores serão necessários para evitar efeitos indesejáveis na adesão.

SOARES; SOUZA; SANTIAGO ${ }^{64}$, em 2001, avaliaram, in vitro, o efeito de dois dessensibilizantes dentinários : Gluma ${ }^{\circledR}$ (Kulzer) e Pain Free (Parkell), em relação à adesão de uma resina restauradora e ao vedamento dos túbulos dentinários. Foram utilizados, neste estudo, 30 dentes humanos recém- extraídos, os quais foram divididos em 3 grupos com 10 dentes em cada grupo. Foram desgastados até a exposição da dentina, sendo em seguida feita uma profilaxia, e, depois, lavados com água e secados com bolinhas de papel absorvente. Em seguida, foi feito o condicionamento ácido da superfície dentinária com o ácido fosfórico a 37\%, lavado com água, e secado. Os dentes foram, então, divididos em três grupos e tratados da seguinte forma: Grupo 1- (grupo controle) foi aplicado o sistema adesivo Scotchbond Multi Uso (3M). Grupo 2- depois do condicionamento ácido foi 
aplicado o dessensibilizante Gluma®; Grupo3- foi aplicado o Pain Free. Nos Grupos 2 e 3 deu-se continuidade na aplicação do sistema adesivo de forma igual ao Grupo 1. Em todas as amostras foram aplicadas uma resina restauradora Z100 (3M), sobre a dentina tratada,com o auxílio de uma forma de teflon, de $3 \mathrm{~mm}$ de altura, com uma perfuração central de $3 \mathrm{~mm}$ de diâmetro. Os corpos de prova foram armazenados em água a $37^{\circ} \mathrm{C}$, por 48 horas, e foram, depois, submetidos a um teste de tração, em uma máquina Universal de ensaios e levados para análise ao MEV, para avaliar a eficácia dos dessensibilizantes usados, em relação ao vedamento dos túbulos dentinários. Foram analisados estatisticamente pelo teste ANOVA, onde $p>0.05$, demonstrando não haver diferença entre os três grupos estudados. Os autores puderam concluir que não houve alteração na força de adesão da resina restauradora, quando usados o Gluma ${ }^{\circledR}$ e o Pain. O Gluma $\AA$ e 0 Pain Free não interferiram nos processos de adesão ao substrato dentinário. O terceiro grupo (Pain Free) mostrou ao MEV melhoria no vedamento dos túbulos dentinários.

PASHLEY et al. ${ }^{50}$, em 2001, analisaram a hipótese de que a aplicação da técnica combinada de oxalato de potássio e agente adesivo sobre a superfície da dentina exposta seria efetiva na redução da permeabilidade, e avaliaram o comprometimento da resistência adesiva. Foram usados, neste estudo, terceiros molares humanos dos quais se obteve discos de $0.5 \mathrm{~mm}$, sendo que o lado pulpar dos discos foi condicionado com ácido cítrico a $6 \%$. Avaliou-se também a permeabilidade da dentina para determinar pela filtração do fluido através do disco e expressa como condutibilidade hidráulica. Os discos foram comprimidos entre duas borrachas com anéis de aro "O" e colocados na câmara com o lado do esmalte voltado para o lado aberto da câmara. A câmara pulpar foi conectada com aparatos para medir a permeabilidade, avaliando sequencialmente: 1- na presença de uma smear layer intacta; 2- depois do condicionamento da superfície com gel de ácido fosfórico a 32\% por 15 segundos; 3- depois da aplicação de uma solução de cloreto de sódio a 3\% por 2 minutos; 4- depois da aplicação de MRMHO a 
3\% por 2 minutos; 5- depois da aplicação de duas camada consecutivas de One-Step (sistema adesivo) e fotopolimerizado por 20 segundos. A condutibilidade hidráulica da dentina medida depois do tratamento com ácido fosfórico a $32 \%$ foi estabelecida um valor de 100\% (valor controle) e a medida da condutibilidade hidráulica, após os outros tratamentos, foi expressa como uma porcentagem do valor controle. Deste modo, cada disco serviu como seu próprio controle. Analisou-se também, por meio de um SEM, a correlação da aparência da superfície de dentina com os dados de permeabilidade, sendo, desta forma, analisado o interior dos túbulos. No teste de resistência à adesão, a dentina foi exposta, criando-se uma smear layer artificial, e depois foram usados 2 sistemas adesivos, o One-Step e Scotchbond Multi-Purpose. As superfícies analisadas foram condicionadas com ácido fosfórico, lavadas e nelas foi aplicado o oxalato gel. Como grupo controle, foi aplicada uma solução de $\mathrm{NaCl}$ a 3\%, e depois de lavadas, aplicou-se o sistema adesivo e a resina composta Z100, sendo metade do dente com oxalato e a outra metade do dente com $\mathrm{NaCl}$. Foi feita uma marcação para facilitar a identificação. As amostras foram armazenadas em água a $37^{\circ} \mathrm{C}$ por 24 horas, posteriormente foram seccionadas para separar as duas metades e cada metade foi transformada em muitos pedaços de 0.7 $\mathrm{mm}$ e cada um dividido em duas metades, sendo submetidas a testes de resistência à tensão em uma máquina Instron, e os resultados foram analisados estatísticamente. A dentina que recebeu o condicionamento com oxalato de potássio gel reduziu, significativamente, a condutibilidade hidráulica em aproximadamente $20 \%$ do valor máximo. A colocação do agente adesivo sobre os discos da dentina bloqueou completamente a sua permeabilidade a um valor Lp próximo a zero. Quando se usou OS (base de acetona) a média da força adesiva no grupo controle foi de $25.9 \mathrm{MPa}$, enquanto que a média da força adesiva do grupo experimental foi de 27.9 MPa., um valor que não é estatisticamente diferente ( $P>0.5$, Student's t-test). Quando se utilizou SBMP, com um primer aquoso, os resultados foram similares. As resistências adesivas tensivas dos espécimes do grupo controle aderidas com SB foi de 23.0 MPa, enquanto que os espécimes do 
grupo experimental aderidos com o mesmo adesivo foi $22.9 \mathrm{MPa}$. . Este resultado demonstrou que o tratamento com oxalato de dentina condicionada previamente com ácido não diminui estatisticamente a resistência adesiva da resina. O exame com SEM, na superfície da dentina, que foram condicionadas com ácido e tratadas com uma solução de $\mathrm{NaCl}$ a $3 \%$ (controle) não revelou sinais de qualquer precipitação. Tanto a superfície da dentina quanto os túbulos vistos nos espécimes fraturados estavam limpos e a aparência geral era semelhante à normalmente encontrada em imagens de dentina condicionada (não mostradas). A aplicação do gel de oxalato de potássio experimental sobre a camada da smer layer cobriu os discos da dentina mostrou uma grande formação de cristais sobre a superfície, mas os cristais não foram vistos dentro dos túbulos dentinários quando os margens fraturadas dos discos tratados foram examinadas. Quando o gel experimental de oxalato foi aplicado nas superfícies dentinárias condicionadas com ácido, o exame SEM revelou poucos cristais sobre a superfície dentinária. Entretanto, quando as margens fraturadas dos discos foram examinadas uma grande quantidade de formação de cristais cúbicos foi vista ao longo das paredes dos túbulos dentinários. O depósito de cristais apareceu para começar aproximadamente a $5 \mu \mathrm{m}$ abaixo da superfície e se estende para baixo aproximadamente $20 \mu \mathrm{m}$ dentro do túbulo. O exame das superfícies fraturadas de interfaces condicionadas e aderidas com tratamento de oxalato revelou uma característica peculiar de formação de Tag de resina. O top da superfície mostrou a formação de uma camada híbrida dentro da dentina desmineralisada e uma porção superior leve de tags de resina que preencheram a parte superior dos túbulos que não continham cristais. O monômero de resina penetrou dentro dos túbulos dentinários, preenchendo os espaços em volta dos cristais intra tubulares, a uma profundidade de aproximadamente 15-20 $\mu \mathrm{m}$. Quando os espécimes foram fraturados alguns cristais foram extraídos da superfície dos tags, revelando uma aparência de fenda. Alguns cristais puderam também ser vistos além do término dos tags de resina em alguns espécimes. Os autores concluíram que a aplicação de um gel de oxalato de potássio sobre as 
superfícies da dentina previamente condicionada para uma restauração adesiva pode ser um método útil para melhorar o selamento da dentina e reduzir a sensibilidade pós-operatória associada a restaurações adesivas.

SANTINI; PLASSCHAERT; MITCHELL ${ }^{61}$, em 2001, avaliaram a microinfiltração de cavidades Classe $\mathrm{V}$, restauradas com resina composta através da técnica de um ou três incrementos de RBC para determinar se o método restaurador afetaria a microinfiltração, usando dois diferentes sistemas adesivos alto-condicionantes. Para comparação as restaurações foram colocadas similarmente em um grupo controle usando-se um sistema de frasco único e a técnica de condicionamento total. Foram usados para este trabalho 60 dentes humanos, pré-molares e molares, extraídos, ficando armazenados em uma solução thymol a $0.2 \%$ até o uso, nos quais foram preparadas as cavidades na região da junção cemento-esmalte, em ambas as faces Vestibular e Lingual de cada dente. Metade de cada cavidade localizava-se no esmalte e metade em dentina-cemento, com medidas padronizadas de $3 \mathrm{~mm}$ de largura, $1.5 \mathrm{~mm}$ de profundidade, e $2 \mathrm{~mm}$ de altura. Os agentes adesivos usados foram Etch \& Primer 3.0, Clearfil Liner Bond 2V e um grupo controle Primer \& Bond N.T. Os espécimes foram divididos em 6 grupos $(\mathrm{N}=20)$. As cavidades foram restauradas com Tetric Ceram, sendo que metade da cavidade foi restaurada com um único incremento e a outra metade com 3 incrementos, sendo polimerizadas com fotopolimerizador. Após o término das restaurações, as superfícies foram polidas com discos Sof-Lex. Os ápices das raízes foram seladas com resina acrílica e o dente foi coberto com duas camadas de esmalte de unha, exceto na área da restauração e a $1 \mathrm{~mm}$ à sua volta. Os espécimes foram submetidos a termociclagem com 500 ciclos em banhos a uma temperatura de $5^{\circ} \mathrm{C}$ e $55^{\circ} \mathrm{C}$, por um tempo de 10 segundos em cada banho.Após a termociclagem, as amostras foram imersas em solução a 5\% de Procion Brilliant Red com pH 7 por 24 horas e depois lavados por 15 minutos com água destilada. As raízes foram separadas da coroa e esta foi seccionada no sentido Mésio Distal. Foram feitos dois cortes no sentido Vestíbulo-Lingual, 
passando através da restauração. A extensão da microinfiltração foi avaliada com um aumento de $10 \mathrm{x}$. Os espécimes foram analisados da seguinte forma: $0=$ nenhuma infiltração; $1=$ penetração do corante até $1 / 3$ da cavidade; 2=penetração até $2 / 3$ da cavidade; $3=$ =penetração do corante até o fundo da cavidade; e 4=penetração do corante dentro da parede axial. Após cada seccionamento, os espécimes foram analisados pelo SEM. Nenhuma infiltração foi detectada na margem do esmalte em todos os grupos. Todos os grupos mostraram microinfiltrações mas margens gengivais, não apresentando diferença significativa entre eles, e também com cada material, quando foi usada a técnica de incremento único comparada à técnica de 3 incrementos. O SEM mostrou que o material alto condicionante produziu um condicionamento mais raso e foi menos abundante o número de tags de resina composta do que o do material com gel de ácido fosfórico usado separadamente. Os autores concluíram que, de acordo com estes resultados, os valores normalmente atribuídos pela força de contração de polimerização podem provocar microinfiltrações, até mesmo em esmalte, devido à ruptura da união.

TOLEDANO et al. $^{73}$, em 2001, avaliaram a resistência ao cisalhamento da resina composta no esmalte e na dentina, usando três sistemas adesivos, sendo um convencional e dois auto-condicionantes. Avaliaram, também, a molhabilidade ou medida do ângulo de contato dos primers desses sistemas adesivos, tanto na dentina superficial quanto na mais profunda. A análise de mensuração do ângulo de contato foi feita pela técnica "Axisymmetric Drop Shape Analysis - CD". A gota do adesivo usado para análise apresentou um volume de $0.3 \mu \mathrm{m}$, onde a imagem era captada por um sistema de microvideo com um aumento de 10 vezes, sendo transmitido para "Data Translation Frame Grabber Board", que por sua vez era transmitido a um computador que analisava o ângulo de contato. Foram usados, para esse estudo, 30 dentes humanos, molares, extraídos e livres de cáries. Os espécimes foram seccionados paralelamente à superfície oclusal para expor a dentina superficial, a qual foi aplainada para promover 
uma superfície uniforme. Os dentes foram divididos em três grupos, sendo que cada grupo era composto por $n=10$. Receberam o seguinte tratamento: Grupo 1- Scotchbond Multi-Purpose (SBMP); Grupo 2- Clearfil SE Bond (CSEB); Grupo 3- Etch \& Primer (E\&P). Os espécimes foram seccionados abaixo do nível original para expor a superfície mais profunda da dentina e receberam o mesmo tratamento. O ângulo de contato foi medido tanto na dentina superficial quanto na mais profunda, em todos os grupos. As medidas dos ângulos de contato foram realizadas a uma temperatura de $25^{\circ} \mathrm{C}$ e a umidade estava próxima da saturação. Foram feitas análises das propriedades físicas dos primers. O teste de tensão superficial foi feito pelo método ADAS-Profile, a uma temperatura de $25^{\circ} \mathrm{C}$; foi medido o $\mathrm{pH}$ e calculada a viscosidade de cada um. Para o teste de resistência ao cisalhamento à dentina, foram usados 60 dentes molares humanos, extraídos e livres de cáries; estes foram divididos em 3 grupos, e cada grupo era composto por $n=20$. Metade dos dentes foram seccionados abaixo da junção esmalte-dentina e o restante seccionado a $1 \mathrm{~mm}$ abaixo do nível original, para expor a dentina mais profunda. Para o teste SBS (teste de resistência ao cisalhamento) no esmalte, foram usados 30 dentes incisivos bovinos, extraídos, os quais foram divididos em 3 grupos e cada grupo era composto por $n=10$. A superfície vestibular de cada dente foi aplainada e condicionada com cada um dos sistemas adesivos, de acordo com as instruções do fabricante, e sobre ela colocada resina composta. Depois foram armazenadas em água a $37^{\circ} \mathrm{C}$ por 24 horas. Posteriormente, foram submetidas a termociclagem, por 500 ciclos à temperatura de $6^{\circ} \mathrm{C}$ e $60^{\circ} \mathrm{C}$ com banhos de 30 segundos em cada temperatura. Depois foram levadas para teste em uma máquina de teste Instron. Depois, as fraturas foram analisadas através de stereomicroscópio para determinar se o tipo da fratura era coesiva, adesiva ou mista. Os resultados foram submetidos a análises estatísticas One-Way ANOVA e múltiplas comparações através do teste Student-Newman-Keuls. Os autores observaram que entre os ângulos de contato do CSEB e E\&P não houve diferença estatística entre eles, embora apresentaram maior ângulo de contato do que o SBMP. Sobre o esmalte, o 
E\&P apresentou resistência mais baixa, mas não houve diferença significativa do SBMP. Sobre a dentina, o CSEB apresentou resistência mais alta, não havendo diferença estatística entre o E\&P e o SBMP. Os autores concluíram que o uso de primers auto-condicionantes deve ser uma alternativa para o pré-tratamento com ácido fosfórico convencional em técnicas para resinas compostas em esmalte ou dentina, por reduzir os passos e o tempo dos procedimentos adesivos. Clearfil SE Bond apresentou a mais alta resistência ao cisalhamento em ambos esmalte e dentina.

CAMPS et al. ${ }^{19}$, em 2002, compararam, in vitro, a eficácia de 5 agentes dessensibilizantes (Seal and Protect, Gluma ${ }^{\circledR}$ Desensitizer, Pain Free, Health-Dent Desensitizer, Isodam e Protect como grupo controle) na redução da permeabilidade dentinária e compararam também a sua citotoxicidade. Todos os agentes dessensibilizantes eram à base de resina; como grupo controle foi usado um dessensibilizante à base de oxalato (Protect). Sessenta dentes molares humanos, extraídos, não erupcionados, foram usados neste estudo. Cada grupo era composto por 10 espécimes. A coroa foi fatiada, e a fatia mais próxima da polpa, mas sem que houvesse exposição dos cornos pulpares, foi escolhida. Cada fatia foi mantida presa a um anel com uma face voltada para a atmosfera (onde foi aplicado o agente dessensibilizante), e o lado pulpar ficou conectado em um pequeno tubo, preenchido com uma mistura de fosfato, solução salina tamponado a $10 \%$ (soro); em seu interior havia, também, uma pequena bolha que servia como um marcador, ou seja, era feito uma pequena pressão interna do líquido, no interior do tubo e, com qualquer movimento da bolha, este era registrado em um computador (o movimento da bolha era seguido automaticamente por uma luz infravermelha que passava através da borda da bolha para uma luz sensível de fotodiodo). As fatias foram condicionadas com EDTA para remoção da smear layer. A condutibilidade hidráulica de cada amostra foi testada antes e após a aplicação de cada agente dessensibilizante, sendo que em cada uma foi aplicado na porção exposta à atmosfera. Para o estudo da citotoxicidade, foram usados 60 dentes, sendo 10 para cada grupo 
de estudo. As fatias foram também colocadas em anéis e, a seguir, levadas para uma máquina especial para simular a pressão pulpar. O lado pulpar foi colocado em contato com um meio de cultura de células, e na parte superior (voltada para a atmosfera) foram aplicados os agentes dessensibilizantes. Sete fatias adicionais foram preparadas e condicionadas com os agentes dessensibilizantes; depois, foram analisadas através do SEM. Os autores concluíram que o uso dos agentes dessensibilizantes resultou em uma grande diminuição na permeabilidade da dentina. No teste da citotoxicidade, todos apresentaram menos de $20 \%$, sendo que nenhum foi considerado citotóxico. No exame com SEM puderam observar que o Gluma® Desensitizer, Isodan e Health Dent não mostraram modificações na superfície da dentina; os túbulos estavam abertos e livres de qualquer resina. O contrário pôde ser observado em Pain Free, onde foi encontrado uma grossa camada de resina. No Seal and Protect também foi constatada uma pequena camada de resina. Quando foi usado o Protect, encontraram também alguns túbulos preenchidos com cristais. Para todos os agentes dessensibilizantes, puderam observar que os túbulos foram claramente reduzidos. Todos foram efetivos na diminuição da condutibilidade hidráulica, embora o Seal and Protect apresentaram a mais baixa redução de condutibilidade hidráulica, pois, quando os observaram no SEM, puderam concluir que ocorreram algumas falhas na resina. O mecanismo comum que todos eles mostraram é que todos ocluiram os túbulos dentinários. Para o Protect, o material específico que ocluiu os túbulos deve ser o oxalato de cálcio. Para o Seal and Protect e Pain Free, o que ocluiu deve ser uma tira de resina, e para HEMA (Gluma® Desensitizer, Health Dent Desensitizer e Isodan) deve ser a precipitação das proteínas do plasma.

Uma possível técnica para otimizar a infiltração de monômeros resinosos e subseqüentemente criar adesão mais forte e estável é prolongando o seu tempo de difusão. EL-DIN; EL-MOHSEN ${ }^{25}$, em 2002, testaram a hipótese de que aumentando o tempo de aplicação do primer e do adesivo antes da polimerização poderia aumentar a resistência adesiva 
da resina composta com a dentina. Foram analisados dois sistemas adesivos de dois frascos (Scotchbond Multi-Purpose e OptiBond FL) e um sistema adesivo frasco único (Single Bod). 100 espécimes de discos de dentina foram preparados de molares humanos, extraídos. Aproximadamente $1 \mathrm{~mm}$ de estrutura dental foi desgastada para exposição da dentina superficial. Os espécimes foram padronizados e divididos para os três sistemas adesivos e no mínimo 5 espécimes foram usados para cada condição de teste. Para cada adesivo de dois frascos foram utilizados 40 espécimes, os quais foram divididos em 4 grupos com tempo de aplicação do primer de 10, 20, 30 e 40 segundos. Cada grupo foi ainda subdividido em dois subgrupos com tempo de aplicação do adesivo de 20 e 40 segundos. Os espécimes que receberam o adesivo de frasco único foram divididos em 4 grupos com um tempo de espera de 10, 20, 30 e 40 segundos antes de secar e polimerizar o sistema adesivo. Os testes de resistência adesiva ao cisalhamento foram realizados usando uma máquina de teste universal Instron, numa velocidade de deslocamento de $0,5 \mathrm{~mm} /$ minuto. Os resultados mostraram que para os sistemas adesivos de dois frascos, aumentando o tempo de aplicação do primer superior a 30 ou 40 segundos houve um aumento significante na média da resistência ao cisalhamento $(P<0,0001)$. $O$ aumento no tempo de aplicação do adesivo antes da polimerização não causou qualquer aumento significante na média da resistência adesiva $(P=0,05)$ a não ser nos grupos onde o primer foi aplicado por um tempo superior a 30 segundos. Para o sistema Single Bond, aumentando o tempo de aplicação antes de secar e polimerizar para 30 segundos resultou em um aumento estatisticamente significante $(P<0,002)$ na média da resistência ao cisalhamento.

BABA; MATSUMURA; ATSUTA ${ }^{8}$, em 2002, avaliaram os efeitos dos desinfectantes na força adesiva de resina à dentina. A superfície de dentina bovina foi exposta à solução aquosa de formaldeido (FA), solução aquosa de glutaraldeido (GA), solução aquosa de HEMA, primer de dentina (GLUMA® CPS, GLUMA®), solução isotônica de cloreto de sódio (IS), e água destilada 
(DW); depois, foi colocada numa estufa $(\mathrm{HU})$ a $37^{\circ} \mathrm{C}$, ou não armazenada (linha de base). Para este estudo foram utilizados 175 dentes bovinos anteriores. A face vestibular de cada dente foi desgastada até a exposição da dentina. Todas as amostras foram condicionadas com ácido cítrico a 10\% e solução de cloreto férrico a $3 \%$; sobre esta área condicionada foi usada uma fita adesiva com uma perfuração central com diâmetro de $5 \mathrm{~mm}$ para delimitar a área, sendo, então, aplicada nesta área a resina adesiva autocondicionante Super-Bond $C \& B$, unindo a dentina a uma resina acrílica. Depois, as amostras foram levadas a uma estufa por 30 minutos e então imersas em água destilada a $37^{\circ} \mathrm{C}$ por 24 horas. Terminado este tempo, as amostras foram submetidas ao teste de tensão e, depois, à análise com microscopia eletrônica (SEM). Os tipos de falhas observadas foram: (A) falha adesiva; (C) falha coesiva; (D) fratura de dentina e alguns tipos de combinações, tais como ( $A C, A D, C D)$. A média dos testes de resistência à tensão foi determinada após 24 horas e comparada através da análise estatística de variança ANOVA e Fisher's. A exposição da dentina em IS, DW e HU por 48 e 168 horas resultou em diminuição na força adesiva, quando comparado a uma linha de base. As forças adesivas mais altas, após 168 horas de exposição, foram obtidas com o uso de GA a 5\% (GLUMA $®$ Desensitizer), as quais foram significativamente mais altas do que a do FA. De acordo com os resultados, os autores puderam concluir que o uso combinado do Gluma ${ }^{\circledR}$ e do adesivo dentinário Superbond pode ser aplicado clinicamente. A aplicação do agente Gluma® dentro do canal radicular, durante um período temporário, deverá ser útil quando for removido muito do dente para se construir um núcleo.

PEREIRA, J.C.; MARTINELI,A.C.B.; TUNG ${ }^{55}$, em 2002, procuraram determinar uma metodologia capaz de determinar in vitro a superfície dentinária para observação no MEV, após o uso de diferentes agentes dessensibilizantes. Discos de dentina provenientes de terceiros molares humanos, extraídos, foram condicionados com ácido cítrico a $6 \%$, foi criada uma smear-layer artificial e a superfície dos discos de dentina foi dividida em 
quatro quadrantes. Os quadrantes 2, 3 e 4 de cada disco foram condicionados com ácido cítrico. Os agentes dessensibilizantes (Oxa- Gel囚), Gluma ${ }^{\circledR}$ Desensitizer e um experimental) foram aplicados nos quadrantes 3 e 4. O quadrante 4 foi novamente condicionado com ácido cítrico a $6 \%$ para avaliar a resistência ao condicionamento. Foi realizada então, a moldagem com Aquasil ULV. Após 6 minutos, cada disco foi removido da moldagem e acondicionado em ambiente livre de umidade por 24 horas a $37^{\circ} \mathrm{C}$. Decorrido este período, uma resina epóxica de baixa viscosidade (Araltec GY 1109 BR) foi vazada na moldagem, deixando-a polimerizar por 24 horas. Todos os espécimes foram metalizados para análise no MEV. A comparação das fotomicrografias dos discos de dentina e suas respectivas moldagens e réplicas mostrou que essa técnica pode reproduzir as características da superfície dentinária tratada com os agentes anti-hiperestésicos.

SEARA et al. ${ }^{63}$, em 2002, avaliaram a influência do pré-tratamento com um dessensibilizante dentinário sobre a resistência de microtensão com o uso de dois sistemas adesivos diferentes que foram também analisados, microscopicamente, para observação do efeito desse tratamento sobre a superfície dentinária. Utilizou-se, neste estudo, 16 terceiros molares, os quais tiveram as suas superfícies oclusais desgastadas, removendo-se todo o esmalte, e a coroa foi seccionada perpendicularmente ao longo eixo do dente. As raízes foram também removidas, deixando a área mais próxima possível da câmara pulpar, aproximadamente $0.5 \mathrm{~mm}$ na junção cementoesmalte. As superfícies dos dentes foram desgastadas de uma tal forma que apresentasse padronização na smear layer. Os dentes foram, então, armazenados em água destilada por 7 dias antes do começo do procedimento. Foram divididos em 4 grupos, e receberam o seguinte tratamento: G.1- D/Sense + condicionamento ácido + Prime \& Bond 2.1; G.2D/Sense 2 + Bistite II SC; G.3- Condicionamento ácido + Prime \& Bond e G.4- Bistite II SC. Depois de condicionados, em cada dente foi aplicado resina TPH com $8 \mathrm{~mm}$ de espessura. Os dentes foram armazenados, novamente, em água destilada a $37^{\circ} \mathrm{C}$ por uma semana. Cada amostra foi 
seccionada em série, novamente, no sentido vestíbulo-lingual, para produzir bastões com espessura de 1 X 1X $8 \mathrm{~mm}$, sendo que estes, posteriormente, foram submetidos a um teste de resistência de união em uma máquina de ensaios Instron. Uma amostra de cada grupo foi preparada para avaliação da camada híbrida em SEM. Os resultados foram analisados estatisticamente através do teste ANOVA e Tukey e mostraram diferenças significativas entre os grupos $(p<0.05)$. Os valores em Mpa. foram: G1=17.85; G-2=9.88; G-3=35.16; G-4=15.57. Baseando-se nos resultados deste estudo, concluiu-se que o dessensibilizante D/Sense 2 diminuiu a força de adesão dos sistemas adesivos Prime \& Bond 2.1 e Bistite II SC.

DALL'OROLOGIO; LONE; FINGER ${ }^{25}$, em 2002, avaliaram, clinicamente, se a adição de Glutaraldeido (GA) para one-bottle (GCB) tem a função de dessensibilizar, insinuada pela marca Gluma® Confort Bond + Desensitizer $(G C B+D)$. Dois estudos da dor foram feitos com idênticos protocolos e foram conduzidos em Abu Dhabi (A) e Bologna (B). Foram selecionados 60 pacientes para A e 59 para $B$, com idade que variaram de 22 a 64 anos, os quais apresentavam sensibilidade cervical em dois lados do dente, caracterizada por uma escore de 3 ou mais de 5 passos da escala da dor, sendo: 1 ( nenhuma dor), 2 (dor leve),3 (dor média), 4 (dor severa) e 5 (dor muito severa). Os dentes apresentavam um desconforto com uma aplicação de 2 segundos de ar frio. No Grupo A, somente um avaliador trabalhou; no Grupo B, 3 operadores foram calibrados para este trabalho. Durante o estímulo com ar, os dentes adjacentes, aos serem testados, eram cobertos pelo dedo do operador para evitar falso positivo. O paciente indicava a sensação de dor dentro dos 5 passos; uma sensibilidade mínima de 3 para 2 dentes sensíveis foi requerida para ser inclusa nesta triagem. Os pacientes receberam na mesma sessão, casualmente, o tratamento tópico com GCB e GCB + D, respectivamente, sobre os dois dentes nas áreas de sensibilidade selecionadas. Após a aplicação de cada um dos adesivos, foram novamente testadas com os mesmos estímulos de ar. Os pacientes foram reavaliados após 1 semana, 1 mês, 6 meses. Quando a sensibilidade 
não reduzia significativamente após uma semana, eram oferecidos aos pacientes um tratamento alternativo com Gluma® Desensitizer. No Grupo A, com GCB e GCB + D, as sensibilidades foram efetivamente iguais, após a imediata aplicação e polimerização. Após uma semana, o mesmo paciente relatou a mesma sensibilidade. Durante o período de observação de 1 semana a 6 meses, a dessensibilidade com GCB + D foi significativamente melhor do que com GCB. Os resultados sugerem que o glutaraldeído (GA), componente do GCB $+D$, reage com o líquido da proteína da dentina, coagulando e bloqueando os túbulos perifericamente. Isto deveria, então, explicar o efeito de dessensibilização obtido através da esperada oclusão que deveria ter sido incompleta ou perdida. Desde que um selamento dentinário incompleto, resultado de uma técnica de aplicação seca deveria ocorrer, onde o adesivo é aplicado com um agente conectado entre a dentina e o material restaurador de base-resina, a adição de GA para o adesivo é considerada uma forma conveniente de medida de prevenção da sensibilidade pós-operatória. Os autores concluíram que GA é um conveniente componente ativo e efetivo em GCB + D para prevenir sensibilidade pós-operatória, quando um selamento adequado na dentina não é obtido.

WOLFART; LINNEMANN; KERN ${ }^{79}$, em 2003, avaliaram a retenção da coroa depois de usarem diferentes sistemas de selamentos na dentina preparada. Usou-se suspensão de $\mathrm{Ca}(\mathrm{OH}) 2$ em comparação com 3 sistemas adesivos (Gluma ${ }^{\circledR}$ desensitizer, Optibond FL, Prompt L-Pop). Foram usados para este estudo pré-molares humanos, extraídos, que foram uniformemente preparados com o uso de um paralelometro especial. Grupos com 20 dentes cada foram tratados com cada sistema adesivo. Depois as coroas foram montadas e temporariamente cimentadas duas vezes. Depois de serem limpadas as coroas foram cimentadas com cimento de ionômero de vidro Ketac-Cem. Subgrupos de 10 coroas foram removidos com uma máquina de teste universal após armazenagem em água destilada ou por 3 dias ou por 50 dias. Antes do deslocamento as coroas de ambos os grupos 
foram submetidas a uma simulação de mastigação. A médias de estresses de deslocamento em MPa. foi entre 4.9 e 6.9. Um teste classificatório de Student-Newmann-Keuls revelou significativas diferenças entre $\mathrm{Ca}(\mathrm{OH}) 2$ e Optibond FL $(P<0.05)$, enquanto o tempo de armazenagem não teve efeito significativo. O nível de microinfiltração aumentou significativamente com o

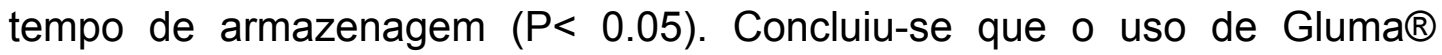
Desensitizer e Prompt L-Pop não afetou a retenção da coroa quando comparada com $\mathrm{Ca}(\mathrm{OH}) 2$, podendo assim ser usado em combinação com o cimento de ionômero de vidro para dessensibilizar os dentes preparados.

TITLEY; CALDWELL; KULKARNI ${ }^{72}$, em 2003, estudaram os efeitos da termociclagem e a integridade da união, a longo prazo, utilizando sistemas adesivos dentinários de frasco único e de múltiplas etapas. Foram utilizadas para este trabalho coroas de incisivos bovinos. A superfície da dentina foi exposta com lixas \#600 de SiC e incluída em resina acrílica. Uma área de $4 \mathrm{~mm}$ de diâmetro de dentina foi delimitada para a realização dos procedimentos adesivos e um cilindro de resina composta de $4 \mathrm{~mm}$ de diâmetro foi posicionado nesta área e fotopolimerizado. Os sistemas adesivos utilizados neste estudo foram: Scotchbond Multipurpose, Single Bond, All Bond 2, One Step e Primer \& Bond 2.1. Os espécimes foram divididos em 5 grupos, contendo 12 espécimes cada um: (1) foram mantidos em água por 7 dias; (2) foram submetidos a termociclagem após 24 horas de estocagem e por mais 6 dias antes do teste; (3) foram novamente submetidos a termociclagem após 6.5 dias de estocagem e testados após 7 dias; (4) estocagem em água por 24 horas e este grupo serviu como grupo controle do período de estocagem; (5) estocagem em água por 270 dias. Todos foram estocados em água a $37^{\circ} \mathrm{C}$. Todos os espécimes foram submetidos ao teste de resistência ao cisalhamento no final de cada período de estocagem e os espécimes fraturados foram examinados microscópicamente. Todos os resultados dos testes de cisalhamento para os 5 sistemas adesivos usados deterioraram com o tempo; os efeitos da termociclagem mostraram ser variáveis e dependetes do adesivo; os tipos 
de falha das fraturas mostraram ser adesivo-coesivo ou misto; após muito tempo (270 dias) de estocagem houve uma grande tendência de falhas de fraturas adesiva/coesiva. Quando One-Step foi usado, armazenado por 7 dias, apresentou um resultado de resistência ao cisalhamento de $8.1 \mathrm{MPa}$., e este resultado foi maior (13.4 MPa.) após 24 horas de termociclagem. Scotchbond Multi Purpose após armazenagem de 7 dias apresentou resistência de 14.3 MPa. e após submetidos a termociclagem diminuiu a resistência. O Single Bond, após 7 dias apresentou resistência de $9.5 \mathrm{MPa}$., e esta resistência foi aumentada após a termociclagem. Para All Bond 2, após 7 dias a resistência foi de 9.6 MPa. e diminuiu após a termociclagem. Prime \& Bond 2.1 apresentaram resistência ao cisalhamento após 7 dias de 5.7 MPa e esta aumentou após termociclagem de 24 horas e diminuiu após termociclagem de 6.5 dias. Os autores concluíram que a termociclagem neste estudo mostrou que as uniões entre resina e dentina deterioram com o tempo e isto deve ser mais uma grande preocupação dos dentistas, pesquisadores e fabricantes do que dos métodos atualmente usados nos testes.

PEREZ; SÉRGIO; SILVA ${ }^{56}$, em 2003, observaram, clinicamente, os efeitos do uso de um novo dessensibilizante dentinário (D/Sense 2- centrix) sobre diferentes causas de quadros hiperestésicos. Para este estudo, analisaram um grupo de 40 pacientes afetados pela hipersensibilidade dentinária, de diferentes etiologias, tais como: 1- lesões hiperestésicas cervicais; 2- preparos de apoio e plano guia, e 3- sensibilidade após restaurações com resina composta. Foi também observado a intensidade da dor, adotando o seguinte critério para a avaliação: os dentes foram isolados com isolamento relativo e, sobre a área sensível, foi colocada a ponta de uma seringa tríplice, aplicando um jato de ar com máxima potência por 3 segundos. A partir deste exame, distinguiram três grupos. Os pacientes foram tratados com D/sense, seguindo as recomendações do fabricante. $O$ exame de sensibilidade após aplicação foi realizado imediatamente e depois de 7 , e de 30 dias. Concluiu-se que o produto estudado foi efetivo no 
tratamento da hiperestesia com quadro típico (área cervical). Os resultados foram melhores em quadro de dor leve ou moderada. Parte dos casos, de dor intensa, não foi solucionada de forma satisfatória. O material mostrou-se menos efetivo para os quadros de hiperestesia, relacionados a preparos de apoios e planos guia de dentes com sensibilidade, após restauração com resina composta.

TAY et al. ${ }^{71}$, em 2003, tiveram como objetivo analisar o efeito da subsuperfície da dentina quando esta recebia, como tratamento após o condicionamento ácido, a aplicação de um dessensibilizante dentinário e, sobre este, a utilização de um sistema adesivo. Os dessensibilizantes utilizados e analisados foram: - três tipos de dessensibilizantes sem resina (Protect, John O. Butle Co., IL, USA; Oxagel, Art-Dent, São Paulo, Brasil; Super Seal, Phoenix Dental Inc., Fenton, MI USA) e - um tipo de dessensibilizante com resina (MS Coat, Sun Medical Co. Ltd., Shiga, Japan). Foram utilizados, neste trabalho, 50 dentes, terceiros molares humanos. Após a extração, 8 dentes foram fraturados com um martelo e cinsel, com o objetivo de se obter uma dentina exposta sem a presença de smear layer. As fatias utilizadas foram as da dentina coronária mais profunda. Quarenta e dois dentes foram desgastados por meio de pedras em baixa velocidade, sob água fria, e desgastados com lixas para criar smear layer sobre a dentina; depois, esta recebeu um condicionamento ácido e sobre ela foi aplicado o sistema adesivo One-Step (Bisco Inc., Schaumburg, IL, USA). Os espécimes foram submetidos aos testes de microtensão. Para isto, foram utilizados 4 dentes de cada 2 grupos experimentais, designados para os quatro dessensibilizantes, e um grupo controle que não recebeu tratamento (total 36 dentes). Os dessensibilizantes foram aplicados antes ou após o condicionamento ácido (ácido fosfórico a 32\%, Uni-Etch, Bisco), sendo depois, aplicado o sistema adesivo na dentina condicionada com ácido ou não e com o dessensibilizante. A dentina apresentava-se úmida. Sobre esta área foi construído um incremento com resina composta híbrida fotopolimerizável. Nos grupos controles não se fez uso dos 
dessensibilizantes. Depois, as amostras foram armazenadas em água destilada a $37^{\circ} \mathrm{C}$ por 24 horas. Cada dente foi seccionado no sentido oclusogengival formando várias lâminas com espessura de $0.9 \mathrm{~mm}$. As lâminas maiores foram preparadas para serem analisadas por TEM. Uma comparação adicional foi realizada com o objetivo de analisar infiltrações dentro da camada híbrida nos espécimes com o uso do oxalato, com ou sem condicionamento ácido, para isto os espécimes foram cobertos com um verniz de unha e a $1 \mathrm{~mm}$ de distância da interface de união, e foram imersos em solução de nitrato de prata por 24 horas. Depois, as amostras foram examinadas com o microscópio TEM. Os resultados foram analisados estatisticamente pelo teste ANOVA. Através do resultado com o teste de microtensão, os autores puderam observar que a resistência adesiva foi significativamente mais baixa, comparada com o grupo controle, quando os oxalatos foram usados antes dos espécimes serem condicionados; em contraste, com o grupo onde os oxalatos foram usados, após o condicionamento ácido, os resultados foram similares ao grupo controle sem nenhum oxalato. Ambos, Oxagel e agente dessensibilizante contendo resina, apresentaram uma redução na força adesiva $(p<0,05)$, mais do que ocorreu com os outros agentes, onde foram aplicados em dentina sem condicionamento. Na superfície dentinária, onde foram aplicados os dessensibilizantes, os orifícios tubulares estavam cobertos com uma camada de cristais e a dentina fraturada estava coberta com smear layer, antes dos espécimes serem condicionados. Entretanto, quando a dentina foi condicionada antes da aplicação do oxalato, os cristais estavam largamente limitados na subsuperfície dos túbulos dentinários, mas não interferiram na subseqüente união da resina.

ARRAIS; CHAN; GIANNINI ${ }^{4}$, em 2004, avaliaram as características de obliteração dos túbulos dentinários de três agentes dessensibilizantes: 1- um produto à base de oxalato de potássio (Oxa-Gel/OG); 2- um produto à base de HEMA e Glutaraldeído (Gluma® Desensitizer/GD) e; 3- um produto à base de flúor-fosfato acidulado (Nupro Gel/ AF). Foram utilizados neste 
trabalho 24 terceiros molares, humanos, extraídos. Na região vestibular de cada dente foi confeccionada uma área planificada, as quais foram polidas com lixas de SiC e pastas de diamante para simular superfícies vestibulares dentinárias cervicais expostas, as quais apresentam hipersensibilidade. Os dentes foram aleatoriamente divididos em 4 grupos com $n=6$. Cada grupo recebeu o seguinte tratamento: G 1: sem tratamento; G 2: OX; G 3: GD; G 4: AF. Depois do tratamento, os dentes foram fraturados no sentido linguovestibular e preparados para análise com microscopia eletrônica de varredura (MEV). O Grupo 2, OX, promoveu oclusão dos túbulos, pela deposição de cristais no seu interior. O Grupo 3, GD, criou uma camada delgada sobre a superfície da dentina. O Grupo 4, AF, produziu a formação de precipitados que ocluiram os túbulos. De acordo com a análise em MEV, todos os agentes dessensibilizantes testados foram capazes de obliterar os túbulos dentinários.

YIU et al. ${ }^{81}$, em 2004, tiveram como objetivo fazer um estudo (1) para comparar as resistências adesivas de microtensão de 4 adesivos com condicionamento em frasco único, com diferente acidez, em dentina condicionada com ácido e tratada com o dessensibilizante de oxalato e (2) para examinar, com o uso de microscópio eletrônico, a ultra-estrutura da interface aderida. A hipótese nula testada foi de que não há diferença na adesão de adesivos condicionados em frasco único com acidez diferente à dentina condicionada com ácido e tratada com o dessensibilizante de oxalato. Foram usados para este estudo, 84 terceiros molares humanos, livres de cáries, que foram armazenados em uma solução de cloramina $T$ a $0,5 \%$ a uma temperatura de $4^{\circ} \mathrm{C}$ num período de um mês após as extrações. O esmalte da superfície oclusal foi removido. Um papel de carbeto de silicone com granulação de 180 foi usado sob refrigeração para criar uma smear layer, clinicamente relevante, na superfície da dentina. Os sistemas adesivos usados foram One-Step (OS); Single Bond (SB); Optibond Solo Plus (OB) e Prime \& Bond NT (PB). Os agentes dessensibilizantes de oxalato foram: Bisblock (BB) e Super Seal (SS). Cada adesivo foi dividido 
em 3 grupos experimentais com 7 dentes cada. Cinco dentes restaurados foram usados para avaliação da resistência adesiva de microtensão e 2 dentes para exame ultra-estrutural. O teste de resistência de microtensão realizou-se em superfície oclusal na dentina profunda e coronária. Os 3 grupos experimentais foram: Grupo 1- condicionamento da superfície com ácido fosfórico gel a $32 \%$ por 15 segundos e os espécimes foram lavados com água por 20 segundos. Grupo 2- Após o condicionamento com ácido aplicou-se Bisblock com movimentos ativos por 30 segundos e os espécimes foram lavados com água por 60 segundos. Grupo 3- Após o condicionamento com ácido aplicou-se o Super Seal com movimentos ativos por 30 segundos e os espécimes foram lavados com água por 60 segundos. Os dentes foram tratados com adesivos seguindo as instruções dos fabricantes. A superfícies aderidas foram secada com ar e depois fotopolimerizadas por 10 segundo. Restaurações com resina composta foram realizadas, usando-se um composto fotopolimerizável (Z250) em cinco incrementos de $1 \mathrm{~mm}$ e individualmente fotopolimerizadas por 40 segundos. Os dentes foram armazenados em água destilada a $37^{\circ} \mathrm{C}$ por 24 horas. Os dentes foram a seguir seccionados no sentido ocluso-gengival em fatias seriadas e, em seguida, seccionados em fachos de dentina composta de 0,9 x 0,9 $\mathrm{mm}$. Oito fachos foram recuperados de duas fatias mais largas de cada dente. Cinco dentes de cada grupo produziram 40 fachos para avaliação da força adesiva. Os espécimes foram levados a estresse para avaliação de falha sob tensão em um aparelho Bencor Multi-T usando-se uma máquina de teste universal Model 4440, numa velocidade de $1 \mathrm{~mm} / \mathrm{min}$. Os fachos com falhas adesivas prematura foram designados com valor de resistência adesiva nula e foram incluídos na compilação da média da força adesiva. Os dados coletados foram analisados, usando-se a SigmaStat Version 2.03. Como os dados $\mu$ TBS não foram normalmente distribuídos, eles foram analisados usando KrusKal-Wallis one Way ANOVA nas classificações e os testes de comparações múltiplas de Dunn's com significância estatística estabelecida em $\alpha=0,05$. Para o teste de microscopia eletrônica e espectroscopia de raio- $X$ de energia dispersiva foram usados 6 fachos 
fraturados de cada grupo com $\mu$ TBS próximos da média de resistência adesiva de cada grupo os quais foram selecionados para análise fractográfica. A dentina de 4 espécimes fraturados foram secados e examinados com SEM. Os espécimes de duas dentinas restantes foram secados e analisados com SEM/EDX. Na transmissão de microscopia de elétron foram analisados dois dentes de cada grupo condicionados com ácido e igualmente tratados com os dessensibilizantes de oxalato como descrito anteriormente. Os dentes foram seccionados e as duas fatias mais largas foram cobertas com duas camadas de esmalte de unha aplicado a um milímetro das interfaces aderidas. Eles foram imersos em solução amoníaca de nitrato de prata a $50 \mathrm{wt} \%$ por 24 horas e foram analisados usando o TEM. Os adesivos livres de água que são dissolvidos em solventes polares não se dissociam normalmente em espécies iônicas. Para resolver este problema amostras de $2 \mathrm{ml}$ de cada adesivo foram coletadas e distribuídas dentro de um vidro limpo contendo $3 \mathrm{ml}$ de etanol a $70 \%$ e água destilada a $30 \%$. Os valores de $\mathrm{pH}$ das 4 soluções adesivas foram medidos a uma temperatura ambiente, usando-se um metro digital de $\mathrm{pH}$. Três leituras foram feitas para cada adesivo, e o seu valor médio de $\mathrm{pH}$ foi calculado. Igualmente para a medida do $\mathrm{pH}$ uma amostra de $2 \mathrm{ml}$ de cada adesivo passo-simplificado foi coletada e distribuída dentro de um vidro limpo contendo $3 \mathrm{ml}$ de etanol a $70 \%$ e água destilada a $30 \%$. A solução foi tamponada com TISAB III. As concentrações de fluoreto foram igualmente determinadas a uma temperatura ambiente através de um eletrodo seletivo de íon. Como resultado à resistência adesiva de microtensão, ambos OB e PB mostraram redução significativa na força adesiva de microtensão quando aplicados à dentina condicionada com ácido e tratada com o dessensibilizante de oxalato $(p<0,05)$. Em contraste, SB e OS não mostraram diferenças significativas nas forças adesivas quando aplicados à dentina condicionada com ácido fosfórico a 32\%, tratada e não tratada com oxalato $(p>0,05)$. Nenhuma diferença significativa foi observada entre o Bisblock e o Super Seal quando usados com os 4 adesivos. Na análise com SEM e EDX, a falha adesiva ocorreu predominantemente ao longo da interface dentinária- 
adesiva em PB-SS. As superfícies dentinárias foram caracterizadas por glóbulos esféricos com diâmetro de 2-4 $\mu \mathrm{m}$ que foram localizados preferencialmente nos orifícios dos túbulos dentinários. Os glóbulos esféricos puderam também ser vistos nos espaços vazios das camadas adesivas de PB-BB. Igualmente ao PB, numerosos glóbulos esféricos ficaram evidentes nas superfícies dentinárias fraturadas de OB-BB. Em contraste, o tipo de falha dos sub-grupos de oxalato SB e OS foi predominantemente misto, e não foram vistos glóbulos esféricos. Espectros EDX representativos dos glóbulos esféricos da superfície dentinária de PBSS revelaram a presença de $\mathrm{F}$ juntamente com os grandes componentes da dentina. Os picos de $\mathrm{F}$ somente foram observados nos glóbulos esféricos, mas não na dentina adjacente. Da mesma forma, a composição de corpos esféricos de OB-BB foi diferente na dentina adjacente, devido à presença de F. Resultados com TEM: - as interfaces de união dos espécimes com PB-SS revelaram uma extensiva nanoinfiltração de prata dentro da camada híbrida e glóbulos eletrolucentes com depósito de prata foram observados na camada adesiva. Espaços eletrolucentes descontínuos puderam ser identificados ao longo da interface adesiva-dentinária. A nanoinfiltração também foi observada dentro de toda a camada híbrida OB-BB. Os túbulos dentinários foram preenchidos com depósitos de prata sem cristais de oxalato identificados na sub-superfície. Os espaços descontínuos das margens foram encontradas entre as camadas híbridas e adesivas em OBBB. Nenhuma grande diferença pôde ser reconhecida entre os dois dessensibilizantes de oxalato após a aplicação de OB e PB. Diferentemente de OB e PB, depósitos de prata isolados apenas foram encontrados em algumas áreas da camada híbrida de SB-SS. Os autores concluíram que as forças adesivas de OS e SB não foram comprometidas com o uso adjunto dos dessensibilizantes de oxalato (One-Step=48,7 $(4,2)$ e com Bisblock 43,4 $(4,8)$. A boa infiltração de resina e a formação da camada híbrida ocorreram diante de cristais de deidrato de oxalato bipiramidal nos túbulos dentinários. Esses cristais puderam ser observados mais claramente nos espécimes fraturados. Em contraste, as forças adesivas significativamente mais baixas 
foram observadas em OB e PB quando aplicadas na dentina tratada com dessensibilizante de oxalato, que poderia ser atribuído à presença de glóbulos esféricos, ao longo da interface adesiva-dentinária. Concluindo, os resultados do atual estudo indicaram que a força adesiva dos adesivos simplificados aplicados à dentina condicionada com ácido e tratada com o dessensibilizante de oxalato pode ser comprometida pela acidez e disponibilidade de fluoretos de adesivos totalmente condicionados. Os clínicos devem estar cientes do pequeno potencial da força adesiva com o uso de $\mathrm{PB}$ e $\mathrm{OB}$ na dentina condicionada com ácido e tratada com dessensibilizante de oxalato. 
3 PROPOSIÇÃO

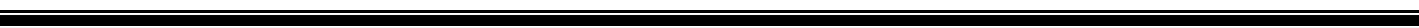




\section{PROPOSIÇÃO}

O presente trabalho tem como objetivo avaliar:

1- A resistência adesiva obtida com o uso do sistema adesivo OneStep combinado ou não com o dessensibilizante BisBlock.

2- A resistência adesiva obtida com o uso do sistema adesivo Scotchbond Multi-Purpose combinado ou não com o dessensibilizante GLUMA® Desensitizer.

3- O tipo de fratura obtida nos diferentes grupos.

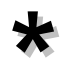


4 MATERIAIS E MÉTODOS 


\section{MATERIAIS E MÉTODOS}

\subsection{Seleção dos dentes}

No presente estudo foram selecionados 40 terceiros molares humanos, extraídos, livres de cáries, defeitos estruturais e trincas. Imediatamente, após as extrações, os mesmos foram armazenados em solução de cloramina $\mathrm{T}$ a $1 \%$ (ASMUSSEN; JORGENSEN ${ }^{6}$, 1972; PENTEADO; ASMUSSEN ${ }^{53}$, 1995; FINGER; UNO ${ }^{28}$, 1996), para evitar o crescimento de micro-organismos, sendo posteriormente limpos e armazenados em água deionizada, em refrigerador à temperatura aproximada de $4^{\circ} \mathrm{C}$, até o momento de utilização.

\subsection{Preparo dos espécimes}

Inicialmente, os dentes tiveram suas raízes seccionadas, um pouco abaixo da junção cemento-esmalte, com auxílio de um micrótomo para tecidos duros (Bronwill,Spec B 2907C8, Motor Appliance Corp., Saint LouisMO, - EUA) sob irrigação constante. Os condutos radiculares e a câmara pulpar foram tamponados com cera utilidade (Wilson, Polidental, Ind \& Com. LTDA., Brasil) com o intuito de evitar a penetração de resina epóxica no interior dos dentes. As coroas foram inseridas individualmente em formas 
cilíndricas de silicona de condensação (Difibra Com. de Produtos para Fiberglass LTDA. São Paulo - SP), obtidas a partir de uma matriz metálica e com as faces vestibulares voltadas para o fundo das mesmas (Fig. 1). Para a inclusão, foi utilizada uma resina epóxica (Redelease, São Paulo, SP, Brasil) com baixa liberação de calor durante a polimerização. A proporção da resina utilizada foi de $10 \mathrm{~g}$ da base para $1 \mathrm{~g}$ do catalisador e utilizou-se, para aferir esta proporção, uma balança de precisão (Onda Científica Ltda, Campinas São Paulo, Brasil). Logo após a manipulação, o material foi vertido no interior das formas. Após a polimerização da resina (aproximadamente 24 horas), os espécimes foram retirados das formas, obtendo-se discos de resina com as coroas incluídas em seu interior, cujas dimensões eram de $2,5 \mathrm{~cm}$ de diâmetro por $1 \mathrm{~cm}$ de altura (Fig. 1). As superfícies vestibulares das coroas incluídas foram desgastadas em uma politriz (modelo DP-92, fabricada pela Panambra Industrial e Técnica S.A. São Paulo - SP) com lixas de carbeto de silício e granulação decrescente, com as numerações de 120, 220, 600 e 1200 (Norton-SP,), sob refrigeração abundante de água, de tal forma a expor apenas a camada do tecido dentinário, livre de esmalte, e, após a exposição da dentina, estes permaneceram por 15 segundos na lixa 600 e 15 segundos na lixa 1200, tentando padronizar a smear layer da superfície dos espécimes. Posteriormente, estes discos foram armazenados em água deionizada e mantidos à temperatura ambiente.

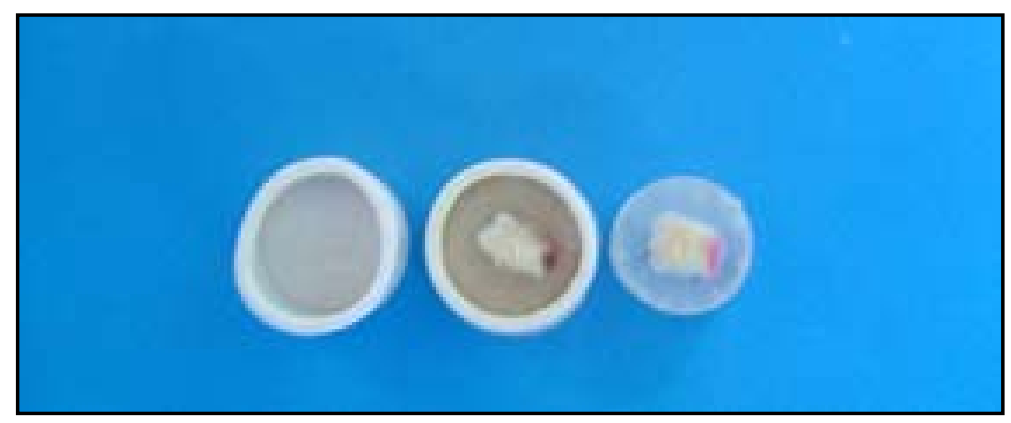

FIGURA 1 - Seqüência de inclusão. 1- matriz de silicona, 2- e com resina epóxica foi realizada a inclusão da porção coronária, 3- após a remoção e exposição da dentina com lixadeira, obtivemos o espécime para os testes. 


\subsection{Materiais utilizados}

Foram empregados:

* 2 sistemas adesivos, de quarta geração:

Scothbond Multi-Purpose (Fig. 2)

One-Step (Fig. 3)
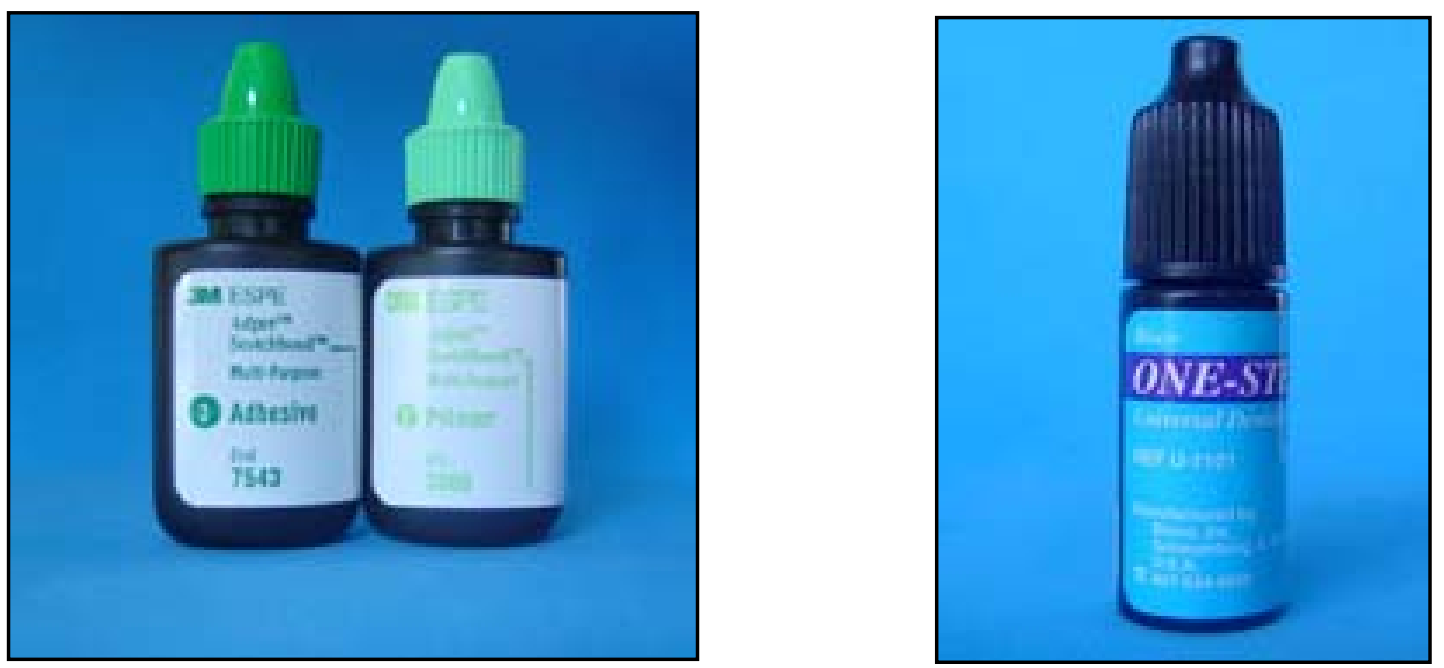

FIGURA 2 - Scotchbond Multi-Purpose.

FIGURA 3 - One-Step. 
* 2 sistemas dessensibilizantes dentinários

GLUMA® Desensitizer (Fig. 4)

Bisblock (Fig. 5)

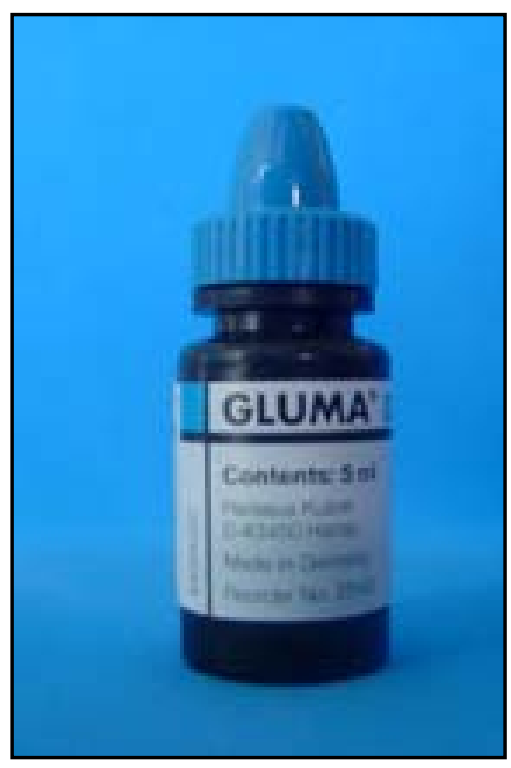

FIGURA 4 -GLUMA® Desensitizer.

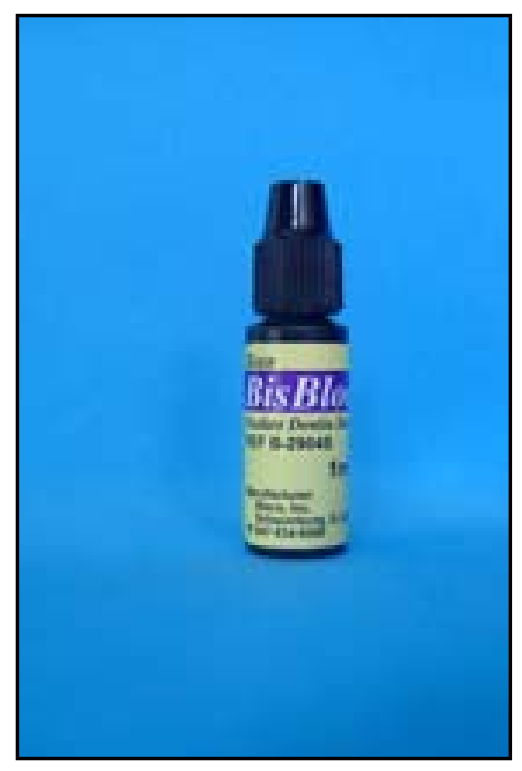

FIGURA 5 - BisBlock.

\section{* 1 condicionador ácido}

Ácido fosfórico a 37\%, comercial, espessado com sílica coloidal (Dentsply Ind. Com. Ltda., Petrópolis, Rio de Janeiro, Brasil). Lot: 228736. Validade 10/07 (Fig. 6).

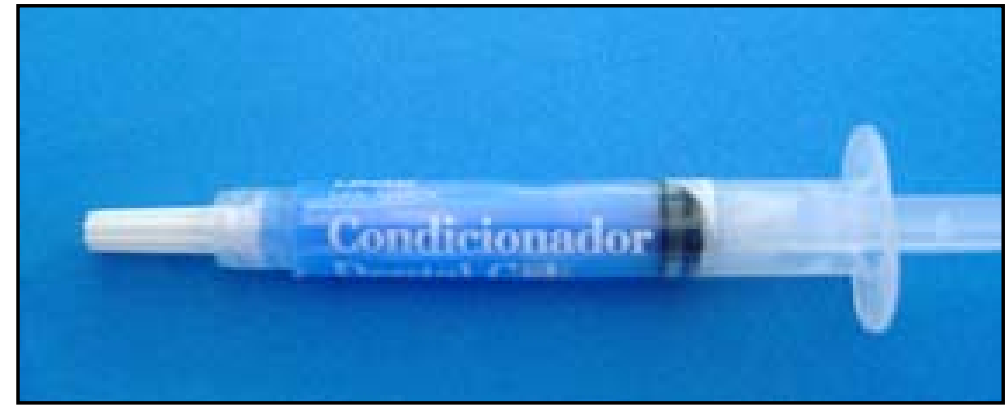

FIGURA 6 - Ácido fosfórico a 37\%. 
Os materiais testados neste estudo estão relacionados abaixo:

QUADRO 1 - Materiais testados.

\begin{tabular}{|c|c|c|c|}
\hline Materiais & Fabricantes & Lote & Validade \\
\hline $\begin{array}{c}\text { Scotchbond Multi- } \\
\text { Purpose adesivo }\end{array}$ & $3 \mathrm{M}$ & $4 \mathrm{AL}$ & $01 / 07$ \\
\hline One-Step & Bisco & 0300014713 & $11 / 05$ \\
\hline GLUMA® Desensitizer & Heraeus Kulzer & 030049 & $07 / 05$ \\
\hline BisBlock & Bisco & 0500000521 & $12 / 06$ \\
\hline
\end{tabular}

QUADRO 2 - Composição química dos sistemas empregados.

\begin{tabular}{|c|c|c|c|}
\hline Nome comercial & Condicionador & Primer & Adesivo \\
\hline $\begin{array}{l}\text { Scotchbond Multi- } \\
\text { Purpose }\end{array}$ & $\begin{array}{c}\text { Ácido fosfórico } \\
37 \%\end{array}$ & $\begin{array}{c}\text { HEMA } \\
\text { Copol. do ácido } \\
\text { Polialcenóico }\end{array}$ & $\begin{array}{c}\text { BIS-GMA } \\
\text { HEMA }\end{array}$ \\
\hline One-Step & $\begin{array}{c}\text { Ácido fosfórico } \\
37 \%\end{array}$ & \multicolumn{2}{|c|}{$\begin{array}{c}\text { BIS-GMA } \\
\text { BDPM } \\
\text { HEMA } \\
\text { Acetona }\end{array}$} \\
\hline $\begin{array}{c}\text { GLUMA® } \\
\text { Desensitizer }\end{array}$ & $\begin{array}{c}\text { (2-HIDROXIETIL) } \\
\text { METACRILATO } \\
\text { 35\% } \\
\text { glutaraldeido 5\% } \\
\text { água } \\
\end{array}$ & & \\
\hline Bisblock & Oxalato & & \\
\hline
\end{tabular}

\section{* Material restaurador}

Filtek-Z 250 (3M do Brasil Ltda.- Produtos Dentários, Sumaré, São Paulo, Lote \# 3 NW), composta por: BisEMA, UDMA, BisGMA. Data de validade 06/06 (Fig. 7) 


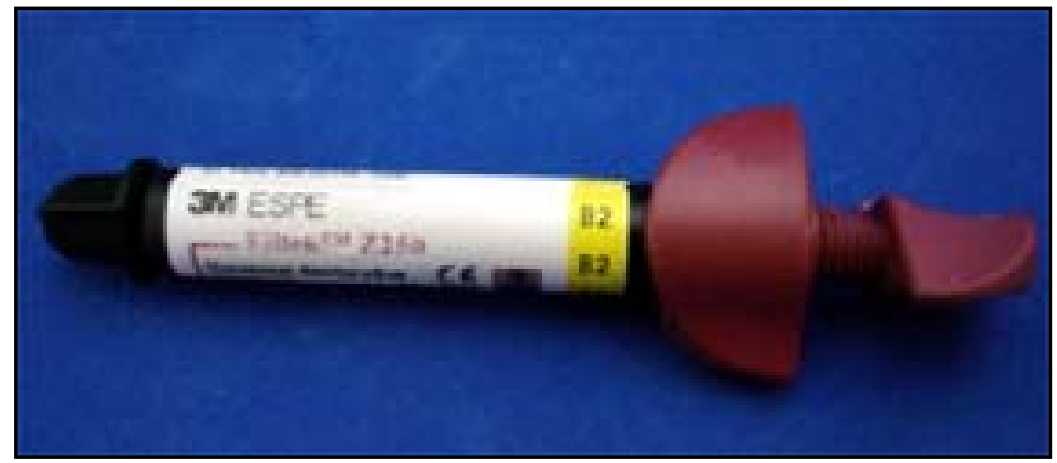

FIGURA 7 - Resina Composta Z250.

\subsection{Procedimento adesivo}

Os dentes, que estavam armazenados em água deionizada, foram aleatoriamente divididos em 4 grupos, com dez unidades cada um, que, de acordo com a metodologia utilizada, receberam os devidos tratamentos dos sistemas adesivos ou associados aos respectivos dessensibilizantes. Uma fita adesiva (3M) que apresentava uma perfuração central de $4 \mathrm{~mm}$ de diâmetro foi posicionada na superfície da dentina exposta para demarcar a região adesiva (Fig. 8). Este método foi adotado para garantir que a área, na qual o sistema adesivo aplicado ou a sua associação ao dessensibilizante previamente usado, fosse padronizada para obter-se precisão nos valores de resistência adesiva (HOLTAN; NYSTROM; OLIN ${ }^{34}$, 1994).

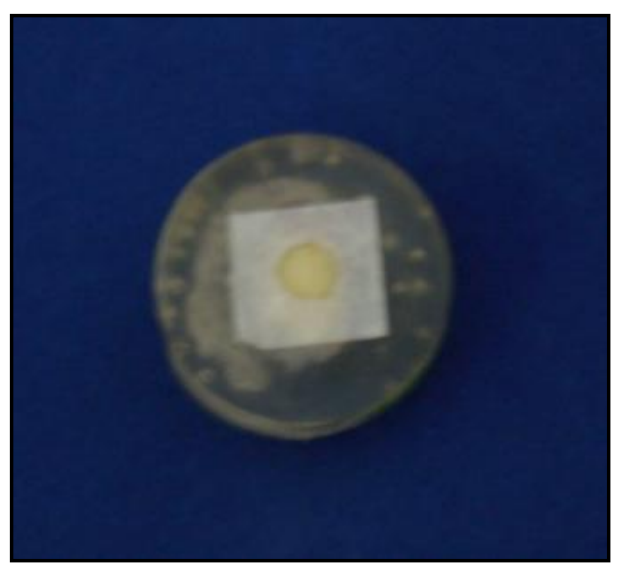

FIGURA 8 - Área demarcada. 


\section{Grupo 1 - Scotchbond Multi-Purpose}

A seqüência deste procedimento adesivo envolveu: secagem da cavidade com jatos de ar, condicionamento da dentina com ácido fosfórico a 37\% (Condicionador Dental Gel) por 15 segundos; lavagem com água deionizada por 30 segundos e secagem com papel absorvente para não dessecar a dentina (PEREIRA ${ }^{54}, 2000$; MIEARS et al. $^{42}$, 1995). Depois, foi aplicado o Scotchbond Primer de forma ativa (MIYAZAKI ${ }^{43}$, 1996) por 15 segundos, com aplicador descartável Microbrush Original Fino, permanecendo por mais 20 segundos na superfície; em seguida, efetuou-se uma suave secagem com jato de ar, para evaporação dos solventes, por 5 segundos, com seringa tríplice a $10 \mathrm{~cm}$ de distância. Seguiu-se a aplicação de uma fina camada do Scotchbond Adesivo com um pincel de nylon. Tal camada foi, então, fotopolimerizada por 10 segundos, com o aparelho de luz, empregado em todos os grupos.

\section{Grupo 2 - GLUMA® Desensitizer e Scotchbond Multi-Purpose}

Para este grupo a seqüência do procedimento adesivo foi a seguinte: condicionamento da dentina com ácido fosfórico a 37\% por 15 segundos; lavagem com jatos de água deionizada por 30 segundos; secagem com papel absorvente, sem dessecar a dentina; aplicação do GLUMA® Desensitizer com aplicador descartável Microbrush Fino de forma ativa, permanecendo por 30 segundos na superfície; suave secagem com jato de ar por 10 segundos para evaporação dos solventes (PENTEADO; ASMUSSEN $^{53}$, 1995) aplicação do Scotchbond Multi-Purpose Primer e Scotchbond Adesivo da mesma forma que no Grupo 1 e fotopolimerização por 10 segundos. 


\section{Grupo 3 - One-Step}

Para este grupo a seqüência do procedimento adesivo foi a seguinte: condicionamento da dentina com ácido fosfórico a 37\% por 15 segundos; lavagem com jatos de água deionizada por 30 segundos; secagem com papel absorvente, sem dessecar a dentina; aplicação do sistema adesivo ONE-STEP, com um pincel de nylon, permanecendo por mais 30 segundos na superfície, realizando-se em seguida ligeira secagem por 5 segundos; reaplicação de uma nova camada do adesivo, permanecendo por 30 segundos; secagem com leve jato de ar por 5 segundos com seringa tríplice a $10 \mathrm{~cm}$ de distância e fotopolimerização por 10 segundos.

\section{Grupo 4 -Bisblock e One-Step}

Para este grupo a seqüência do procedimento adesivo foi a seguinte: condicionamento da dentina com ácido fosfórico a 37\% por 15 segundos; lavagem com jatos de água deionizada por 30 segundos; secagem com papel absorvente, sem dessecar a dentina; aplicação do Bisblock por 30 segundos; lavagem por 60 segundos e secagem com papel absorvente sem dessecar a dentina; aplicação do sistema adesivo One-Step da mesma forma que no grupo 03 e fotopolimerização por 10 segundos.

Após a aplicação dos sistemas adesivos, o dente foi acoplado a um dispositivo que permitiu pressionar a superfície dentinária de encontro a uma matriz de teflon, em forma de cilindro, que se separa ao meio devido à existência de um encaixe tipo macho-fêmea, para possibilitar sua remoção tão logo ocorresse a polimerização da resina, que é condensada no interior de sua perfuração central (3,57 mm de diâmetro e 2,0 mm de altura), situada 
em uma depressão concêntrica, idêntica ao utilizado por ARAÚJO; ASMUSSEN ${ }^{2}$, em 1989 (Fig.9).

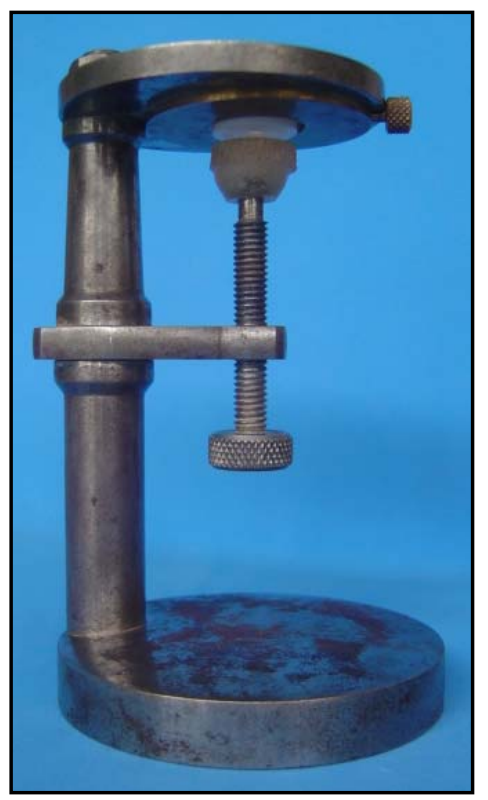

FIGURA 9 - Aparelho para confecção da restauração.

Desta forma, foi possível a justaposição da área dentinária com a matriz de teflon, delimitada pela fita adesiva, possibilitando, assim, a confecção de um pequeno cilindro de resina composta exatamente na área de dentina onde foram aplicados os sistemas adesivos empregados neste estudo.

Estando o dente adaptado ao dispositivo, através da parte superior do orifício da matriz de teflon, foi inserida a resina composta Z-250, com o auxílio de um calcador de plástico, em pequenas porções, até o preenchimento total da cavidade (Fig. 10). Em seguida, a resina composta foi polimerizada em uma única etapa, por um período de 20 segundos, com a utilização de um aparelho fotopolimerizador de lâmpada halógena (Optilux, Demetron Reserch Co. - Danbury, EUA) (Fig. 11) e com uma distância de sua ponta ativa à superfície dentinária delimitada pela própria espessura da matriz de teflon. Anteriormente ao início de cada grupo, o desempenho da 
luz foi novamente aferido com auxílio do radiômetro, com cerca de $600 \mathrm{~mW} / \mathrm{cm}^{2}$ de densidade de potência (Demetron model 100, fabricado pela Demetron Research Corp.-Danbury CT-USA). Alcançada a polimerização da resina composta, o conjunto, formado pelo dente incluído em resina epóxica e a matriz de teflon, foi removido do dispositivo, para, em seguida, a matriz ser destacada e removida. Desta forma, obteve-se um cilindro de resina composta aderido ao tecido dentinário de $3,57 \mathrm{~mm}$ de diâmetro, por aproximadamente 2,0 $\mathrm{mm}$ de altura (Fig.12).

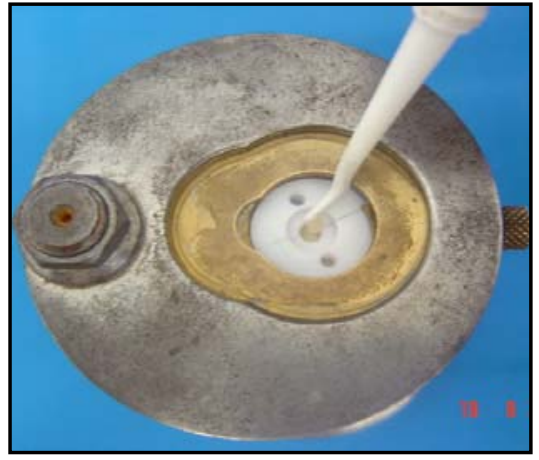

FIGURA 10 - Confecc.ão da restauracão.

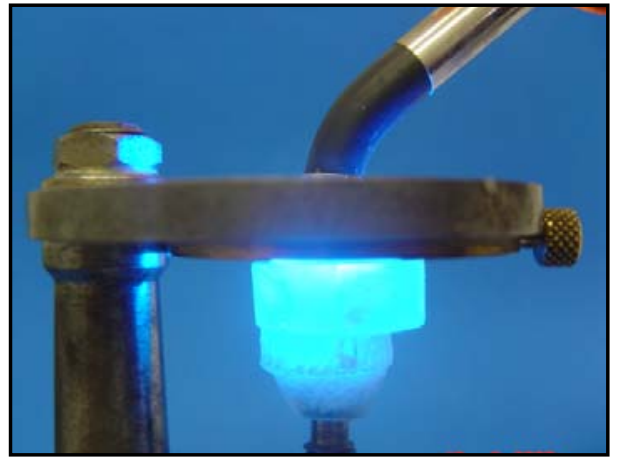

FIGURA 11 - Polimerização.

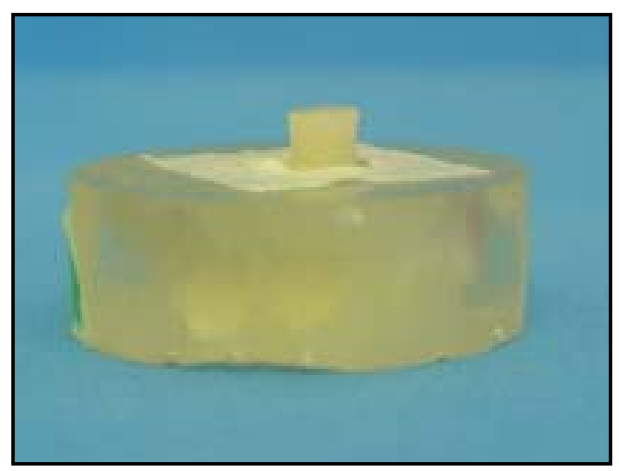

FIGURA 12 - Restauração.

O trabalho foi realizado em um laboratório com temperatura controlada de $23 \pm 1^{\circ} \mathrm{C}$ e umidade relativa de $50 \pm 5 \%$.

Logo após a fotopolimerização e, subseqüentemente, a remoção da matriz de teflon, os corpos-de-prova foram mergulhados em um recipiente 
com água deionizada, devidamente identificados e armazenados em estufa de cultura (Fanem) à temperatura de $37^{\circ} \mathrm{C}$ por 7 dias.

Terminado o período de armazenamento, cada espécime foi acoplado ao dispositivo para ensaio de cisalhamento, pela técnica de laço de fio ortodôntico, com diâmetro de 0,7 mm e $32 \mathrm{~cm}$ de comprimento, em uma máquina de Ensaios Universal (Kratos-SP, Brasil) (Fig. 13). O laço foi realizado pela soldagem das duas pontas do fio ortodôntico e adaptado ao dispositivo. Ele tem uma dobra feita na extremidade que abraça o espécime, a fim de ser mantido sempre em contato com a união dentina/resina (Fig. 14). Foi, então, tracionado com uma célula de carga de $500 \mathrm{Kgf}$ a uma velocidade de deslocamento de $0,5 \mathrm{~mm} /$ minuto até a ruptura do conjunto material restaurador/dente. Após o teste, os valores foram registrados em Kgf e convertidos para MPa., sendo esses valores divididos pela área da superfície de união (3,57 mm).

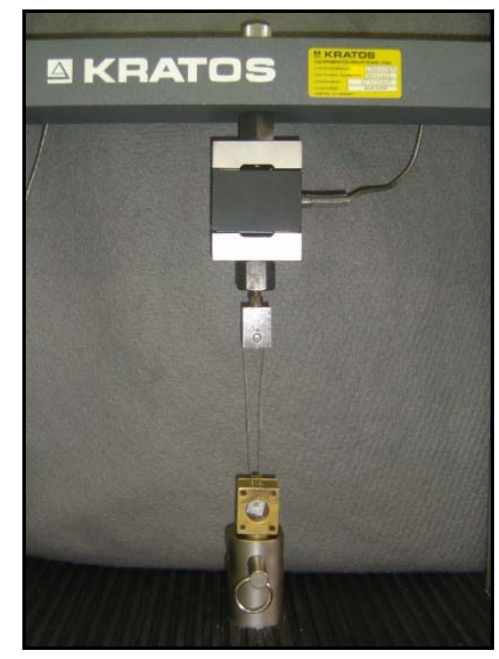

FIGURA 13 - Máquina de ensaio universal Kratos.

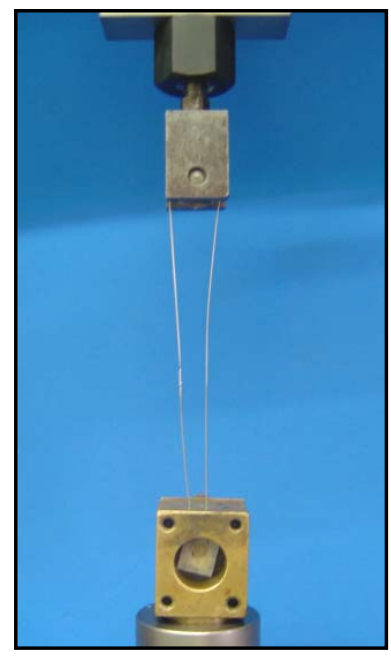

FIGURA 14 - Espécime acoplado no dispositivo para o teste de resistência ao cisalhamento. 
Após o teste de resistência ao cisalhamento, foram realizadas análises das regiões fraturadas através do método da lupa estereoscópica (SANO;SHONO;TAKATSU ${ }^{60}$, 1994; NAKAJIMA et $\mathrm{al}^{45}$, 1995), com um aumento de 40x.

O tipo de falha foi considerado como adesiva, uma vez localizada na interface adesiva, coesiva, quando a fratura ocorreu em um dos materiais ou no tecido dentinário e mista, ou seja, coesiva e adesiva.(SUDSANGIAN; VAN NOORT $\left.{ }^{68}, 1999\right)$. 
5 RESULTADOS 



\section{RESULTADOS}

Os quadros 3 e 4 mostram os valores das resistências adesivas ao cisalhamento, registrados em MPa., obtidos para os dois sistemas adesivos e os do uso prévio dos dessesibilizantes dentinários, utilizados nesta pesquisa.

QUADRO 3 - Scotchbond Multi-Purpose

\begin{tabular}{|c|c|c|}
\hline & Grupo 1 & Grupo 2 \\
\hline Espécime & SMP & GLUMA® Desensitizer \\
\hline $\mathbf{1}$ & 28.2 & 23,45 \\
\hline $\mathbf{2}$ & 24,55 & 41,05 \\
\hline $\mathbf{3}$ & 18,8 & 27,125 \\
\hline $\mathbf{4}$ & 23,8 & 23,75 \\
\hline $\mathbf{5}$ & 15.275 & 32,7 \\
\hline $\mathbf{6}$ & 17,7 & 25,15 \\
\hline $\mathbf{7}$ & 21,625 & 20,925 \\
\hline $\mathbf{8}$ & 17,725 & 31,675 \\
\hline $\mathbf{9}$ & 16,125 & 27,975 \\
\hline $\mathbf{1 0}$ & 13,475 & 19,1 \\
\hline
\end{tabular}


QUADRO 4 - One-Step

\begin{tabular}{|c|c|c|}
\hline Espécime & Grupo 3 & Grupo 4 \\
\hline 1 & One-Step & Bisblock \\
\hline 2 & 7,1 & 4,2 \\
\hline 3 & 7,7 & 7 \\
\hline 4 & 8,95 & 6,125 \\
\hline 5 & 14,25 & 4,7 \\
\hline 6 & 13,7 & 3,825 \\
\hline 7 & 6,6 & 4,55 \\
\hline 8 & 1,875 & 5,05 \\
\hline 9 & 12,075 & 6,475 \\
\hline 10 & 16,8 & 8,85 \\
\hline
\end{tabular}

Estes valores de forças adesivas, obtidos nos diferentes testes, foram submetidos à análise estatística, com dois objetivos: o de comparar se existia diferença significativa entre os sistemas adesivos utilizados na dentina, e a influência do tratamento prévio da dentina com um dessensibilizante dentinário.

Quadros com estatísticas descritivas (valores arredondados em MPa.)

QUADRO 5 - Resultados das médias dos grupos em MPa.

\begin{tabular}{|l|l|l|}
\hline STAT. GENERAL & \multicolumn{2}{|l|}{ Medias (estatística.sta) 1 Variável dependente } \\
MANOVA & Força & Valid N \\
\hline Material & 19,72750 & 10 \\
\hline SMP & 27,29000 & 10 \\
G-SMP & 10,06250 & 10 \\
OS & 5,73750 & 10 \\
B-OS &
\end{tabular}


QUADRO 6 - Análise de variância.

\begin{tabular}{|l|l|l|}
\hline STAT. GENERAL & \multicolumn{2}{|l|}{ Desvios padrões (estatistica.sta) } \\
MANOVA & 1 Dependent Variable \\
\hline Material & DP - Força & Valid N \\
\hline SBP & 4,667893 & 10 \\
G-SBP & 6,478825 & 10 \\
OS & 4,436187 & 10 \\
B-OS & 1,552786 & 10 \\
\hline
\end{tabular}

QUADRO 7 - Teste de homogeneidade de variância.

\begin{tabular}{|l|l|l|c|c|c|}
\hline $\begin{array}{l}\text { STAT. GENERAL } \\
\text { MANOVA }\end{array}$ & \multicolumn{6}{l|}{ Teste de homogeneidade de variância } \\
(estatistica.sta)
\end{tabular}

Como ocorreu uma variação muito grande entre os grupos, não apresentando homogeneidade entre eles, foi então feita transformação pela raiz quadrada para que se pudesse fazer a Análise de Variância (ANOVA).

QUADRO 8 - Teste de homogeneidade de variância

\begin{tabular}{|l|l|l|l|l|c|}
\hline $\begin{array}{l}\text { STAT. } \\
\text { GENERAL } \\
\text { MANOVA }\end{array}$ & \multicolumn{5}{|l|}{ Teste de homogeneidade de variância (estatistica.sta) } \\
\hline Variable & $\begin{array}{c}\text { Hartley } \\
\text { F-max }\end{array}$ & $\begin{array}{c}\text { Cochran } \\
\text { C }\end{array}$ & $\begin{array}{c}\text { Bartlett } \\
\text { Chi-sqr }\end{array}$ & df & P \\
\hline RAIZ_FOR & 6,190558 &, 460294 & 6,605163 & 3 &, 085628 \\
\hline
\end{tabular}

Desta forma foi obtida a homogeneidade e foi realizada a Análise de variância a um critério. 
QUADRO 9 - Análise de variância a um critério.

\begin{tabular}{|c|c|c|c|c|c|c|}
\hline $\begin{array}{l}\text { STAT } \\
\text { GENERAL }\end{array}$ & \multicolumn{6}{|c|}{$\begin{array}{l}\text { Resumo para todos os efeitos; desing: (estatistica. Sta) } \\
\text { 1- Material }\end{array}$} \\
\hline Effect & $\begin{array}{c}\mathrm{df} \\
\text { Effect }\end{array}$ & $\begin{array}{c}\text { MS } \\
\text { Effect }\end{array}$ & $\begin{array}{c}\text { df } \\
\text { Error }\end{array}$ & $\begin{array}{c}\text { MS } \\
\text { Error }\end{array}$ & $\mathrm{F}$ & p-level \\
\hline 1 & 3* & 16,18156 & $36^{*}$ & ,339617* & $47,64657^{*}$ & ,000000* \\
\hline
\end{tabular}

Como o resultado mostrou que havia diferença significante entre os grupos, pois o Grupo 2 apresentou valores mais altos do que os outros grupos e o Grupo 4 apresentou o valor mais baixo dos 4 grupos. Após foi realizado o teste de Tukey para as comparações múltiplas entre os 4 grupos.

QUADRO 10 - Teste de Tukey para as comparações múltiplas.

\begin{tabular}{|c|c|c|c|c|}
\hline \multirow{2}{*}{\begin{tabular}{|l} 
STAT. \\
GENERAL \\
MANOVA \\
Material
\end{tabular}} & \multicolumn{4}{|c|}{$\begin{array}{l}\text { Teste de Tukey HSD ; variable RAIZ_FOR (estatística.sta) } \\
\text { Probabilidade para Post Hoc Tests } \\
\text { MAIN EFFECT: MATERIAL }\end{array}$} \\
\hline & $\mathrm{MP}$ & G-SMP & OS & B-OS \\
\hline SMP & & ,024945* & ,000214* & ,000159* \\
\hline G-SMP & ,0249 & & ,000159* & ,000159 \\
\hline OS &, $000214^{*}$ & ,000159* & &, 04838 \\
\hline B-OS & ,000159* & ,000159* & ,048386* & \\
\hline
\end{tabular}

Pode-se concluir a análise estatística, afirmando-se que há diferenças estatisticamente significantes entre os 4 grupos.

Após os testes de resistência ao cisalhamento todos os espécimes foram analisados através da ajuda do microscópio, para análise do tipo de falha ocorrida. 
As falhas foram do tipo: Adesiva (A); Coesiva dentinária e coesiva resina/dentina (C); Mista coesiva resina e adesiva (M)

QUADRO 11 - Tipos de falhas.

\begin{tabular}{|c|c|c|c|}
\hline GRUPOS & A & C & M \\
\hline 1 & 4 & 2 & 4 \\
\hline 2 & 0 & 10 & 0 \\
\hline 3 & 8 & 0 & 2 \\
\hline 4 & 10 & 0 & 0 \\
\hline
\end{tabular}

De acordo com o tipo de falha, no Grupo 1, 40\% das falhas foram do tipo adesiva, $20 \%$ do tipo coesiva e $40 \%$ do tipo mista (coesiva/adesiva).

No Grupo 2, não se observou nenhum tipo de falha adesiva; as falhas foram 100 \% coesivas; as fraturas corresponderam à resistência do dente e/ou resistência do dente e material restaurador.

No Grupo 3, as falhas foram $80 \%$ do tipo adesiva e $20 \%$ foram do tipo mista (coesiva/adesiva).

No Grupo 4, as falhas foram $100 \%$ do tipo adesiva.

Para melhor visualização, o quadro 5 foi transformado em gráfico. 


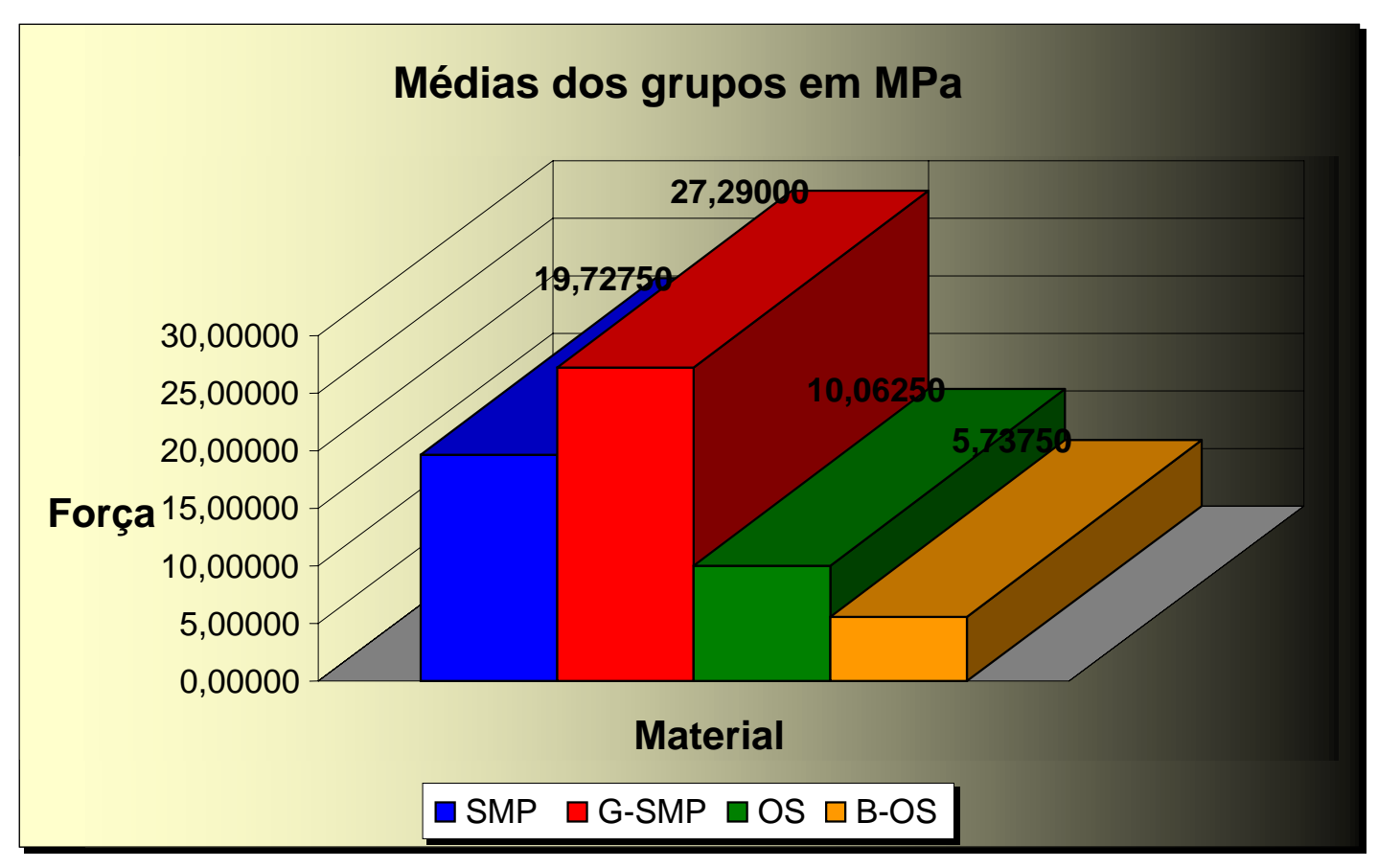

FIGURA 15 - Gráfico das médias dos grupos em MPa.

O gráfico mostra a existência de diferença entre as médias obtidas através dos tipos de adesivos e entre os grupos com o uso de dessensibilizante. 
6 DISCUSSÃO 


\section{DISCUSSÃO}

Neste capítulo será feita a análise do comportamento verificado, quanto à resistência adesiva, para cada um dos dois sistemas adesivos utilizados - Scotchbond Multi Purpose e One-Step - nas duas diferentes condições testadas, ou seja, dentina previamente tratada de acordo com as orientações do fabricante e com o tratamento prévio dos dessensibilizantes dentinários - Gluma ${ }^{\circledR}$ Desensitizer e Bisblock, respectivamente.

A realização deste experimento baseou-se em resultados de estudos divulgados por inúmeros autores constantes na literatura especializada (SEARA et al. ${ }^{63}$, 2002; HANSEN; ASMUSSEN ${ }^{31}$, 1997; YIU et al. ${ }^{81}$, 2004).

Os dentes utilizados para este tipo de pesquisa in vitro são dentes humanos, extraídos, livres de cáries e defeitos, particularmente molares, assim sendo, optamos por terceiros molares, pela facilidade na obtenção.

Diferentes testes de adesão foram estudados por PASHLEY ${ }^{49}$, em 1995, concluindo que o ensaio de resistência ao cisalhamento pode apresentar tendência à flexão, porém foi o método considerado como o de maior facilidade de execução. AL-SALEHI; BURKE ${ }^{1}$, em 1997, concluíram que os testes de cisalhamento predominaram em $80 \%$ dos trabalhos analisados sobre resistência adesiva. Sendo assim, no presente estudo o ensaio de resistência ao cisalhamento foi o escolhido para avaliar a adesão dos sistemas adesivos experimentais e a associação destes com 
dessensibilizantes dentinários à estrutura dentinária após o condicionamento com ácido fosfórico a 37\%.

O mecanismo tradicional de união da resina composta com dentina consiste em três etapas diferentes: condicionamento ácido dentinário, aplicação do primer e do agente adesivo (VAN MEERBEEK et al. ${ }^{77}, 1998$ ), ou agente adesivo quando este for em passo único.

A sensibilidade pós-operatória é um problema significativo, associado aos procedimentos restauradores, pois preparos para restaurações diretas e indiretas, freqüentemente envolvem a exposição da dentina próxima à polpa, onde os túbulos dentinários são maiores e mais numerosos (BRANNSTRÖM; AASTROM ${ }^{14}$, 1972; GARBEROGLIO; BRANNSTRÖN ${ }^{29}$, 1976). Estes túbulos dentinários são parcialmente fechados por uma camada de detritos, chamada smear layer, e a dentina se torna menos sensível do que aquela com os túbulos dentinários abertos (JOHNSON; BRANNSTRÖN ${ }^{35}$, 1974). Contudo, o uso do sistema adesivo requer um condicionamento ácido da dentina vital fazendo com que ocorra a dissolução da smear layer deixando os túbulos abertos, provocando uma hipercondução e hipersensibilidade da dentina (JOHNSON; BRANNSTRÖN ${ }^{35}$, 1974; PASHLEY ${ }^{47}$, 1990; PASHLEY ${ }^{48}$, 1992), devido a um aumento da permeabilidade dentinária (JOHNSON; BRÄNNSTRÖN ${ }^{35}$; 1974). Além disso, estes túbulos dentinários abertos podem servir de caminho para a polpa, através da difusão de estímulos nocivos, incluindo bactérias e toxinas, que podem levar à inflamação pulpar e possível necrose (FELTON; BERGENHOLTZ; KANOY ${ }^{27}$, 1991; BERGENHOLTZ ${ }^{11}$, 1993). Por esta razão, os dentes preparados para restaurações poderiam ser beneficiados com o uso de agentes que bloqueassem perifericamente o fluxo do fluido através da dentina durante o período do preparo cavitário e restauração e, com isto, provocassem uma diminuição na permeabilidade dentinária (CAMPS et al. ${ }^{18}$, 1998; SHUPBACH; LUTZ; FINGER ${ }^{62}$, 1997), reduzindo a sensibilidade. PASHLEY et al. ${ }^{51}$, em 1992, demonstraram que o selamento 
dos túbulos dentinários com polímeros resinosos diminui a sensibilidade e o ingresso de bactérias e toxinas (FELTON; BERGENHOLTZ; COX ${ }^{26}, 1989$, WATANABE et al. ${ }^{91}$, 1991). Outros estudos têm comprovado a eficácia de primers de resina hidrofílica, que ocluem os túbulos dentinários e reduzem, desta forma, a sensibilidade (DALL'OROLOGIO; MALFERRARI ${ }^{23}$, 1993; SCHUPBACH; LUTZ; FINGER ${ }^{62}$, 1997, CAMPS et al. ${ }^{18}$, 1998, PEREIRA; MARTINELI; TUNG ${ }^{55}$, 2002, CAMPS et al. ${ }^{19}$, 2002, ARRAIS; CHAN; GIANNINI ${ }^{4}$, 2004). Além disso, estes primers resinosos bloqueiam os túbulos dentinários sem uma significativa camada adicional em espessura (FELTON; BERGENHOLTZ; KANOY ${ }^{27}$, 1991), embora este mecanismo ainda seja desconhecido.

Este estudo foi designado para simular o tratamento no qual o dentista poderia usar um dessensibilizante dentinário sobre um dente preparado para uma restauração estética.

O Gluma ${ }^{\circledR}$ tem se mostrado um dessensibilizante eficaz quando usado para oclusão dos túbulos dentinários após o preparo de coroas totais (FELTON; BERGENHOLTZ; KANOY ${ }^{27}$, 1991). Hipoteticamente, acredita-se que o Gluma ${ }^{\circledR}$ Desensitizer, com o componente glutaraldeído, pode penetrar nos túbulos (SCHÜPBACH; LUTZ; FINGER ${ }^{62}$, 1997), pois o glutaraldeído é um fixador biológico que deve provocar uma coagulação na superfície da proteína do plasma do fluido dentinário, e, com isto, promover um bloqueio nos túbulos dentinários (DALL'OROLOGIO; MALFERRARI ${ }^{24}$, 1993; SCHÜPBACH; LUTZ; FINGER ${ }^{62}$, 1997; BERGENHOLTZ; LOS; TRILO ${ }^{11}$, 1993). Os primers, contendo HEMA sem glutaraldeído, têm também mostrado eficácia na penetração e selamento dos túbulos dentinários, diminuindo a permeabilidade da dentina (CAMPS et al. ${ }^{18}$, 1998; CALAMIA; STYNER; RATTET ${ }^{17}$, 1996; WATANABE et al. $\left.{ }^{78}, 1991\right)$. 
Embora a desejável redução da sensibilidade seja importante, há necessidade de se avaliar os possíveis efeitos desses agentes dessensibilizantes na interferência da adesão das resinas sobre a dentina.

HANSEN; ASMUSSEN ${ }^{31}$, em 1997, observaram que o uso prévio do Gluma ${ }^{\circledR}$ Desensitizer em restaurações de resina composta, onde foi utilizado o sistema adesivo Scotchbond Multi-Purpose, provocou uma diminuição no tamanho das fendas marginais, e, hipoteticamente, potencializou a sua ação, tanto quando a dentina foi condicionada com ácido fosfórico quanto quando com ácido maleico.

Em outros estudos, onde se analisou a ação do Gluma ${ }^{\circledR}$ na cimentação de coroas, com cimentos resinosos, não se observou interferência negativa em suas retenções (MAUSNER; GOLDSTEIN; GEORGESCU ${ }^{41}$, 1996; COBB; REINHARDT; VARGAS ${ }^{22}, 1997$; YIM et al. ${ }^{80}$, 2000; WOLFART et al. ${ }^{79}$, 2003).

No presente trabalho, pôde-se observar, através dos resultados do teste de resistência ao cisalhamento, que o Grupo 1, onde foi aplicado o sistema adesivo Scotchbond Multi-Purpose, apresentou uma média de resistência adesiva de 19,72750 MPa, em concordância com o trabalho de EL-DIN; EL-MOHSEN ${ }^{25}$ em 2002, onde foram comparados diferentes tempos de aplicação do primer, e observou-se que, quando aplicado em tempo de 30-40 seg., a média de resistência ao cisalhamento foi de 19,6710 Mpa. Entretanto, segundo a literatura consultada, os resultados apresentados em relação à resistência adesiva, nos testes de cisalhamento, apresentaram maiores diferenças em relação a este trabalho, provavelmente devido a alterações dos materiais testados, sendo que, alguns pesquisadores utilizaram o ácido maleico a 10\% para condicionamento dentinário e outros o ácido fosfórico a 35\%; alguns também variaram a forma de aplicação do primer e no número de camadas. (BARKMEIER; ERICKSON $^{9}$, 1994 (25,5 MPa); CHAPPEL; EICK ${ }^{20}, 1994$ (25,5 MPa); 
PASHLEY et al. ${ }^{52}, 1993$ (8,9 MPa); NAKAJIMA et al. ${ }^{45}$, 1995; MIEARS JR.; CHARRLTON; HERMESCH ${ }^{42}, 1995$ (13,5 MPa); TRIOLO; SWIFT; BARKMEIER $^{74}, 1995$ (23 MPa); MIYAZAKI et al. ${ }^{43}, 1996$ (18,43 MPa); PEREIRA; PAULILLO; DIAS ${ }^{54}, 2000$ (16,1 MPa); TITLEY; CALDWELL; KULKARNI $^{72}, 2003$ (14,3 MPa).

O Grupo 2, onde foi aplicado o sistema adesivo Scotchbond MultiPurpose, tendo como pré-tratamento o Gluma ${ }^{\circledR}$ Desensitizer, apresentou maior resistência adesiva, em média 27,29 MPa, em concordância com o trabalho de HANSEN; ASMUSSEN ${ }^{31}$, 1997, onde a aplicação prévia do Gluma ${ }^{\circledR}$ (desensitizer) aumentou a eficácia do sistema adesivo Scotchbond Multi-Purpose.

O adesivo testado no Grupo 3 foi o One-Step (OS, Bisco Inc., Schaumburg, IL), que apresentou uma média de resistência ao cisalhamento de 10,06250 MPa, enquanto TITLEY; CALDWELL; KULKARNI ${ }^{72}$, em 2003, obteve a média do resultado de resistência ao cisalhamento de 8,1 $\mathrm{MPa}$, embora o ácido usado neste trabalho, para o condicionamento da dentina, foi o ácido fosfórico a 32\%, e os dentes utilizados foram dentes bovinos.

Um outro modo de tratamento para hipersensibilidade pós-operatória é através do uso do oxalato como dessensibilizante dentinário, após o condicionamento ácido da dentina e o uso do sistema adesivo (BRÄNNSTRÖN ${ }^{13}$, 1986; PASHLEY et al. ${ }^{50}$, 2001; TAY et al. ${ }^{71}$, 2003).

Com o condicionamento ácido da dentina, esgota-se o cálcio da sua superfície, forçando os íons de oxalato a difundirem-se para o interior da dentina até encontrarem cálcio, para que eles possam reagir, formando cristais de oxalato de cálcio. Estes, então formados, proporcionam uma oclusão na subsuperfície, reduzindo a condutibilidade hidráulica da dentina e trazendo, como conseqüência, uma diminuição da permeabilidade da dentina e de sua sensibilidade (KOTZ; TREICHEL ${ }^{40}, 1999$ ). 
No Grupo 4, usou-se o dessensibilizante de oxalato Bisblock antes do sistema adesivo One-Step, que teve como condicionamento dentinário o ácido fosfórico a 37\%; a média de resistência ao cisalhamento foi de 5,73750 $\mathrm{MPa}$., onde constatou-se que este interferiu na adesividade, diminuindo a união entre a dentina e o material restaurador, enquanto que no trabalho apresentado por YIU et al. ${ }^{81}$ (2005), onde se usou o sistema adesivo One-Step, os autores observaram que o uso prévio do dessensibilizante Bisblock na dentina condicionada com ácido fosfórico a $32 \%$, não interferiu nas resistências adesivas testadas, uma vez que as diferenças verificadas no experimento revelaram-se não significativas, ou seja, muito embora do ponto de vista observado neste trabalho, verificou-se diferenças, mas não puderam ser estendidas à população como sendo efetivas.

De acordo com os tipos de falhas, o Grupo 1 apresentou 4 falhas adesivas e 4 falhas mistas (coesiva da restauração e adesiva), e 2 falhas coesivas dentinárias. Embora na revisão da literatura os resultados encontrados discordem do presente trabalho, ou seja, na pesquisa realizada por MIEARS JR.; CHARLTON; HERMESCH ${ }^{42}$, em 1995, não se observou nenhuma falha adesiva, o maior número das falhas foram do tipo coesiva entre a resina composta ou dente, e ocorreu apenas uma falha mista, entre coesiva e adesiva; entretanto, no trabalho de TOLEDANO et al. ${ }^{73}$, em 2001, as falhas encontradas foram todas adesivas

Com base na literatura e nos resultados obtidos no presente estudo, foi observado que o dessensibilizante dentinário Gluma ${ }^{\circledR}$ Desensitizer, aplicado após o condicionamento prévio da dentina com ácido fosfórico a $37 \%$ e, previamente, ao sistema adesivo Scochbond Multi-Purpose, apresentou resultados confiáveis, confirmando sua viabilidade e adequado desempenho laboratorial em concordância com o trabalho de HANSEN; ASMUSSEN $^{31}$ (1997) e COBB; REINHARDT; VARGAS ${ }^{22}$ 
Hipoteticamente, isto se deve à adicional penetração do HEMA, como resultado de uma dupla aplicação de primer sobre a superfície da dentina $($ GLUMA $®+$ STB $)$.

O uso do dessensibilizante Bisblock, aplicado após 0 condicionamento com ácido fosfórico a 37\% e seguido pelo sistema adesivo One-Step, interferiu negativamente, diminuindo a adesividade do material à dentina.

Em última análise, espera-se que este trabalho possa, de alguma forma, ajudar o clínico na escolha de um sistema adesivo dentinário associado a um dessensibilizante e na conscientização de que os procedimentos por ele adotados possam influenciar, de modo decisivo, no sucesso ou fracasso da utilização do mesmo.

Sugere-se ainda a continuidade deste estudo, fazendo-se a inclusão de outras variáveis nos testes de resistência adesiva dos materiais, tais como: termociclagem, interação química entre os dessensibilizantes e o agente adesivo, e análise através de microscopia eletrônica, a fim de simular condições que mais se aproximem das existentes in vivo. 


\section{CONCLUSÕES}




\section{CONCLUSÕES}

Em virtude da metodologia empregada e dos resultados obtidos, concluiu-se que:

1. A ação do sistema adesivo Scotchbond Multi-Purpose, quanto à resistência ao cisalhamento, foi potencializada quando este sistema adesivo foi combinado com o dessensibilizante Gluma ${ }^{\circledR}$ Desensitizer na dentina previamente condicionada com ácido fosfórico a 37\%, havendo diferença significativa entre o grupo em que não foi usado o sistema dessensibilizante.

2. A ação do sistema adesivo One-Step foi influenciada negativamente na resistência ao cisalhamento, quando este sistema adesivo foi usado após o dessensibilizante Bisblock na dentina condicionada com ácido fosfórico a $37 \%$, havendo diferença significativa entre o grupo em que não foi usado 0 sistema dessensibilizante.

3. Observou-se que houve diferença significativa nos padrões de fraturas entre os grupos. $O$ grupo 2 apresentou 6 falhas coesivas de dentina e 4 falhas coesivas de restaurações e dentina e nenhuma falha adesiva. $O$ grupo 4 apresentou 10 falhas adesivas. 
REFERÊNCIAS BIBLIOGRÁFICAS 


\section{REFERÊNCIAS BIBLIOGRÁFICAS}

1- AL-SALEHI, S.K.; BURKE, F.J.T. Methods used in dentin bonding tests : an analysis of 50 investigations on bond strength. Quintessence Int, v. 28, n. 11, p. 717-723, Nov. 1997.

2- ARAUJO, P.A.; ASMUSSEN, E. Bonding to dentin with a simplified Gluma system. Int Dent J, v. 39, n. 4, p. 253-257, Dec. 1989.

3- ARAUJO, P.A.; ASMUSSEN, E. Effect of dentin adhesives on contraction of restorative resin in cavities surrounded by acid-etched enamel. Acta Odontol Scand, v. 48, p. 333-336, 1990.

4- ARRAIS, C.A.G.; CHAN, D.C.N.; GIANNINI, M. Effects of desensitizing agents on dentinal tubule occlusion. J Appl Oral Sci, v. 12, n. 2, p. 144-148, 2004.

5- ASMUSSEN, E. The effect of temperature changes on adaptation of resin fillings. Acta Odont Scand, v. 32, n. 2, p. 161-171, 1974.

6- ASMUSSEN, E.; JORGENSEN, K.D. A microscopic investigation of the adaptation of some plastic filling materials to dental cavity walls. Acta Odont Scand, v. 30, p. 3-21, 1972.

\footnotetext{
* Normas recomendadas para uso no âmbito da Universidade de São Paulo, com base no documento "Referências Bibliográficas: exemplos", emanado do Conselho Superior do Sistema Integrado de Bibliotecas da USP, em reunião de 20 de setembro de 1990.
} 
7- ASMUSSEN, E.; MUNKSGAARD, E.C. Bonding of restorative resins to dentine: status of dentine adhesives and impact on cavity design and filling techniques. Int Dent J, v. 38, n. 2, p. 97-104, 1988.

8- BABA, N.; MATSUMURA, H.; ATSUTA, M. Effect of disinfectants containing glutaraldehyde on bonding of a tri-n-butylborane initiated to dentine. J Oral Rehabil, v. 29, p. 478-483, 2002.

9- BARKMEIER, W.W.; ERICKSON, R.L. Shear bond strength of composite to enamel and dentin using Scotchbond Multi-Purpose. Amer J Dent, v. 7, n. 3, p. 175-9, Jun. 1994.

10- BARKMEIER, W.W.; LOS, S.A.; TRIOLO,JR.P.T. Bond strengths and SEM evaluations of clearfil liner bond 2. Amer J Dent, v. 8, n. 6, p. 289-293, Dec. 1995.

11- BERGENHOLTZ, G.; JONTELL M.; TUTTLE A, et al. Inhibition of serum albumin flux across exposed dentin following conditioning with Gluma primer, glutaraldehyde or potassium oxalates. J Dent, v. 21, p. 220227, 1993.

12- BOWEN, R.L. Dental filling material composing vinyl treated fused silica and binder consisting of a reaction product of bisphenol and glycidyl acrylate. U.S. Patent n. 3066, 112, 1962 apud BARATIERI, et al. Dentística : procedimentos preventivos e restauradores. Rio de Janeiro, Quintessence, 1989.

13- BRÄNNSTRÖM, M. The cause of postrestorative sensitivity and its prevention. J Endod, v. 12, n. 10, p. 465-481, Oct. 1986. 
14- BRÄNNSTRÖM, M.; ASTRÖM, A. The hydrodynamics of the dentine; its possible relationship to dentinal pain. Int Dent J, v. 22, n. 2, p. 219226, Jun. 1972.

15- BUONOCORE, M.G. A simple method of increasing the adhesion of acrylic filling materials to enamel surfaces. J Dent Res, v. 34, n. 6, p. 849-53, Dec. 1955.

16- BURKE, F.J. et al. Restoration longevity and analysis of reasons for the placement and replacement of restorations provided by vocational dental practitioners and their trainers in the United Kingdom. Quintessence Int, v. 30, n. 4, p. 234-242, Apr. 1999.

17- CALAMIA, J.R.; STYNER, D.L.; RATTET, A. H. Effect of amalgambond on cervical sensitivity. Amer J Dent, v. 8, p. 283-284 1996.

18- CAMPS, J. et al. Effects of desensitizing agents on human dentin permeability. Amer J Dent, v. 11, n. 6, p. 286-290, Dec. 1998.

19- CAMPS, J. et.al. Efficiency and cytotoxicity of resin-based desensitizing agents. Amer J Dent, v. 15, n. 5, p. 300-304, Oct. 2002.

20- CHAPPELL, R.P.; EICK, J.D. Shear bond strength and scanning electron microscopic observation of six current dentinal adhesives. Quintessence Int, v. 25, n. 5, p. 359-368, May 1994.

21- CHRISTENSEN, G. Resin cements and postoperative sensitivity. J Amer Dent Assoc, v. 131, n. 8, p 1197-1199, Aug. 2000.

22- COBB. D.S.; REINHARDT, J.W.; VARGAS.M.A. Effect of HEMAcontaining dentin desensitizers on shear bond strength of a resin cement. Amer J Dent, v. 10, n. 2, p. 62-65, Apr. 1997. 
23- DALL'OROLOGIO, G.D.; LONE, A.; FINGER, W.J. Clinical evaluation of the role of glutaraldehyde in a one-bottle adhesive. Amer $\mathbf{J}$ Dent, v. 15, n. 5, p. 3304, Oct. 2002.

24- DALL'OROLOGIO, G.D.; MALFERRARI, S. Desensitizing effects of Gluma and Gluma 2000 on hypersensitive dentin. Amer J Dent, v. 6, n. 6, p. 283-286, Dec. 1993.

25- EL-DIN, A.K.N.; EL-MOHSEN, M.M.A. Effect of changing application times on adhesive systems bond strengths. Amer J Dent, v. 15, n. 5, p. 321-324, Oct. 2002.

26- FELtON, D.; BERGENHOLTZ, G.; COX, C.F. Inhibition of Bacterial Growth under composite restorations following Gluma pretreatment. J Dent Res, v. 68, n. 3, p. 491-495, Mar. 1989.

27- FELTON, D.A.; BERGENHOLTZ, G.; KANOY, B.E. Evaluation of the desensitizing effect of Gluma dentin bond on teeth prepared for complete-coverage restorations. Int J Prosthodont, v. 4, p. 292-298, 1991

28- FINGER, W.J.; UNO, S. Bond strength of gluma CPS using the moist dentin bonding technique. Amer J Dent, v. 9, n. 1, p. 27-30, Feb. 1996.

29- GARBEROGLIO, R.; BRÄNNSTRÖM M. Scanning electron microscopic investigation of human dentinal tubules. Arch Oral Biol, v. 21, n. 6, p. 355-358, Jun. 1976.

30- HAMID, A.; SUTTON, W.; HUME, W.R. Variation in phosphoric acid concentration and treatment time and HEMA diffusion through dentin. Amer J Dent, v. 9, n. 5, p. 211-214, Oct. 1996. 
31- HANSEN, E.K.; ASMUSSEN E. Improved efficacy of dentin-bonding agents. Eur J Oral, v. 105, p. 434-439, 1997.

32- HAVEMAN, C.W. CHARLTON, D.G. Dentin treatment with an oxalate solution and glass ionomer bond strength. Amer J Dent, v. 7, n. 5, p. 247-251, Oct. 1994.

33- HICKS, M.J.; FLAITZ, C.M. Resin-modified glass-ionomer restorations and in vitro secondary caries formation in coronal enamel. Quintessence Int, v. 31, n. 8, p. 570-578, 2000.

34- HOLTAN, J.R.; NYSTROM, G.P.; OLIN, P.S., et al. Bond strength of six dentinal adhesives. J Dent, v. 22, n. 2, p. 92-96, Apr. 1994.

35- JOHNSON, G.; BRÄNNSTRÖM, M. The sensitivity of dentin. Changes in relation to conditions at exposed tubule opertures. Acta Odont Scand, v. 32, n. 1, p. 29-38, 1974.

36- JOHNSON, G.H., LEPE, X.; BALES, D.J. Crown retention with use of a 5\% glutaraldehyde sealer on prepared dentin. J Prosthet Dent, v.79, n. 6, p. 671-676, Jun. 1998.

37- JOHNSON, G.H. et. al. Dentin bonding systems : a review of current products and techniques. J Amer Dent Assoc, v. 122, n. 7, p. 34-41, Jul. 1991.

38- KIDD, E.A.M. Microleakage : a review. J Dent, v. 4, n. 5, p. 199-205. Sep. 1976.

39- KIDD, E.A.M.; TOFFENETTI, F.; MJÖR, I.A. Secondary caries. Int Dent J, v. 42, n. 3, p. 127-138, Jun. 1992. 
40- KOTZ, J.C.; TREICHEL, P. Principles of reactivity: Precipitation reactions. In: Chemistry and chemical reactivity. $4^{\text {th }}$ ed. Forthworth, Saunders College Pub., p. 897-898, 1999.

41- MAUSNER, I.K.; GOLDSTEIN, G.R.; GEORGESCU, M. Effect of two dentinal desensitizing agents on retentions of complete cast coping using four cements. J Prosthet Dent, v. 75, n. 2, p. 129-134, Feb. 1996,

42- MIEARS JR., J. R., CHARLTON, D.G. HERMESCH, C.B. Effect of dentin moisture and storage on resin bonding. Amer J Dent, v. 8, n. 2, p. 80-82, Apr. 1995.

43- MIYAZAKI, M. et al. Influence of dentin primer applications methods on dentin bond strength. Oper Dent, v. 21, p. 167-172, 1996.

44- MUNKSGAARD, E.C.; IRIE,M. ASMUSSEN, E. Dentin-polymer bond promoted by Gluma and various resins. J Dent Res, v. 64, n. 12, p. 1409-1411, Dec. 1985.

45- NAKAJIMA, M. et al. Tensile bond strength and SEM evaluations of caries-affected dentin using dentin adhesives. J Dent Res, v. 74, n. 10, p. 1679-1688, Oct. 1995.

46- NAKAMICHI, I.; IWAKU, M.; FUSAYAMA, T. Bovine teeth as possible substitutes in the adhesion test. J Dent Res, v. 62, n. 10, p. 10761081, Oct. 1983.

47- PASHLEY, D.H. Mechanisms of dentin sensitivity. Dent Clin North Amer, v. 34, p. 449-473, 1990. 
48- PASHLEY, D.H. The effects of acid etching on the pulpodentin complex. Oper Dent, v. 17, p. 229-242. Feb. 1992.

49- PASHLEY, D.H. Adhesion testing of dentin bonding agents : a review. Dent Mater, v. 11, n. 2, p. 117-125, Mar. 1995.

50- PASHLEY, D.H. et al. The use of oxalate to reduce dentin permeabitily under adhesive restorations. Amer J Dent, v. 14, n. 2, p. 89-94, Apr. 2001.

51- PASHLEY, E.L. et al. Dentin permeability: sealing the dentin in crown preparations. Oper Dent, v. 17, n. 1, p. 13-20, Jan/Feb. 1992.

52- PASHLEY E.L. et al. Effects of oxalate on dentin bonding. Amer $\mathbf{J}$ Dent, v. 6, n. 3, p. 116-118, Jun. 1993.

53- PENTEADO, V.A., ASMUSSEN, E. Filling of resin composite and glassionomers : reduced marginal gaps. Rev FOB, v. 3, n. 1/4, p. 19-23, jan./dez. 1995.

54- PEREIRA, G.D.S.; PAULILLO, L.A.M.S.; DIAS, C.T.S. Influence of dentin moisture on adhesive systems shear bond strength. J Dent Res, v. 79, Abstract 2392, 2000.

55- PEREIRA, J.C.; MARTINELI, A.C.B.; TUNG, M.S. Replica of human dentin treated with different desensitizing agents : a methodological SEM study in vitro. Braz Dent J, v. 13, n. 2, p. 75-85, 2002.

56- PEREZ, C.R.; SÉRGIO, P.P.; SILVA, F.S. Avaliação clínica de um novo dessensibilizante dentinário. Rev Bras Odont, v. 60, n. 2, p. 91-94, mar./abr. 2003. 
57- POWELL, L.V. et al. Sensitivity restored of class $V$ abrasion/erosion lesions. J Amer Dent Assoc, v. 121, n. 12, p. 694-696, Dec. 1990.

58- PRATI, C. et al. Effects of dentin surface treatments on the shear bond strength of vitrabond. Dent Mat, v. 28, p. 21-26, Jan. 1992.

59- RETIEF, D.H. Standardising laboratory adhesion test. Amer J Dent, v. 4, n. 5, p. 231-236, Oct. 1991.

60- SANO, H.; SHONO, T.; TAKATSU, T.; et al. Relationship between surface area for adhesion tensile bond strength. Dent Mater, v. 10, n. 4, p. 236-40, Jul. 1994.

61- SANTINI, A.; PLASSCHAERT, A.J.M.; MITCHELL,S. Effect of composite resin placement techniques on the microleakage of two self-etching dentin-bonding agents. Amer J Dent, v. 14, n. 3, p. 132-136, Jun. 2001.

62- SCHÜPBACH, P.; LUTZ, F.; FINGER, W.J. Closing of dentinal tubules by Gluma desensitizer. Eur J Oral Sci, v. 105, n. 5, p. 414-421, Oct. 1997.

63- SEARA, S.F. et al. The influence of a dentin desensitizer on the microtensile bond strength of two bonding systems. Oper Dent, v. 27, n. 2, p. 154-160, Mar/Apr. 2002.

64- SOARES, N.B.; SOUZA, D.P.; SANTIAGO, M. Efeito de dessensibilizadores dentinários na força de adesão. Rev Bras Odont, v. 58, n. 5, p. 309-311, set./out. 2001.

65- SOENO, K.; et al. Effect of desensitizers on bond strength of adhesive luting agents to dentin. J Oral Rehabil, v. 28, p. 1122-1128, 2001. 
66- SORENSEN, J.A.; DIXIT,N.V. Shear bond strength of dentin bonding agents. J Dent Res, v. 68, p. 374, 1988. Special issue /Abstract n. $1542 /$

67- SORENSEN, J.A.; DIXIT,N.V. In vitro shear bond strength of dentin adhesives. Int J Prosthodont, v. 4, n. 2, p. 117-25, 1991.

68- SUDSANGIAM, S.; VAN NOORT, R. Do dentin bond strength tests serve a useful purpose? J Adhes Dent, v. 1, n. 1, p. 57-67, 1999.

69- SWIFT,E.J.; LLOYD, A.H.; FELTON, D.A. The effect of resin desensitizing agents on crown retention. J Amer Dent Assoc, v. 128, p. 195-200, Feb. 1997.

70- TAO, L.; PASHLEY, D.H.; BOYD, L. Effect of different types of smear layers on dentin and enamel shear bond strengths. Dent Mat, v. 4, n. 4, p. 208-216, Aug. 1988.

71- TAY, F.R. et al. Integrating oxalate desensitizers with total-etch two-step adhesive. J Dent Res, v. 82, n. 9, p. 703-707, Sept. 2003.

72- TITLEY, K.; CALDWELL, R.; KULKARNI, G. Factors that affect the shear bond strength of multiple component and single bottle adhesives to dentin. Amer J Dent, v. 16, n. 2, p. 120-4, Apr. 2003.

73- TOLEDANO, M. et al. Influence of self-etching primer on the resin adhesion to enamel and dentin. Amer J Dent, v. 14, n. 4, p. 205-210, Aug. 2001.

74- TRIOLO, P.T.; SWIFT,E.J.; BARKMEIER, W.W. Shear bond strengths of composite to dentin using six dental adhesive systems. Oper Dent, v. 20, n. 2, p. 46-50, Mar./Apr. 1995. 
75- UNEMORI, M.; et al. Composite resin restoration and postoperative sensitivity : clinical follow-up in an undergraduate program. J Dent, v. 29, p. 7-13, 2001.

76- VAN NOORT, R. et al. A critique of bond strength measurements. J Dent, v. 17, n. 2, p. 61-67, Apr. 1989.

77- VAN MEERBEEK, B. et al. A TEM study of two water-based adhesive systems bonded to dry and wet dentin. J Dent Res, v. 77, n. 1, p. 509, Jan. 1998.

78- WATANABE, T. et al. The effects of primers on the sensitivity of dentin. Dent Mater, v. 7, p. 148-150, Jul. 1991.

79- WOLFART, S.; LINNEMANN, J. KERN, M. Crown retention with use of different sealing systems on prepared dentine. J Oral Rehabil, v. 30, n. 11, p. 1053-61, Nov. 2003.

80- YIM, N.H., et al. Effect of dentin desensitizer and cementing agents on retention of full crowns using standardized crown preparations. J Prosthet Dent, v. 83, n. 4, p. 459-465, Apr. 2000.

81- YIU, C.K.Y. et al. Incompatibility of oxalate desensitizer with acidic, fluoride-containing total-etch adhesives. J Dent Res, v. 84, n. 8, p. 730-735, Aug. 2005. 
ABSTRACT 



\section{ABSTRACT \\ INFLUENCE OF DENTIN DESENSITIZERS ON THE SHEAR STRENGTH OF TWO ADHESIVE SYSTEMS .}

This study investigated and compared the bond strengths to the interface shear, created between the dentin and a light-cured restorative resin for two adhesive systems commercially available: Scotchbond MultiPurpose and One-Step, and the influence of the pre-treatment with the dentin desensitizer Gluma ${ }^{\circledR}$ Desensitizer and Bisblock, respectively, after the dentin etching with phosphoric acid at $37 \%$. Forty non-carious human third molars were used, whose layers of dentin were exposed in an attempt to obtain flat surfaces with standardized smear layer. The bond systems were applied according to the manufacturer instructions, and, after the acid etching, it was also used the desensitizing systems according to manufacturer instructions. The bond strength to the shear was measured after the immersion of the specimens, resulting from the bond of small resin composite cylinders lightcured to the dentin surface, in deionized water at $37^{\circ} \mathrm{C}$ for 7 days, using a Kratos testing machine (São Paulo - SP). The data were analyzed by oneway ANOVA and Tukey tests and there was a significant difference among the groups $(P<0.001)$. In the analysis of the failures types, Group 2 showed $100 \%$ of failures cohesive and Group 4 showed $100 \%$ of failures adhesive. It was concluded that the use of the desensitizers influenced the shear strength of the two adhesive systems tested, and the application of the Gluma ${ }^{\circledR}$ Desensitizer, after the dentin acid etching, used previously in the Scotchbond Multi-Purpose adhesive system, resulted in strength values significantly 
higher than when not applied, that is, $19.72750 \pm 4.667893 \mathrm{MPa}$. and $27.29000 \pm 6.478825 \mathrm{MPa}$, after the application of the desensitizer. The Bisblock, applied after the dentin acid etching and used previously to the One-Step adhesive system, showed strength values significantly lower than when not applied, that is, $10.06250 \pm 4.436187 \mathrm{MPa}$. and $5.73750 \pm$ $1.552786 \mathrm{MPa}$. 
APÊNDICE 


\section{Universidade de São Paulo Faculdade de Odontologia de Bauru}

A1. Dr. Octávio Pinheiro Brisolla, 9-75 - Bauru-SP - CEP 17012-901 - C.P. 73 PABX (0XX14)235-8000 - FAX (0XXI4)223-4679

\section{Comitê de Éfica em Pesquisa}

Processo $n^{\circ} 131 / 2002$

Bauru, 2 de dezembro de 2002

Senhor Professor,

O projeto de pesquisa encaminhado a este Comitê de Ética em Pesquisa em Seres Humanos, denominado "Avaliação de fendas marginais com diferentes condicionamentos no esmalte e dentina", de autoria de Vera Aun Penteado, que será desenvolvido sob sua orientação, foi enviado ao relator para avaliação.

Na reuniāo de 27 de novembro de 2002 o parecer do relator, aprovando o projeto, foi aceito pelo Comitê, considerando que não existem infraçōes éticas pendentes.

Informamos que após o envio do trabalho concluido, este Comitê enviará o parecer final, que será utilizado para publicação do trabalho.

Atenciosamente,

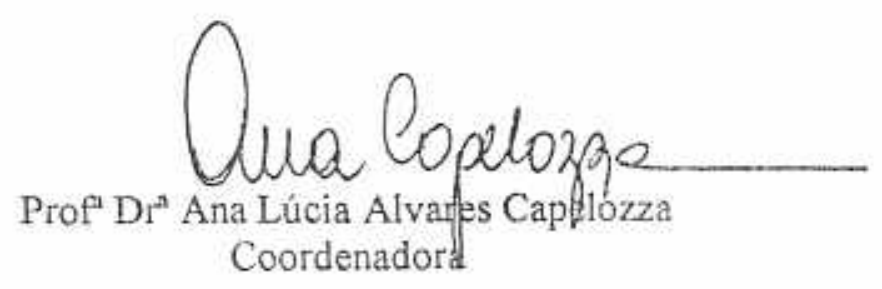

$\mathrm{Ilm}^{\circ} \mathrm{Sr}$. Prof. Dr. Paulo Afonso Silveira Francisconi

DD. Docente do Departamento de Dentistica, Endodontia e Materiais Dentários (Materiais Dentários 